\title{
MATERIALS BEHAVIOR IN A PLUTONIA-238/IRIDIUM/GRAPHITE RADIOISOTOPE HEAT SOURCE MOCKUP TEST CONFIGURATION
}

\author{
J. D. WATROUS \\ T. A. GOLDING \\ W. E. FERGUSON
}

MCDONNELL DOUGLAS ASTRONAUTICS COMPANY

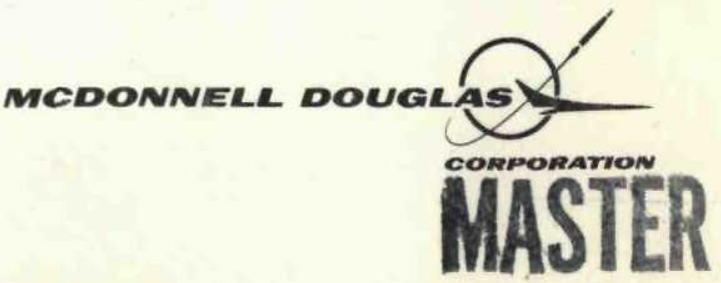

DISTRIBUTION OF THIS DOCUMENT IS UNLIMITED 


\section{DISCLAIMER}

This report was prepared as an account of work sponsored by an agency of the United States Government. Neither the United States Government nor any agency Thereof, nor any of their employees, makes any warranty, express or implied, or assumes any legal liability or responsibility for the accuracy, completeness, or usefulness of any information, apparatus, product, or process disclosed, or represents that its use would not infringe privately owned rights. Reference herein to any specific commercial product, process, or service by trade name, trademark, manufacturer, or otherwise does not necessarily constitute or imply its endorsement, recommendation, or favoring by the United States Government or any agency thereof. The views and opinions of authors expressed herein do not necessarily state or reflect those of the United States Government or any agency thereof. 


\section{DISCLAIMER}

Portions of this document may be illegible in electronic image products. Images are produced from the best available original document. 


\title{
MATERIALS BEHAVIOR IN A PLUTONIA-238/IRIDIUM/GRAPHITE RADIOISOTOPE HEAT SOURCE MOCKUP TEST CONFIGURATION
}

\author{
J. D. WATROUS \\ T. A. GOLDING \\ W. E. FERGUSON
}

DONALD W. DOUGLAS LABORATORIES

RICHLAND, WASHINGTON

\author{
PREPARED FOR THE ATOMIC ENERGY COMMISSION \\ DIVISION OF SPACE NUCLEAR SYSTEMS \\ UNDER CONTRACT NO. AT(45-1)-2138 \\ DATE PUBLISHED - MARCH 1974
}

MCDONNELL DOUGLAS ASTRONAUTICS COMPANY 


\section{ABSTRACT}

As a technology effort in support of the Multi-Hundred Watt (MHW) Radioisotope Thermoelectric Generator ( $R$ TG) program, a systems oriented test configuration was designed and utilized to determine materials behavior and interactions, helium vent behavior and iridium mechanical properties. The configuration incorporated a steep thermal gradient, and mocked up materials combinations, and their relative volumes. Microsize 0.75 in length) and sub-size (1.5 in. length) tensile specimens were utilized. Exposure times were 1250 and 8000 hours at temperatures of $1440^{\circ}$ to $1100^{\circ} \mathrm{C}$. Selected specimens received a post-exposure thermal pulse to $1950^{\circ} \mathrm{C}$ to simulate postulated orbital reentry conditions.

Results indicated that the plutonia fuel form maintained dimensional and structural integrity and did not react directly with the iridium containers. Plutonia did transport to cooler iridium surfaces. Oxygen from the plutonia reacted with external graphite to produce $\mathrm{CO}$ and $\mathrm{CO}_{2}$ gases but in insufficient quantities to be detrimental to the system. At least two mechanisms, iridium transport and impurity oxide movement, contributed to vent plugging which increased with time. Tensile strength and elongation of iridium was unaffected by these thermal exposures when in contact with plutonia or graphite as tested. at $1400^{\circ} \mathrm{C}$ at strain rates everaging 19,000 to $26,000 \mathrm{~min}^{-1}$.

\footnotetext{
This report was prepared as an account of work sponsored by the United States Government. Neither the United States nor the United States A tomic Energy Commission, nor any of their employees, nor any of their contractors, subcontractors, or their employees, makes any warranty, express or implied, or assumes any legal liability or responsibility for the accuracy, completeness or usefulness of any information, apparatus, product or process disclosed, or represents that its use would not infringe privatelyowned rights.
} 
Blank page 


\section{CONTENTS}

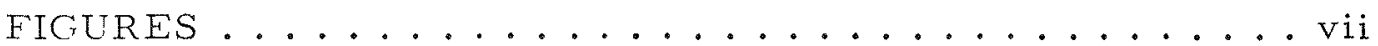

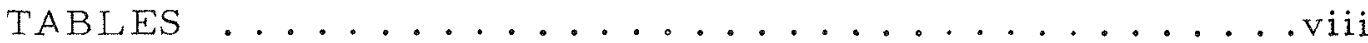

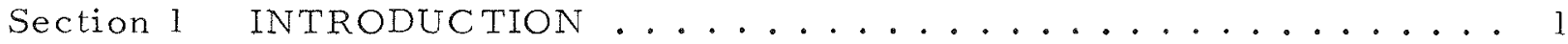

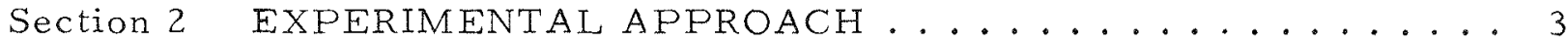

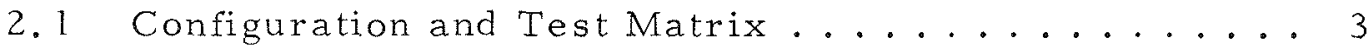

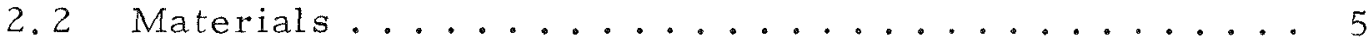

2.2.1 Plutonia-238 Powder and Pellets ...... 5

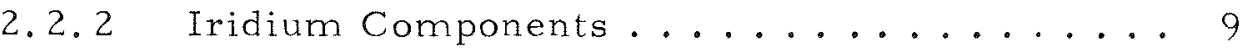

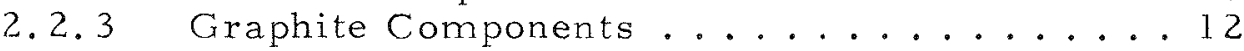

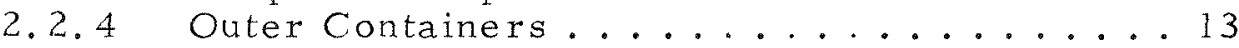

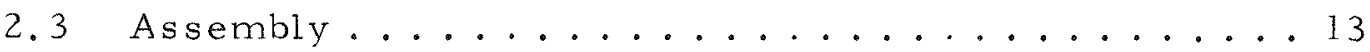

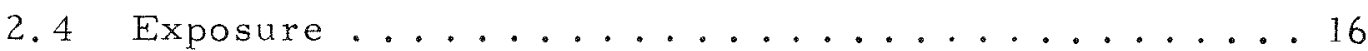

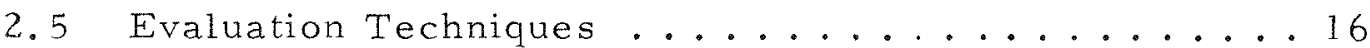

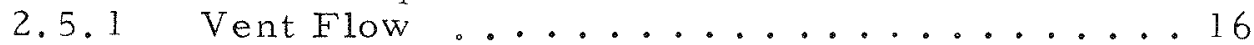

2.5.2 Helium Release Measurement ........ 17

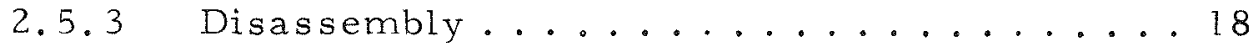

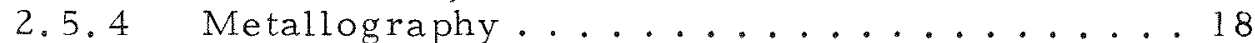

2.5.5 Chemistry and Microprobe .......... 19

2.5.6 Mechanical Properties ........... 19

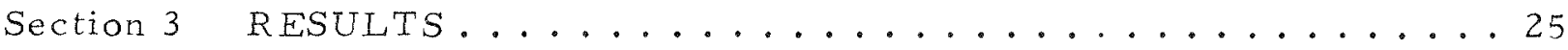

3.1 Helium Release and Formation of $\mathrm{CO} / \mathrm{CO}_{2} \ldots \ldots 25$

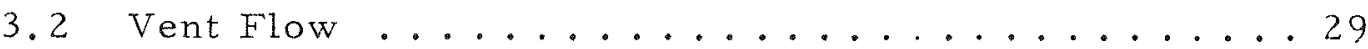

3.3 Encapsulation Material Observations .......... 31

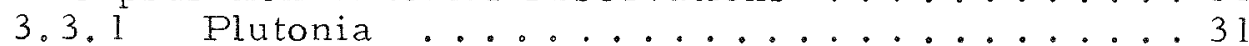

3.3 .2 Iridium Inner Containers ..........44

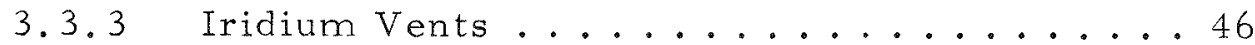

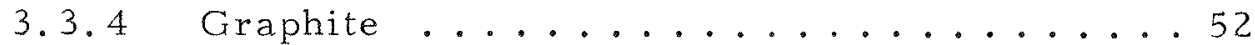

3.3 .5 Outer Iridium Containers .......... 54

3.3.6 Tungsten and Tantalum-10\% Tungsten

Guard Capsules ............... 55

3.4 Iridium Tensile Tests ............... 55

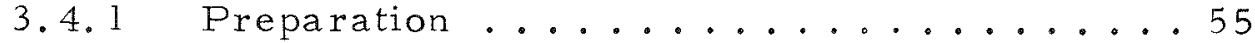

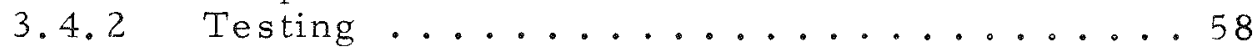

3.4.3 Data Comparison................6 63

3.4.4 Metallography and Microhardness .......6 64 


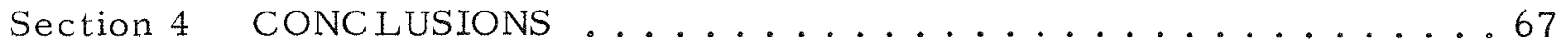

4. 1 Iridium Did Not Chemically React with Either Plutonia or Graphite under MHW Heat Source Conditions . . . 67

4.2 Mechanical Properties of Iridium Were Not Degraded by Simulated MHW Life Cycles............ . 67

4.3 Plutonia Maintained Its Integrity unde $r$ MHW Heat

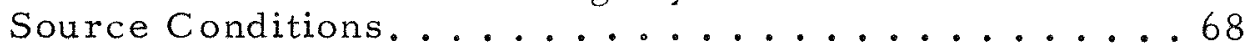

4.4 Helium Vents Plugged as a Function of Time Due to Two Separate Mechanisms ...............68 Section 5

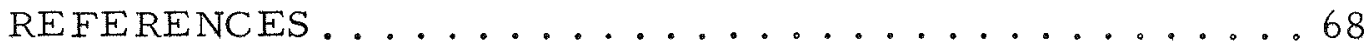


FIGURES

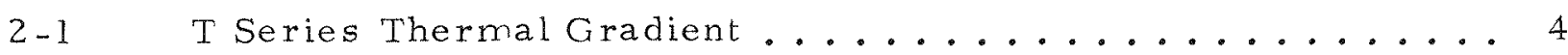

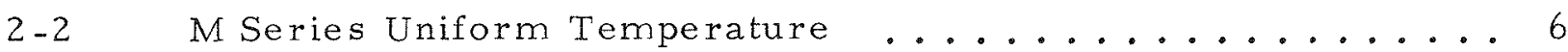

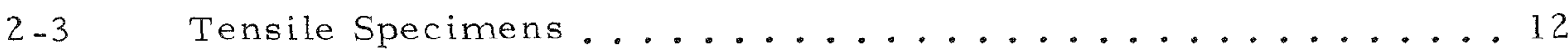

2-4 Components for MHW Mockup Test "T" Series Specimens ... 15

2-5 Components for MHW Mockup Test "M" Series Specimens ....15

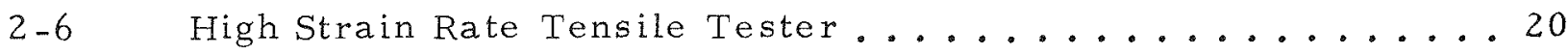

2-7 High Speed Pictures of Tensile Specimen Breaking ...... 22

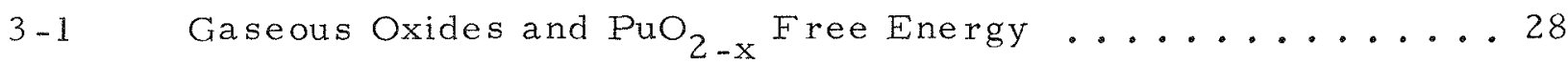

3-2 Post-Test Macrographs of Plutonia, Exposed $1250 \mathrm{hr} \ldots 36$

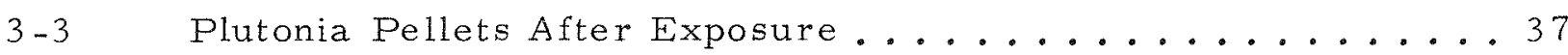

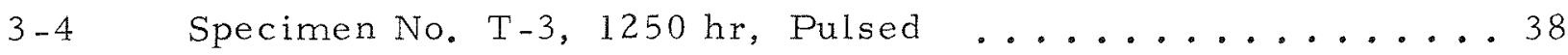

3-5 Inner Iridium Lid Surfaces of $T-2$ (left) and $T-4$ (right) .....40

3-6 Inner Iridium Lid Surfaces of $M-3$ (left) and M-4 (right) ....40

3-7 Sectioned Inner Iridium Containers, $T-2$ (left) and $T-4$ (right) .. 41

3-8 Subsize Tensile Specimen Holders, M-3 (left) and M-4 (right) . . 42

3-9 Specimen No. T-1 Iridium Capsule Reaction Areas ......43

3-10 Specimen No. T-3 Iridium Capsule Reaction Area........44

3-11 Specimen No. M-1 Iridium Capsule Reaction Area ......445

3-12 Iridium Capsule Reaction Area in Specimen T - ........45

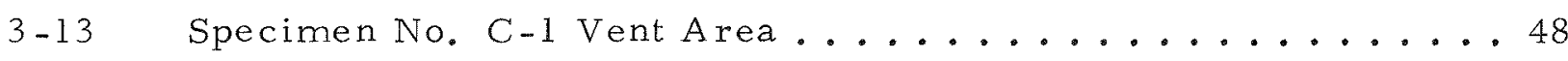

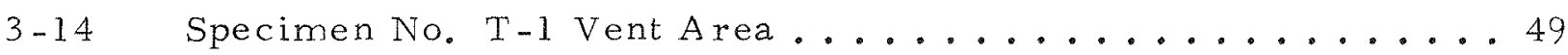

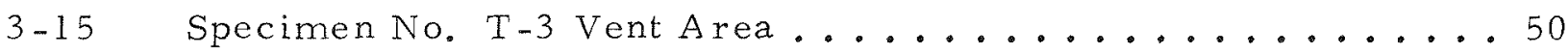

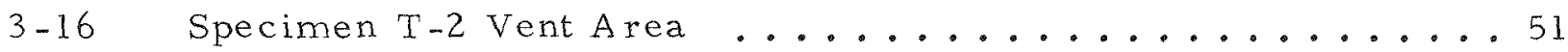

3-17 Post-Test Macrographs of Impregnated Thornel-50 Graphite .. 53

3-18 Macrograph of T-4 Microsize Tensile Specimens........ 56

3-19 Macrograph of M-1 Subsize Specimens............ 57

3-20 Macrograph of Control Microsize Tensile Specimen C-1CG-1 . 58

3-21 Microsize Tensile Specimen Fractures at High Strain Rate ... 65 
TAB LES

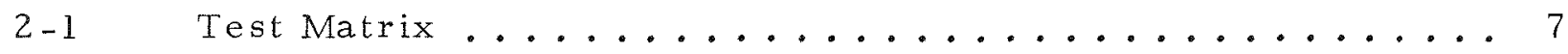

$2-2 \quad$ Chemical Analysis for ML Lot P-242 ............. 7

2-3 Spectrochemical Data for ML Lot P-252 Plutonia ....... 8

2-4 Nominal Particle Size Distribution of ML Lot P-242 ......99

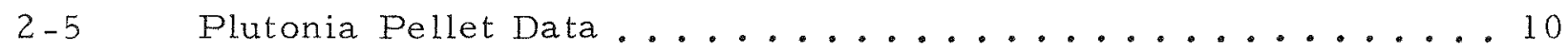

$2-6 \quad$ Iridium Impurity Analyses $\ldots \ldots \ldots \ldots$

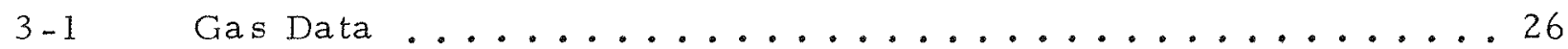

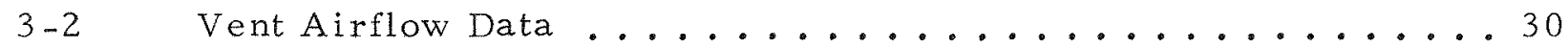

3-3 Macroscopic Observations on 1250 Hour Specimens ......3 32

3-4 Macroscopic Observation on 8000 Hour Specimens.......33

3-5 Microscopic Observations on 1250 Hour Specimens .......34

3-6 Microscopic Observations on 8000 Hour Specimens ......35

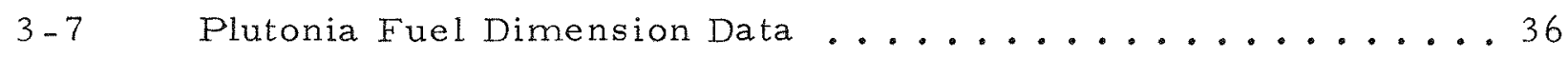

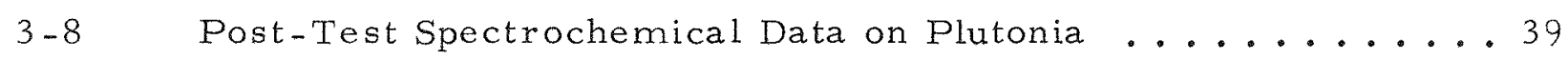

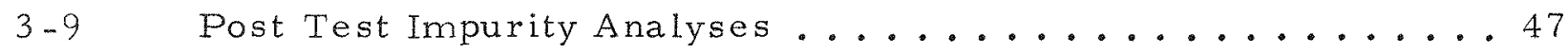

3-10 Iridium Short-Term Exposure Tensile Test Data.......6 60

3-11 Iridium Long-Term Exposure Tensile Test Data........61

3-12 Iridium Tensile Specimen Group Averages ............. 62

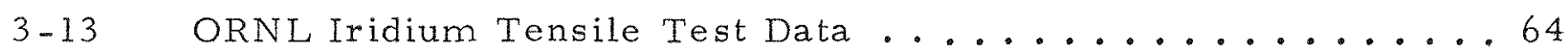


Section 1

\section{INTRODUCTION}

Current design of the multi-hundred watt radioisotope thermoelectric generator (MHW-RTG) requires containment of plutonia-238 spheres by thin-wall vented iridium shells. These $100-\mathrm{w}_{t}$ spheres are further enclosed in resin-impregnated wound-graphite-filament spherical shells which are held together by graphite components and finally contained in a large cylindrical iridium can, vented to space during operation. Previous developmental tests performed at the Donald W. Douglas Laboratories (DWDL) and Los A lamos Scientific Laboratory (LASL) using small (0.5 watt) fuel specimens indicated that there did not appear to be any incompatibility between plutonia and iridium (References 1 and 2). However, an early performance test using a 100 -watt $\mathrm{PuO}_{2}$ sphere encased in iridium and graphite conducted at Mound Laboratory (ML) resulted in material transport and vent plugging which could cause breach of containment during and possibly even subsequent to operation (Reference 3 ).

As a result of this experience, a configuration was designed by DWDL to provide further information concerning materials interactions, vent plugging propensity, and iridium mechanical properties in a systems Mockup test utilizing 6 watt of $\mathrm{PuO}_{2}$. This $\mathrm{MHW}$ thermal gradient test configuration (designated as "T" series) was intended to mockup materials combinations, relative volumes, and temperature differentials. Iridium tensile specimens were inserted adjacent to the plutonia, in contact with graphite at the liner temperature, and in the graphite ablator material at a lower temperature to permit determination of individual and collective effects on the tensile behavior of iridium.

A MHW uniform temperature test set (designated as "M" series) was also included in the matrix to provide a worst case by having plutonia powder surrounding iridium tensile specimens. This series was intended to be exposed at the maximum expected operating temperature. 
About half of the test assemblies were to receive a thermal ramp after exposure for determination of the effects of reentry heating.

Tensile specimens incorporated in the thermal gradient series were specifically designed for the program and were $0.75 \mathrm{in}$. long. These were to be tested at DWDL utilizing a relatively high strain rate produced by a dropping weight. Tensile specimens in the uniform temperature series were machined to a General Electric-Space Systems Organization (GE-SSO) sub-size configuration which was $1.5 \mathrm{in.}$ long. These were to be tested in a GE facility for correlation with earlier test data.

The tests have been completed as planned and have produced results and conclusions relevant to MHW heat sources. These are discussed in the sections which follow. 


\section{Section 2 \\ EXPERIMENTAL APPROACH}

\section{1 CONFIGURATION AND TEST MATRIX}

The thermal gradient, or " $\mathrm{T}$ ", test series was designed to mockup materials combinations, relative volumes, and temperature differentials of the actual $\mathrm{MHW}$ heat source. Hardware sizing was based on use of 0.75 in. long micro-size DWDL tensile specimens in contact with flat-sided plutonia pellets. Figure 2-1 shows essential features of the test configuration.

Four iridium tensile specimens were held in direct contact with the plutonia, or PPO, pellet using shaped iridium foil retainers. The $0.015 \mathrm{in}$. thick iridium inner capsule was vented for release of helium generated by the plutonia-238 during exposure. The vent assembly consisted of a capsule lid with an electron-beam-drilled 0.004 to 0.008 in. diameter hole which had a $0.006-i n$. thick iridium vent cover over the hole with approximately 0.002 to $0.003 \mathrm{in}$, thick baked on iridium powder(frit) similar to the actual MHW heat source. The vent cover was spot welded to the lid in four places.

Four additional iridium tensile specimens were located adjacent to the inner iridium capsule in slots milled in graphite. A block of impregnated Thornel-50 graphite with the same composition as actually used for the impact shell in the heat source was located approximately $0.050 \mathrm{in}$. above the inner iridium capsule to simulate expected spacing over the actual vent area. A large block of POCO AXF-5Q graphite represented the aero-shell components. This graphite block contained two more tensile specimens to represent the iridium outer cladding for tensile testing purposes.

A vented iridium outer capsule surrounded these components to minimize interactions with external tungsten guard capsules.

A tungsten inner guard capsule provided pressure containment of the generated helium. A tantalum-10\% tungsten outer guard capsule provided secondary protection both to and from the furnace environment. 


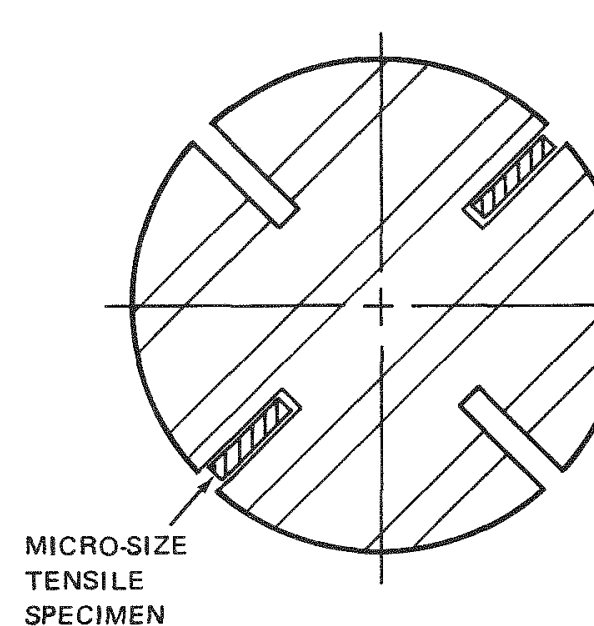

SPECIMEN

SECTION B-B

CENTRAL PARTS ONLY SHOWN

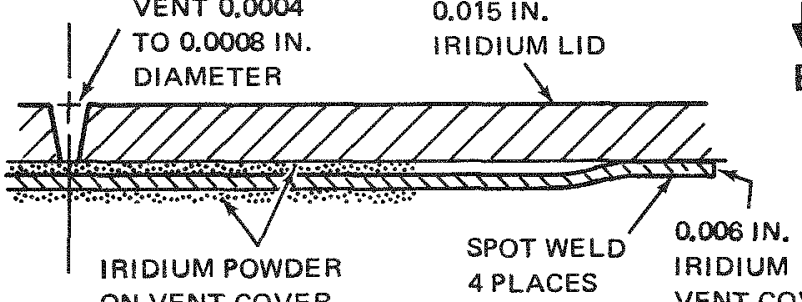

ON VENT COVER

0.002 TO $0.0031 \mathrm{~N}$.

DETAIL C

Tarlow

OUTER GUARD

TUNGSTEN

INNER GUARD

CAPSULE
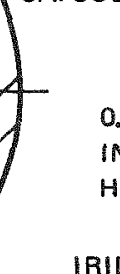

GRAPHITE

0.010
IN. DIA
HOLE
RIDIUN
OUTER
CAPSUL
AXF.

IMPREGNATED

THORNEL-50

IRIDIUM
OUTER
CAPSULE

POCO AXF.5O

COVER GRAPHITE

IRIDIUM
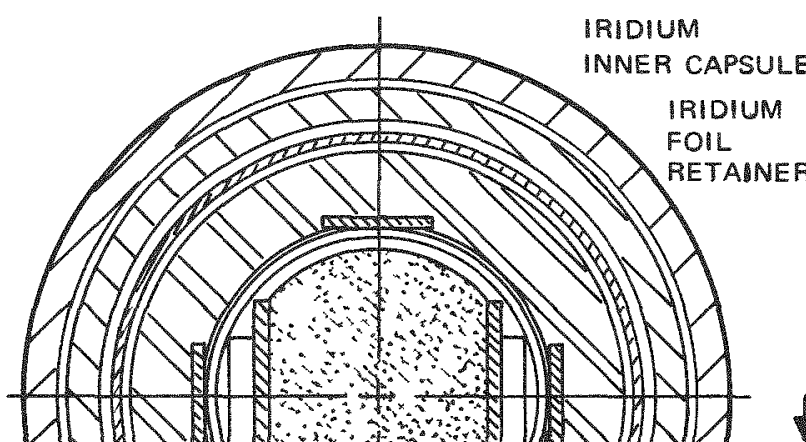



SNo

Ul

$\sqrt{1}$

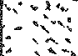

and
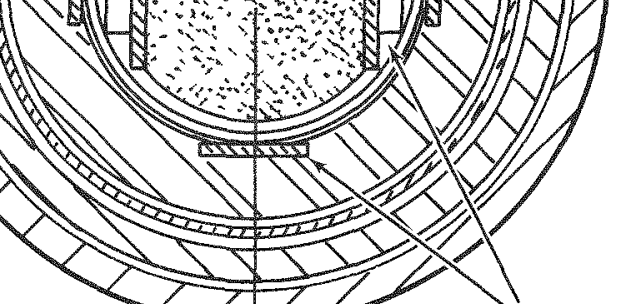

IRIDIUM MICRO-SIZE

TENSILE SPECIMENS

SECTION A-A
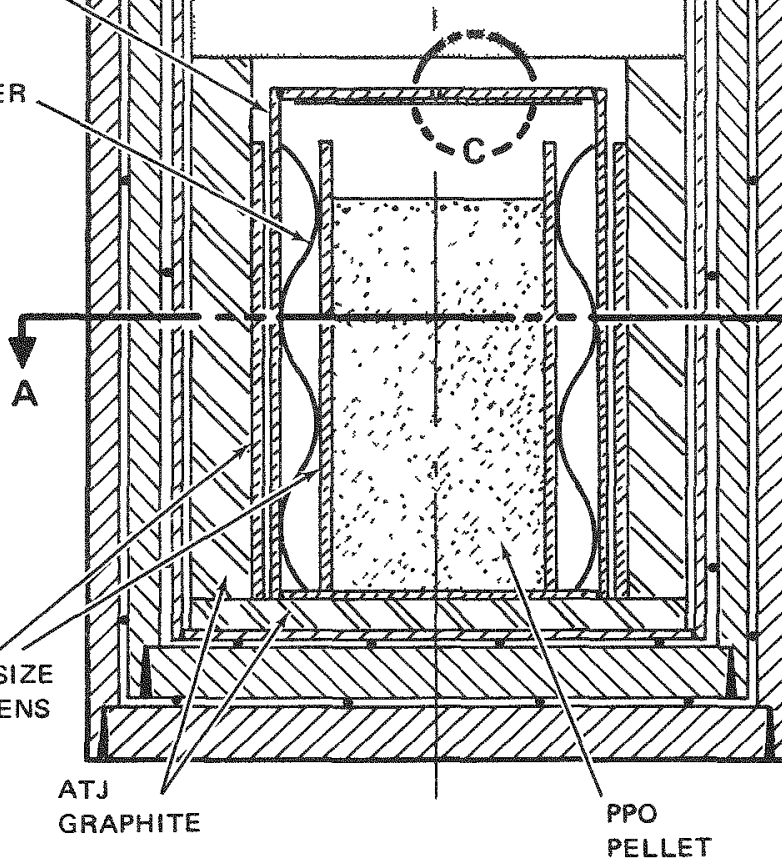

Figure 2-1. T Series Thermal Gradient $\left(1440^{\circ} \mathrm{C}\right.$ at bottom, $1100^{\circ} \mathrm{C}$ at top $)$ 
The entire test assembly was 1.16 in. diameter by 3.3 in. tall. The MHW program team established exposure conditions of $1440^{\circ} \mathrm{C}$ at the bottom surface and $1100^{\circ} \mathrm{C}$ at the top surface.

The uniform temperature, or "M", series was designed to expose GE-SSO type sub-size ( $1.5 \mathrm{in}$. length) tensile specimens to a maximum isothermal temperature condition in a vertical bed of plutonia-238 powder. Figure 2-2 shows the configuration used to provide the desired test condition.

Six iridium sub-size tensile specimens were located between two slotted lids with a 0.003 -in. thick foil cylindrical wall. Plutonia was poured into the sub-container after welding the wall to the lids. The sub-container was fitted directly into a vented iridium container, identical to that used in the " $T$ " series except for extended length. Both ATJ graphite and impregnated Thornel-50 graphite provided the correct materials in a MHW-RTG heat source but at a reduced relative volume. The iridium, tungsten, and Ta-10W container were identical to those used in the " $\mathrm{T}$ " series.

The test matrix is shown in Table 2-1. Test temperatures were established at $1440^{\circ} / 1100^{\circ} \mathrm{C}$. These temperatures matched MHW vacuum mode operating conditions. Exposures times were established with consideration to kinetics and MHW programmatic milestones.

\subsection{MATERIALS}

\subsubsection{Plutonia-238 Powder and Pellets}

All of the plutonia-238 powder and pellets were derived from Mound Laboratory (ML) lot P-242 production stock. Chemical analyses of this lot by ML and LASL as reported in Tables $2-2$ and $2-3$ is representative of production grade material. From this lot, $80 \mathrm{~g}$ of powder were used to assemble the "M" series. Powder particle size characteristics, as reported by ML, are listed in Table 2-4. Each "M" series capsule was loaded with $20 \mathrm{~g}$ of $\mathrm{PuO}_{2}$, or approximately 8 watts. 


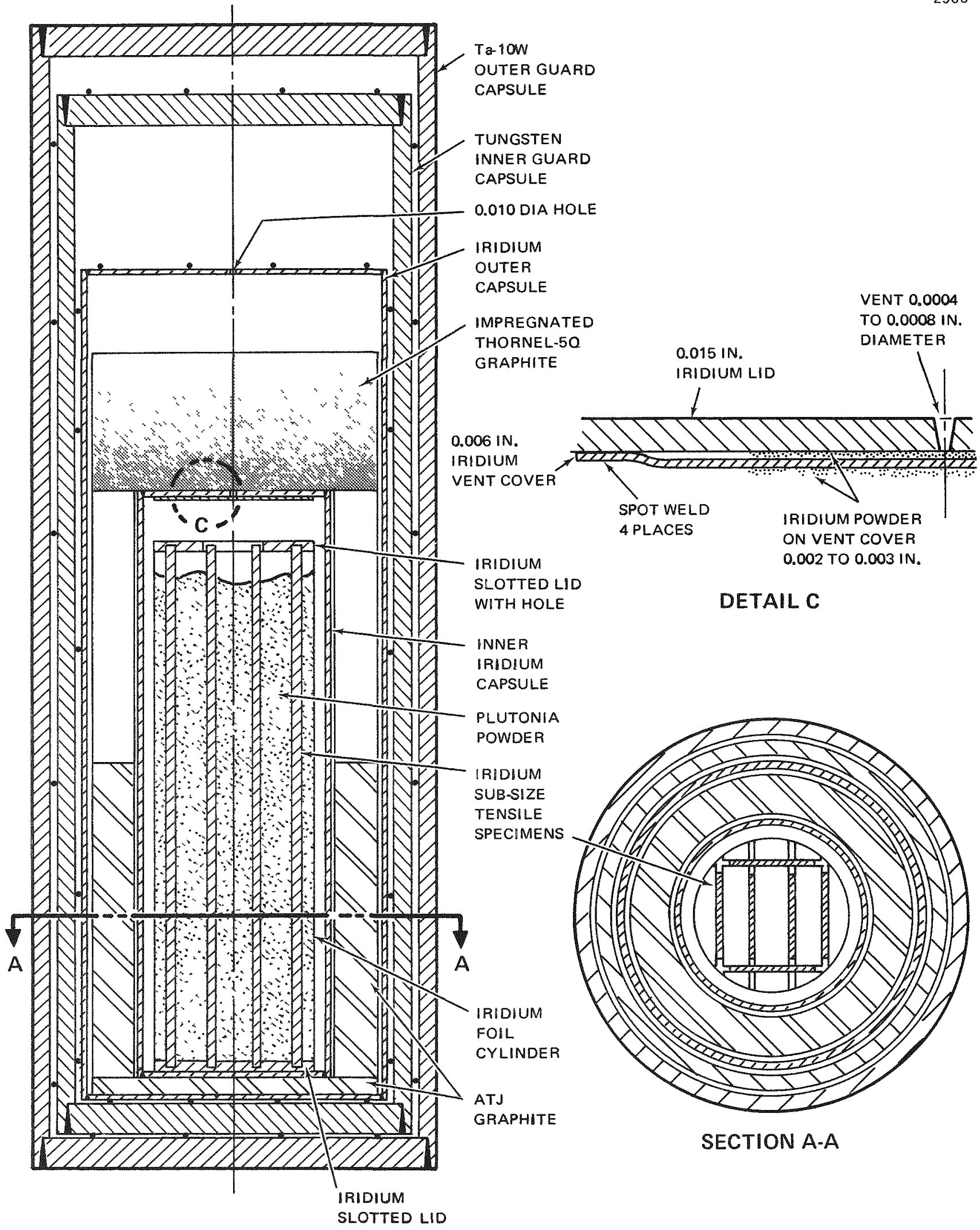

Figure 2-2. M Series Uniform Temperature $\left(1440^{\circ} \mathrm{C}\right)$ 
TAB LE 2-1

TEST MATRIX

\begin{tabular}{|c|c|c|c|c|c|c|}
\hline $\begin{array}{l}\text { Fuel } \\
\text { Test No. }\end{array}$ & Control No. & $\begin{array}{c}\text { Fuel } \\
\text { Form }\end{array}$ & Specimen & $\begin{array}{l}\text { Exposure } \\
\text { Time } \\
\text { (Hours) }^{a}\end{array}$ & $\begin{array}{l}\text { Conditions } \\
\text { Temperature } \\
\left({ }^{\circ} \mathrm{C}\right)\end{array}$ & $\begin{array}{l}\text { Post-Exposure } \\
\text { Thermal Ramp }\end{array}$ \\
\hline$T-1$ & $C-1$ & Pellet & DWDL Micro & 1250 & $1440 / 1100$ & No \\
\hline $\mathrm{T}-2$ & $C-4^{b}$ & Pellet & DWDL Micro & 8000 & $1440 / 1100$ & No \\
\hline$T-3$ & $C-3$ & Pellet & DWDL Micro & 1250 & $1440 / 1100$ & Yes \\
\hline$T-4$ & -- & Pellet & DWDL Micro & 8000 & $1440 / 1100$ & Yes \\
\hline$M-1$ & $\mathrm{MC}-1$ & Powder & GE Subsize & 1250 & 1440 & No \\
\hline$M-4^{\mathrm{C}}$ & $\mathrm{MC}-3$ & Powder & GE Subsize & 8000 & 1440 & No \\
\hline$M-3^{C}$ & $\mathrm{MC}-4$ & Powder & GE Subsize & 8000 & 1440 & Yes \\
\hline
\end{tabular}

Notes: a. Time originally specified as 1500 and 8000 hr but subject to change. Schedule considerations resulted in the tabulated values.

b. Control specimen $\mathrm{C}-4$ was originally intended to be thermal ramped - - schedule and man power constraints did not permit ramping。

c. Fuel Test specimens $M-4$ and $M-3$ were interchanged for post-exposure thermal ramping to provide more valuable test information.

TAB I. E 2-2

CHEMICAL ANALYSIS FOR ML LOT P-242

\begin{tabular}{cc}
\hline Element & Weight Percent \\
\hline $\mathrm{Pu}$ & 87.4 \\
$\mathrm{U}$ & 0.651 \\
$\mathrm{Th}$ & 0.14 \\
$\mathrm{~Np}$ & 0.174 \\
$\mathrm{O}$ & 11.66 \\
$\mathrm{C}$ & 0.065 \\
\hline
\end{tabular}


Table $2-3$

SPECTROCHEMICAL DATA FOR ML LOT P-252 PLUTONIA (ppm by weight)

\begin{tabular}{|c|c|c|c|c|c|}
\hline Element & $\begin{array}{c}\text { ML } \\
\text { Analysis }\end{array}$ & $\begin{array}{l}\text { LASL } \\
\text { Analysis }\end{array}$ & Element & $\begin{array}{c}\text { ML } \\
\text { Analysis }\end{array}$ & $\begin{array}{c}\text { LASL } \\
\text { Analysis }\end{array}$ \\
\hline Li & NR & $<4$ & $\mathrm{Sr}$ & NR & 4 \\
\hline $\mathrm{Be}$ & NR & $<1$ & $\mathrm{Zr}$ & NR & 4 \\
\hline$B$ & NR & 15 & Mo & NR & 15 \\
\hline $\mathrm{Na}$ & $<250$ & $<50$ & $\mathrm{Cd}$ & NR & $<4$ \\
\hline $\mathrm{Mg}$ & $<20$ & 5 & $\mathrm{Sn}$ & $<10$ & 10 \\
\hline $\mathrm{Al}$ & $<50$ & 40 & $\mathrm{Ba}$ & NR & 4 \\
\hline $\mathrm{Si}$ & $<50$ & 110 & $\mathrm{Ta}$ & $<100$ & $<1000$ \\
\hline $\mathrm{Ca}$ & $<250$ & 130 & W & NR & $<50$ \\
\hline $\mathrm{Ti}$ & NR & $<25$ & $\mathrm{~Pb}$ & 25 & 30 \\
\hline $\mathrm{V}$ & NR & $<4$ & $\mathrm{Bi}$ & NR & $<1$ \\
\hline $\mathrm{Cr}$ & 70 & 110 & $\mathrm{Hf}$ & $N R$ & $<4$ \\
\hline $\mathrm{Mn}$ & $<20$ & 10 & $\mathrm{Cs}$ & NR & $<20$ \\
\hline $\mathrm{Fe}$ & 250 & 500 & $K$ & NR & 10 \\
\hline $\mathrm{Co}$ & NR & 4 & La & NR & 4 \\
\hline $\mathrm{Ni}$ & $<50$ & 10 & $R u$ & $\mathrm{NR}$ & $<4$ \\
\hline $\mathrm{Cu}$ & $<50$ & 10 & $\mathrm{Re}$ & NR & $<4$ \\
\hline $\mathrm{Zn}$ & $<50$ & 20 & $\mathrm{Y}$ & NR & $<4$ \\
\hline
\end{tabular}

NR - Not Reported 
Table 2-4

NOMINAL PARTICLE SIZE DISTRIBUTION OF ML LOT P-242

Particle Size Range

(microns)
Weight Percent

in Range

$\begin{array}{cr}297-250 & 8.5 \\ 250-210 & 18.8 \\ 210-177 & 13.1 \\ 177-125 & 21.7 \\ 125-105 & 6.4 \\ 105-63 & 16.7 \\ <63 & 15.5\end{array}$

LASL produced the four plutonia pellets used in the "T" series. These pellets were hot pressed in graphite dies at $1480^{\circ} \pm 20^{\circ} \mathrm{C}$ and 5000 psi maximum load for 30 minutes. After removal from the dies, the pellets were sintered four hours at $1370^{\circ} \mathrm{C}$ in an $\mathrm{Ar}-\mathrm{H}_{2}{ }^{16} \mathrm{O}$ atmosphere. Pellet data as measured at LASL and corroborated at DWDL, a re listed in Table 2-5. Agreement between DWDL and LASL measurements was well within experimental accuracy. The pellets and pellet density appeared very typical of the specified MHW fuel form. Each pellet contained approximately 6.3 watts of plutonia -238 .

Prior to encapsulation at DWDL and upon recommendation of GE-SSO the pellets were baked at $1400^{\circ} \mathrm{C}$ for 6 hours in an argon atmosphere to produce a slightly substoichiometric composition.

\subsubsection{Iridium Components}

Englehard Industries provided all the basic iridium components either directly or through GE-SSO. Inner cans, outer cans, and lids were all made from 0.015 -in. thick iridium sheets having the chemical composition reported by Englehard (Table 2-6). Cylindrical sections of the cans were made by rolling sheet and welding, followed by grinding to remove weld build-up. Electrical discharge machining into the cylinder ends was used to provide recesses for the flat circular lids. Outside diameters of all inner can cylinders were 
Table $2-5$

PLUTONIA PELLET DATA

\begin{tabular}{ccccccc}
\hline $\begin{array}{c}\text { LASL } \\
\text { Pellet } \\
\text { No. }\end{array}$ & $\begin{array}{c}\text { DWDL } \\
\text { Test } \\
\text { No. }\end{array}$ & $\begin{array}{c}\text { Diameter } \\
\text { (in.) }\end{array}$ & $\begin{array}{l}\text { Across } \\
\text { Flats }\end{array}$ & $\begin{array}{c}\text { Length } \\
\text { (in.) }\end{array}$ & $\begin{array}{c}\text { Weight } \\
\text { (g) }\end{array}$ & $\begin{array}{c}\text { Density } \\
\text { (\% Theoretical) }\end{array}$ \\
\hline 1 & T -1 & 0.4890 & 0.3545 & 0.6466 & 15.6864 & 82.46 \\
2 & T -2 & 0.4880 & 0.3549 & 0.6497 & 15.6890 & 82.22 \\
3 & T -3 & 0.4888 & 0.3556 & 0.6531 & 15.6846 & 82.34 \\
4 & T -4 & 0.4880 & 0.3553 & 0.6447 & 15.6924 & 82.69 \\
\hline
\end{tabular}

Table 2-6

IRIDIUM IMPURITY ANA LYSES

(ppm by weight)

\begin{tabular}{|c|c|c|c|c|c|}
\hline Element & $\begin{array}{l}\text { Capsule } \\
\text { Material }\end{array}$ & $\begin{array}{l}\text { Tensile } \\
\text { Specimen } \\
\text { Material }\end{array}$ & Element & $\begin{array}{l}\text { Capsule } \\
\text { Material }\end{array}$ & $\begin{array}{l}\text { Tensile } \\
\text { Specimen } \\
\text { Material }\end{array}$ \\
\hline $\mathrm{Pt}$ & 38 & 21 & $\mathrm{Mg}$ & 10 & 18 \\
\hline $\mathrm{Rh}$ & 30 & 40 & $\mathrm{Ca}$ & 30 & 30 \\
\hline $\mathrm{Pd}$ & 25 & 10 & $\mathrm{Al}$ & 78 & $190 *$ \\
\hline $\mathrm{Ru}$ & $<100$ & 100 & $\mathrm{Ni}$ & 10 & 10 \\
\hline $\mathrm{Au}$ & 1 & 2 & $\mathrm{Cr}$ & 29 & 41 \\
\hline $\mathrm{Ag}$ & $<3$ & $\mathrm{ND}$ & $\mathrm{Mn}$ & 10 & ND \\
\hline $\mathrm{Pb}$ & $<20$ & ND & $\mathrm{Sb}$ & ND & ND \\
\hline $\mathrm{Sn}$ & ND & ND & B & ND & 25 \\
\hline $\mathrm{Zn}$ & ND & ND & $\mathrm{Co}$ & ND & ND \\
\hline $\mathrm{Fe}$ & 330 & 245 & As & $\mathrm{ND}$ & ND \\
\hline $\mathrm{Cu}$ & 23 & 25 & $\mathrm{Bi}$ & ND & ND \\
\hline \multirow[t]{2}{*}{$\mathrm{Si}$} & 39 & $130 \%$ & $\mathrm{Cd}$ & ND & ND \\
\hline & & & W & 100 to 5000 & 8000 \\
\hline
\end{tabular}

Notes: ND - not detected within established limits

* - Above MHW-RTG specification limit 
$0.559 \pm 0.001 \mathrm{in}$. Heights were either $0.850 \mathrm{in}$. or 1.700 in. Outside diameters of outer can cylinders were $0.879 \pm 0.002 \mathrm{in}$. Heights were 2.000 in.

Vented lids of the inner containers had electron-beam drilled holes in the center. Kin-Therm Incorporated, East Windsor, Connecticut, performed the drilling. The hole at beam entrance averaged about 0.005 in. diameter tapering quickly to about half that size and slowly decreasing in size to about 0.0006 to 0.0009 in. diameter at the exit side. Vent covers were supplied by GE-SSO. A 0.500-in. diameter by 0.006-in. thick iridium disc was covered on both sides of the central $0.38 \mathrm{in}$. diameter area with 0.002 - to 0.003 -in. thick iridium powder.

An $1850^{\circ} \mathrm{C}$ vacuum thermal treatment provided adherence. The lid and cover were spot welded in four places at the periphery. The vent hole was arranged with the smallest diameter on the exit side away from the vent cover. Airflow through these vents typically varied from 50 to $250 \mathrm{cc} / \mathrm{hr}$ with one atmosphere pressure differential. One vent was considerably lower (13 std cc/hr) and one considerably higher $(700 \mathrm{std} \mathrm{cc} / \mathrm{hr})$. This variability could affect particulate retention but would not result in any significant pressure differential because the helium generation rate is only about $9 \times 10^{-3} \mathrm{std} \mathrm{cc} / \mathrm{hr}$ for these specimens.

Vents in the outer iridium containers consisted of a 0.010 -in. diameter electrical discharge machined hole.

Tensile specimens were made from one lot of $0.020 \mathrm{in}$. thick iridium supplied by Englehard Industries with the composition listed in Table 2-6. The silicon and aluminum contents were above MHW specification limits; however, these data were not available in time to take corrective action with alternate tensile specimens. All specimens were machined by Northwest Industries, Albany, Oregon, to the GE sub-size and DWDL micro-size configurations shown in Figure $2-3$.

Holders for the $M$ series GE sub-size tensile specimens had slots 0.015 -in. thick in the end discs and 0.003-in. thick iridium foil cylinders. No analysis was obtained on the $0.003-$ in. thick foil. 
Tungsten content of the iridium capsule material was reported as 0.01 to $0.5 \%$, typical of the product at the time of manufacture. Tungsten content of the tensile specimens was reported as $0.8 \%$ which was somewhat high. It was expected that the additional tungsten would result in no chemical effects, but could result in somewhat increased tensile strength. Further discussion on strength effects is included in Section 3.4.3. Hardness of the tensile specimens was measured as being $500 \mathrm{DPH}$, considerably above the $300 \mathrm{DPH}$ typical of commercial iridium.

\subsubsection{Graphite Components}

Original intentions were to machine all graphite parts surrounding the inner iridium container from Hitco resin-impregnated Thornel-50 crush-up graphite to be used in the MHW-RTG heat source. Poor machinability and material unavailability changed plans to using only $0.85 \mathrm{in}$. diameter by $0.40 \mathrm{in}$. thick plugs of the resin-impregnated Thornel-50 material supplied by GE-SSO.

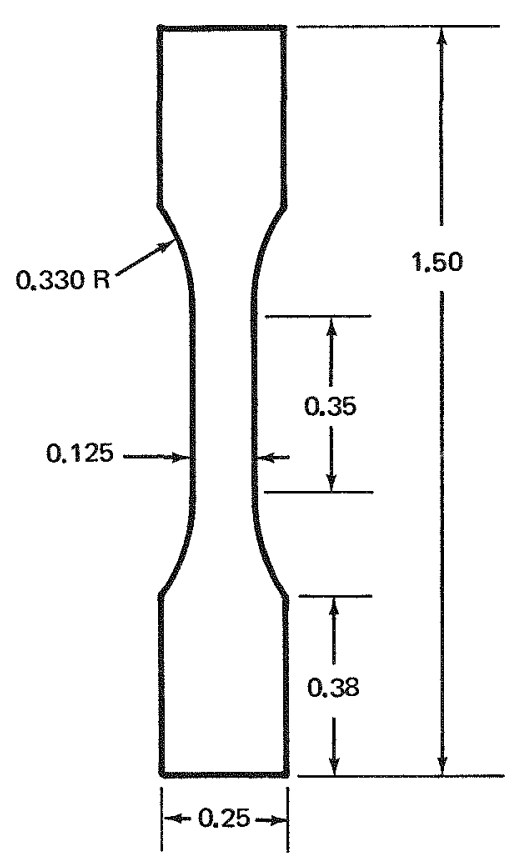

A. GE SUB-SIZE
ALL DIMENSIONS IN INCHES

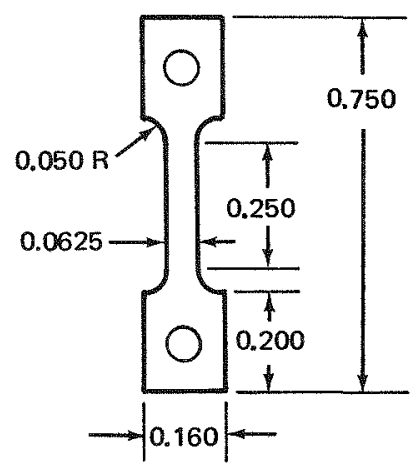

B. DWDL MICRO-SIZE

Figure 2-3. Tensile Specimens 
The remaining graphite parts were made from ATJ or POCO AXF-5Q graphite, considered "pure" graphite materials representative of flight type hardware.

All graphite parts were vacuum outgassed for $2 \mathrm{hr}$ at $1200^{\circ} \mathrm{C}$ followed by $7 \mathrm{~min}$ at $2100^{\circ} \mathrm{C}$ at an average vacuum of $5 \times 10^{-4}$ torr. Parts were then stored under dry argon until assembly.

\subsection{Outer Containers}

Tungsten outer containers were machined at Northwest Industries from powder metallurgy processed raw material. An earlier lot of arc-cast material had proven to be unweldable. Capsules were 1.027-in. outside diameter with a $0.049 \pm 0.002 \mathrm{in.}$ wall and height of $3.000 \pm 0.003 \mathrm{in.}$ Bottom lids were electron-beam welded. Helium leaks checks were made on these assemblies. Only seven of twelve containers were helium leak tight (detection limit $1 \times 10^{-9} \mathrm{std} \mathrm{cc} / \mathrm{sec}$ ). One container leaked at the initial weld. The four remaining containers leaked through the wall. The seven leak-tight containers were used for fueled tests; the remaining five containers were used for control specimens.

The tantalum-10\% tungsten outer guard capsules were machined at Northwest Industries from arc-cast material to DWDL engineering drawing requirements. All components were helium leak-tight and conformed to dimensional requirements.

\subsection{ASSEMBLY}

Components for the " $T$ " series specimens are shown in Figure 2-4. Plutonia pellets were inserted into the inner iridium capsule, four tensile specimens were then slid into place in contact with the flat fuel surfaces, and two bent iridium foil retainers were inserted to maintain intimate contact between the plutonia and tensile specimens. Smear checks were taken to determine that the weld joint had remained uncontaminated. The lid was placed in position. after which the capsule was installed in a holding fixture and transferred to the weld chamber. All welds were performed in a $6 \mathrm{kw}$ Hamilton Standard electron-beam welder. No helium leak checks were made because of the presence of helium vent. All external surfaces remained contamination free. 
Further assembly of the "T" series utilized the large iridium capsule at the right in Figure 2-4, the thin graphite disc, the graphite cylinder with a central hole and slots for tensile specimens, the welded inner iridium capsule, four tensile specimens next to the inner iridium capsule, the resin impregnated Thorne1-50 graphite plug (furthest back in Figure 2-4), the slotted graphite, two additional tensile specimens, and the vented iridium lid. This assembly was electron-beam welded without contamination. The tungsten and Ta-10W guard capsules were then assembled around the iridium assembly using tungsten wire spacers to minimize solid-solid contact. The guard containers were electron-beam welded, pressurized overnight at 150 psi helium pressure and determined to be helium leak tight. Control specimens ("C" series) had no plutonia, no vent cover (with the exception of C-4 which had a cover), utilized an iridium foil sleeve and end discs instead of the outer iridium capsule (with the exception of $\mathrm{C}-4$ which had the capsule), and used only a tungsten guard capsule (with the exception of C-4 which used only a Ta-10W guard capsule). These variations resulted from hardware limitations and making use of all spare hardware wherever possible.

Components for the "M" series specimens are shown in Figure 2-5. The six GE sub-size tensile specimens were vacuum annealed at $600^{\circ} \mathrm{C}$ prior to assembly. All other parts were treated the same as "T" series parts. Slotted iridium end discs were fixtures so that six iridium tensile specimens could be placed into the slots and a spot-welded iridium foil cylinder slid into place, then TIG welded to the two end discs. The tensile specimen subassembly was then vibratory filled with approximately 20 grams of plutonia powder supplied by LASL. The subassembly was heated to $1400^{\circ} \mathrm{C}$ for $6 \mathrm{hr}$ in argon to outgas the fuel. The subassembly was handled as a fuel pellet and loaded into a long iridium capsule; the lid and vent cover combination was electronbeam welded. An ATJ-graphite disc, an ATJ graphite cylinder, the tensile specimen assembly, and a Hitco resin-impregnated Thornel-50 block were placed into the large iridium cylinder and electron-beam welded. Guard capsules of tungsten and Ta-10W were then placed over this assembly, the same as for the " $T$ " series. Control capsules were the same, except for 


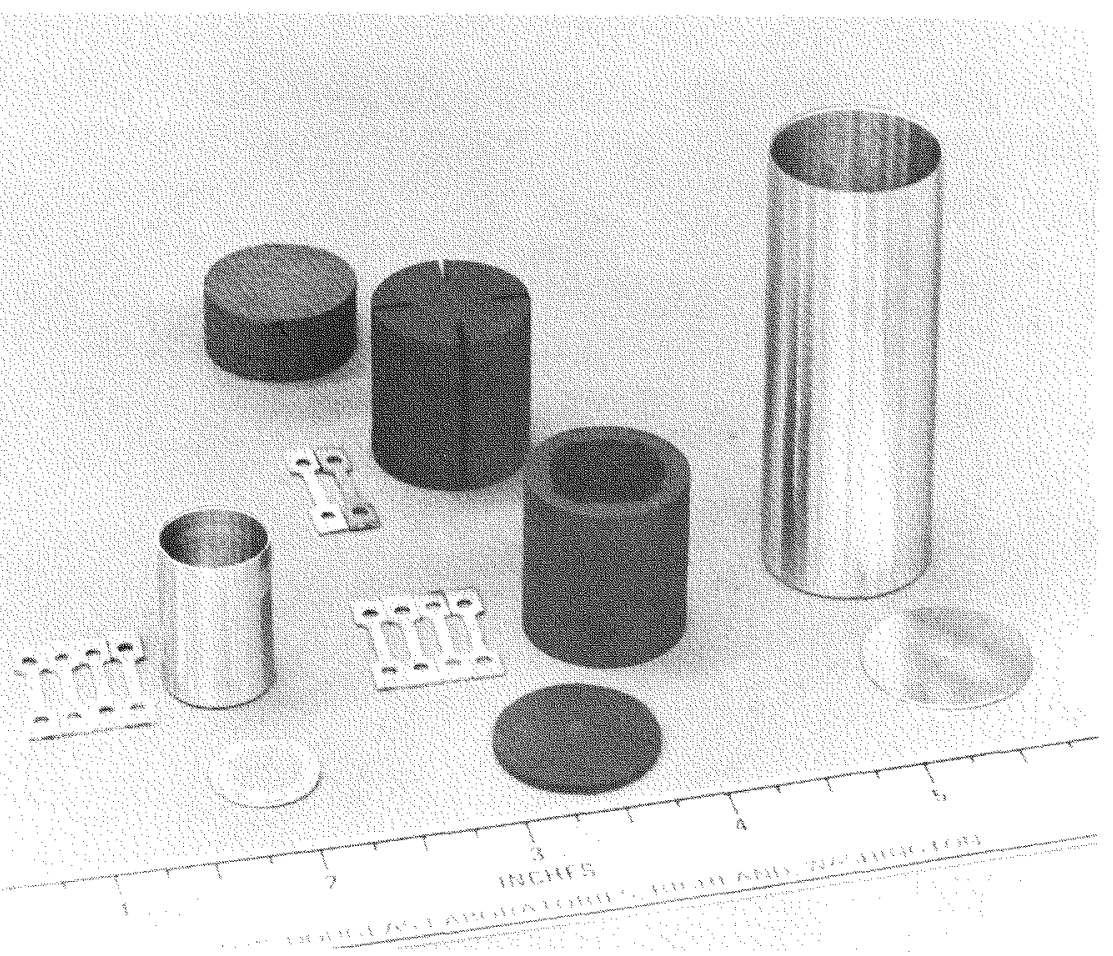

Figure 2-4. Components for MHW Mockup Test " $T$ " Series Specimens

2643

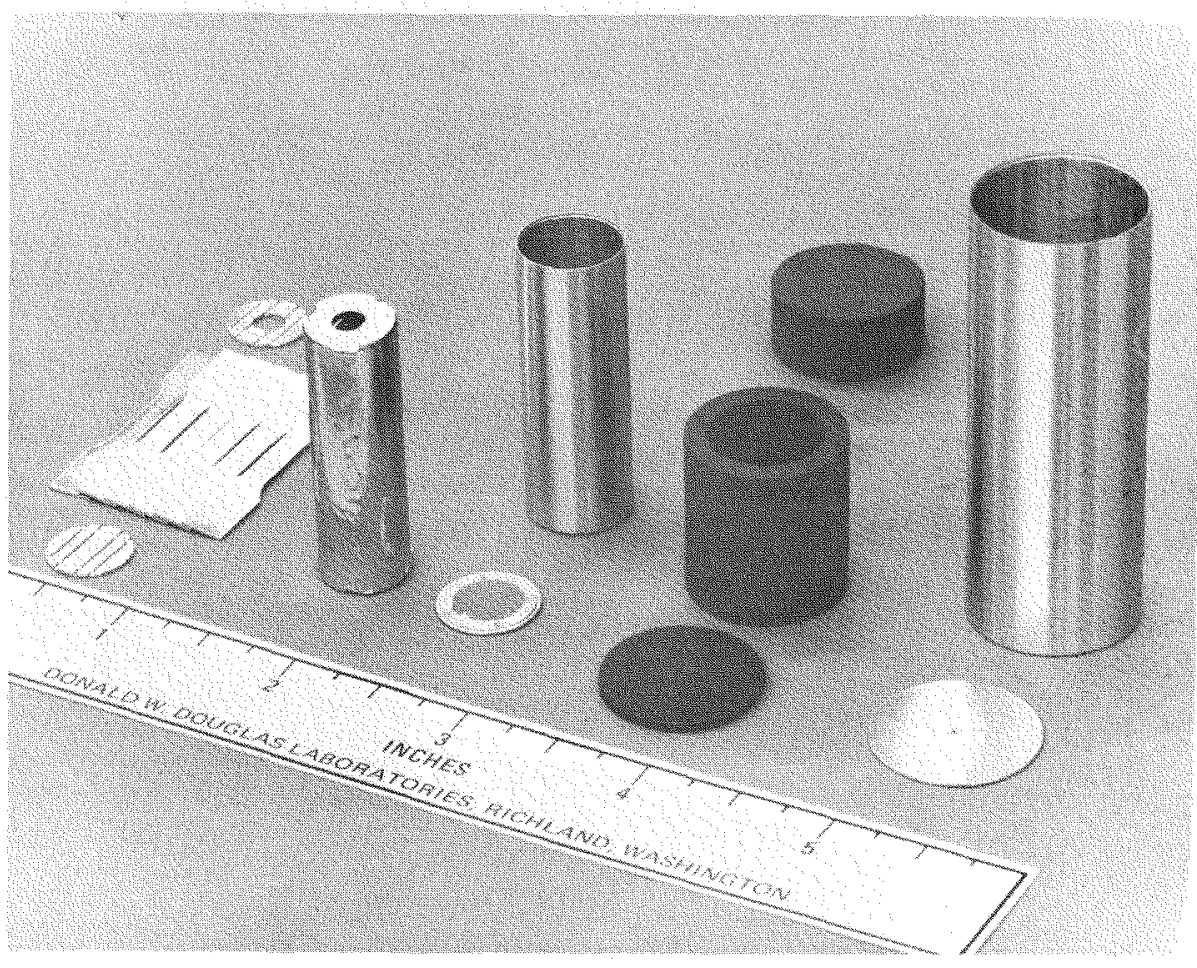

Figure 2-5. Components for MHW Mockup Test " $\mathrm{M}$ " Series Specimens 
omission of plutonia and the inner iridium capsule (except for MC-4), an iridium foil cylinder and end discs in place of the outer iridium cylinder, and only tungsten guard capsules.

\subsection{EXPOSURE}

Four " $T$ " and " $C$ " thermal gradient specimens and two "M" and "MC" uniform temperature specimens were placed into one of Two Varian VF-400 ionpumped furnaces modified specifically for this task. Four tantalum-sheathed W/W-25Re thermocouples were positioned to sense the temperature of the uniform-temperature capsules, the bottom and top of the thermal-gradient capsules, and the top of the water-cooled copper chill block. Problems were encountered with water line leaks, thermocouple failure, and ion pump failure which somewhat delayed the start of continuous exposure. The remaining specimens were loaded into the second Varian VF-400 furnace which started with minimal difficulty and both furnaces operated satisfactorily to the completion of exposure.

At the completion of both the 1250 and $8000 \mathrm{hr}$ exposures, selected specimens were placed back into the furnace (without the thermal-gradient producing components) and given a thermal ramp representative of a reentry thermal pulse. Specimens were allowed to stabilize at about $1400^{\circ} \mathrm{C}$, rapidly heated to $1950^{\circ} \mathrm{C}$ in about 8 minutes, held at $1950^{\circ} \mathrm{C}$ for 5 minutes, and cooled below $1400^{\circ} \mathrm{C}$ in about 4 minutes.

\section{5 EVALUATION TECHNIQUES}

\subsubsection{Vent Flow}

All inner iridium capsule vents were tested for air flow before assembly. The test procedure was based on the rate of pressure rise over the calibrated volume. Pressure rise in the range of interest was timed by an electronic timer. The thermocouple gage was calibrated to read air at 350 to 450 microns with an accuracy of $\pm 2 \%$.

In the preassembly tests, an all-glass vacuum system was used. Volume of the vent rate system was determined in two ways. The first was by pressure dif ferential, comparing the pressure of gas contained in a calibrated volume to 
the pressure of that same gas in the calibrated volume plus the unknown volume. The known volume was calibrated gravimetrically and pressures were read on a reference manometer. The second method was by a volume determination procedure which consisted of a comparison of the time required for pressure to increase to $400 \mathrm{microns}$ in the unknown system and in the unknown system with the calibrated volume added, using a test vent. Flow through the vent is of no importance in this procedure. The two techniques agreed to within $2 \%$.

System leak rates were checked using an unvented disc. The preassembly test apparatus had an equivalent in-leakage rate of $0.001 \mathrm{std} \mathrm{cc} / \mathrm{hr}$. A comparable system was assembled for the contaminated post-test evaluation. Equipment leakage was measured as being 0.1 std cc/hr for the $1250-h r$ test specimens and 0.5 std cc/hr for the $8000-h r$ test specimens.

Flow was determined with an initial one atmosphere pressure differential according to the values in the following equation:

Flow $($ std cc/hr $)=\frac{P(m m)}{760} \times \frac{3600}{t(s e c)} \times v_{\text {system }}(\mathrm{cc}) \times \frac{273}{T\left({ }^{\circ} \mathrm{K}\right)}$

Pretest flow typically varied from 50 to $250 \mathrm{std} \mathrm{cc} / \mathrm{hr}$ with one vent considerably lower (13 std cc/hr) and one considerably higher (700 std cc/hr). This variation was a complex function of the electron-beam-drilled hole size and configuration as well as permeability of the powdered iridium on the vent cover.

\subsubsection{Helium Release Measurement}

A system comparable to that used for air flow measurement was set up to collect gases released from the capsule after exposure. A valved evacuated calibrated system was coupled to a capsule holding chamber. For the 1250-hr tests, the technique proved to be unsuccessful in attempting to drill through the Ta-10W capsule end and puncture the tungsten capsule. Because of schedule constraints and priority of other data, attempts to measure helium release were abandoned for the $1250-\mathrm{hr}$ test series. 
Modifications in technique were made prior to completion of the 8000-hr test specimens. The Ta-10W containers were removed by sawing and only the tungsten container was placed into the apparatus. A centerpunch sealed with three O-rings was used to penetrate the container and release gas to the measuring system. Volume was measured and a sample was then sealed in a stainless-steel container. This container was spectrochemically analyzed at the Westinghouse Hanford Company for gas species.

\subsection{Disassembly}

Outer containers were removed using a high-speed water cooled abrasive cutoff saw. The outer iridium container was also sectioned using the high-speed saw. Contents were then transferred to the metallography gloved-box line for further disassembly. A slow-speed diamond saw was used to remove inner iridium container lids and to later section the container walls and lids. Visual observations were made and photographs were taken at each step.

\subsubsection{Metallography}

Metallographic mounts were made using individual packets of epoxy mounting material. Automated grinding was performed on a Stellapol slow-speed wheel, using multiple sample holders, through 600-grit silicon carbide papers. Polishing was performed in two stages: 1 -micron alumina followed by 1 -micron diamond, both on Syntron polishing machines using Nylon cloth. Water was used as the lubricant for grinding and polishing. Where plutonia was the only material in a mount to be polished, diamond was generally not used because the slight polishing relief obtained from alumina is desirable in resolving two-phase structures.

All surfaces were initially examined in an unetched condition using a Leitz Ortholux microscope. Iridium was electro-etched in a 50-50 hydrochloric acid-water mixture using $60 \mathrm{~Hz}$ ac current. Plutonia was examined in the as-polished condition only. Photographic techniques included use of both a Polaroid attachment on the microscope and a $35-\mathrm{mm}$ camera attachment.

Microhardness measurements were made using a Leitz Miniload microhardness tester using a $100-\mathrm{g}$ load and Vickers pyramidal diamond indentor. 


\subsubsection{Chemistry and Microprobe}

Chemical analyses were performed on selected specimens at LASL on contaminated components. Electron-beam microprobe analyses were performed by LASL on selected plutonia specimens and a limited number of iridium components. Vent areas and plutonia-iridium interfaces were examined in a MAC 400 microprobe at Battelle-Northwest Laboratories.

\subsubsection{Mechanical Properties}

A high-strain tensile tester (Figure 2-6) was designed and fabricated for this effort. Specimen motion was provided by the impact of a falling weight on the end of a shaft attached directly to a pin-loaded tensile specimen. Mass of the falling weight was large enough to overcome inertial forces of the system and provide excess energy to break the specimen. Considerable time was spent determining the strain rates and calibrating forces. Force was measured with a piezoelectric transducer. Elongation was measured by determining pin-to-pin distance before and after testing. Elevated temperature was produced by direct resistance heating through the specimen and measured with an automatic optical pyrometer. A plastic enclosure with gloved ports prevented contamination from spreading beyond the test chamber.

Impacting velosity of the falling weight was $163 \mathrm{in.} / \mathrm{s}$. A hard rubber bumper stopped the falling weight attenuating the ringing problems in the force transducer but also causing a slower buildup in deformation rate. A best estimate of early grip separation rate provided by high-speed (10,000 frames/s) motion pictures is $30 \mathrm{in.} / \mathrm{s}$ average during the first $0.4 \mathrm{~ms}$ with the maximum deformation rate occurring subsequent to about $0.8 \mathrm{~ms}$. Interpolation to the first $0.1 \mathrm{~ms}$ indicates an average grip separation rate of about $3 \mathrm{in} . / \mathrm{s}$. Slopes of the initial deformation rate of nickel-270, Iype 1100 aluminum, and Type 304 stainless steel all provide effective crosshead speeds of 2 to $3 \mathrm{in.} / \mathrm{s}$ during the first $0.1 \mathrm{~ms}$, using the respective elastic moduli of these calibration specimens. 


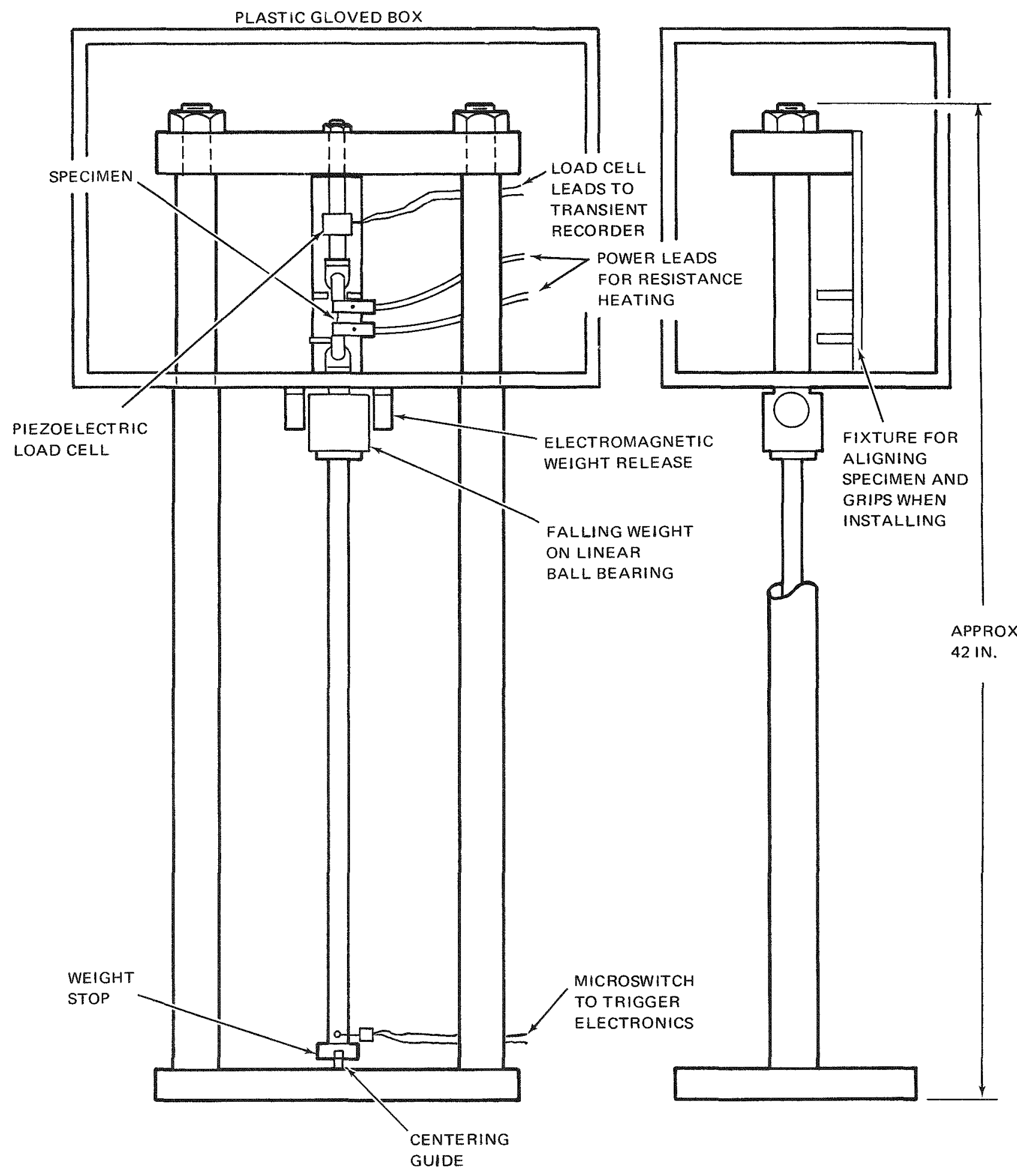

Figure 2-6. High Strain Rate Tensile Tester 
During all tests, a small dc electrical signal was applied through the specimen to determine when the actual break occurred. The signal remained constant until an unknown amount of deformation occurred at which time the output changed as a function of deformation. The time from the initiation of signal change to specimen break is believed to be related to the time during which the largest amount of specimen deformation actually occurred, probably in the range of $80 \%$ to $90 \%$ of total specimen deformation, depending on interpretation of the initiation of signal change, and is considered to be the high deformation rate portion of tensile test. Subtraction of the time of high deformation rate from the total time from load initiation to specimen break resulted in a time of deformation rate buildup averaging $0.60 \mathrm{~ms}$ for the $1400^{\circ} \mathrm{C}$ iridium tests. Using $0.60 \mathrm{~ms}$ as the time for deformation rate buildup, actual time-to-break values, and measured specimen elongations (which was actually a loadingpin-to-pin measurement), the maximum calculated deformation rates are $162 \mathrm{in.} / \mathrm{s}$ if total deformation occurred during that time. However, a more realistic value is 130 or $146 \mathrm{in.} / \mathrm{s}$ for $80 \%$ or $90 \%$ of total specimen elongation occurring during the high deformation rate time span.

High-speed motion pictures were also used to provide estimates of maximum grip separation rates. Estimates varied from $73 \mathrm{in.} / \mathrm{s}$ based on 1000 frames/ sec film speed as shown in Figure $2-7$ to $100 \mathrm{in.} / \mathrm{s}$ based on 10,000 frames/ sec film speed. These maximum rates were derived from room-temperature deformation of nickel-270 specimens and $1370^{\circ} \mathrm{C}$ testing of iridium specimens.

From these tests, deformation rate buildup from zero to maximum takes approximately 0.6 to $0.8 \mathrm{~ms}$ during which time yielding occurs and plastic strair begins. However, the majority of the plastic strain occurs during the maximum deformation rate time interval. This maximum deformation rate is most likely in the range of 100 to $150 \mathrm{in.} / \mathrm{s}$, and for purposes of later discussion, a value of $125 \pm 25 \mathrm{in.} / \mathrm{s}$ will be used.

Initial equipment set up utilized a straingage load cell which was unable to provide the rapid response required for tensile tests performed in 1.0 to $1.5 \mathrm{~ms}$. Improvement was achieved with a piezoelectric transducer connected through a charge amplifier to a transient recorder capable of storing 1024 information bits in a $10 \mathrm{~ms}$ time interval to provide a force signal. This stored signal was then plotted on an X-Y recorder as a load-time curve and, coupled with 
GRIP SEPARATION

BETWEEN FRAMES

(MILS)

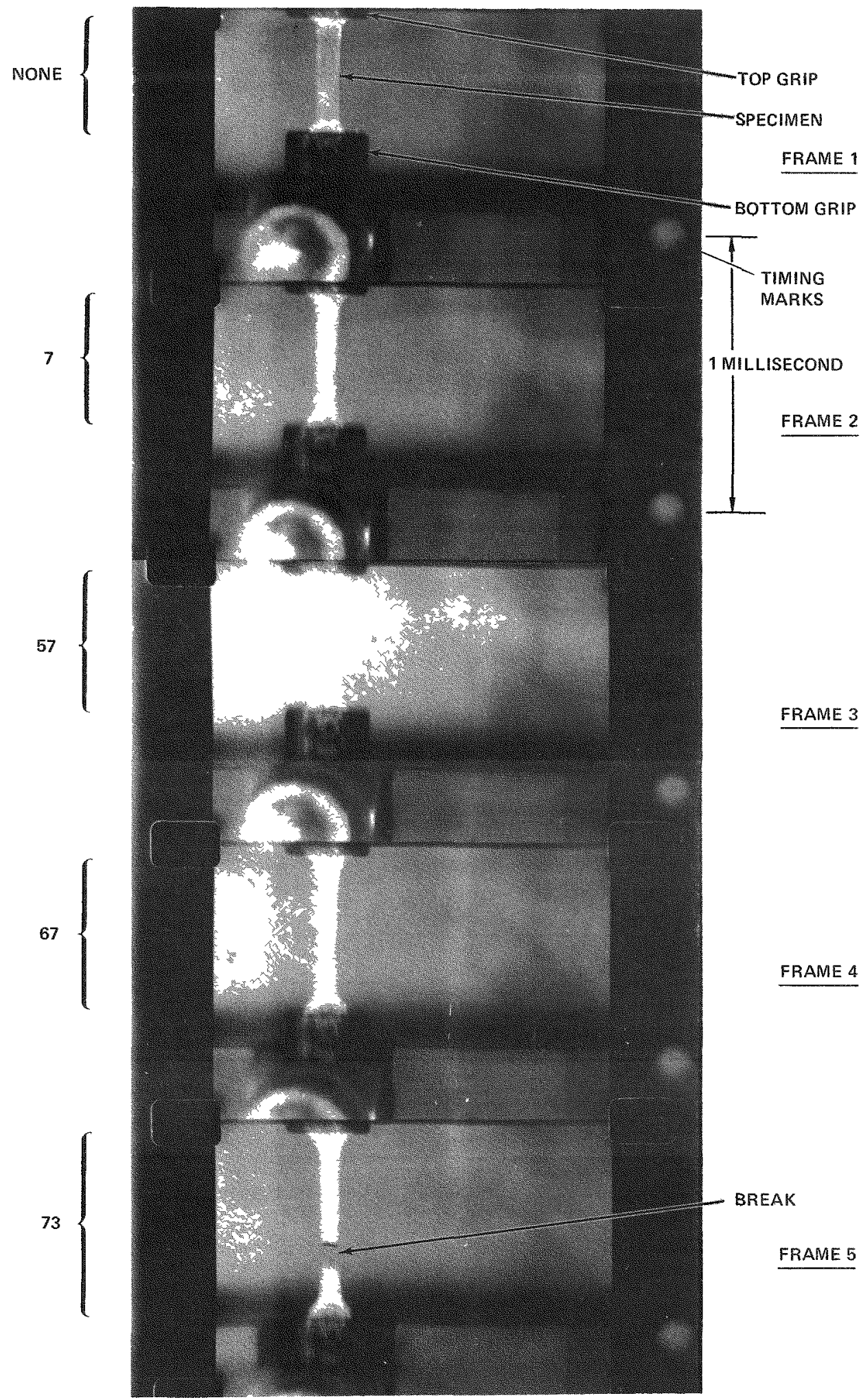

Figure 2.7 High Speed Pictures of Tensile Specimen Breakıng 
the previously described electrical signal-time curve, demonstrated the excellent time response characteristics of the piezoelectric force transducer.

Tensile strength verification tests were performed at both low and high strain rates on micro-tensile specimens of Type 1100 aluminum at room temperature and Type 304 stainless steel at room temperature and $870^{\circ} \mathrm{C}$ (high strain rate only at $870^{\circ} \mathrm{C}$ ). The low strain rates were run on an Instron screw-drive machine at crosshead rates of 0.02 and $2 \mathrm{in.} / \mathrm{min}$. Using a comparable estimate of the high strain rate at $7500 \mathrm{in.} / \mathrm{min}(125 \mathrm{in.} / \mathrm{s})$, the effect of strain rate on the ultimate stress of aluminum was consistent with that reported by Nadai and Manjoine (Reference 4). The effect of strain rate on the ultimate stress of stainless steels was directly comparable to that reported by Steichen (Reference 5 and 6$)$, although strength values were $16 \%$ to $21 \%$ higher than Hanford Engineering Development Laboratory results. Results with previously used nickel-270 were also directly comparable with nickel-200 results in Reference 6. Therefore, results determined for tensile strengths of iridium are believed to be correct for the particular lot of iridium sheet used in the test program. Throughout the test effort, verification tests were performed on nickel-270 specimens to ensure continued correctness of strength measurements.

Elongation of the microtensile specimens was measured by determining pin-topin distance before and after test. For room temperature tests of the standin materials, an effective gage length of approximately $0.3 \mathrm{in}$. was estimated. For the $1400^{\circ} \mathrm{C}$ iridium tests an effective gage length of $0.190 \mathrm{in}$. was determined by scribing two iridium specimens at $0.050 \mathrm{in.}$ intervals on both sides, heating to temperature, testing to fracture using the standard DWDL technique, and then measuring post-test incremental elongations. The central 0.150 in. section of the tensile specimen which was maintained at a $+0^{\circ},-100^{\circ} \mathrm{C}$ of the reported test temperature was taken as exhibiting representative uniform temperature elongation. The cooler portions of the gage length all had incremental elongations of $15 \%$ or less. The overall measured pin-to-pin elongation divided by the representative uniform temperatures elongation resulted in an estimated effective hot gage length for iridium of $0.190 \mathrm{in}$. The effective gage length 
value of $0.190 \mathrm{in.}$ was used for all elongation data generation. Specimen orientation was retained for all elongation measurements which were typically reproducible to within $\pm 1 \%$ of the measured value.

Heating of all iridium specimens took place in a sealed plastic box with flowing welding-grade argon. No attempt was made to purify the gas because of the oxidation resistance of iridium and the short time at temperature. The general test procedure for heating was to raise the specimen temperature to near $1000^{\circ} \mathrm{C}$, check optical pyrometer alignment on the hottest area of the specimen (viewing through an optical glass window having a negligible temperature correction), continue heating to the test temperature within 15 to $30 \mathrm{sec}$, hold until temperature was stabilized (typically 5 to $30 \mathrm{sec}$ ), and deactivate electromagnets holding the weight to effect test completion in approximately one additional second. A welding power supply and large-diameter leads minimized electrical losses in direct resistance heating the specimens. Relatively low-mass stainless-steel pin-loaded-and-clamped grips were used to minimize specimen thermal end losses. Specimen axiality was maintained by fixturing during set-up and universa joints during deformation. 
Section 3

RESULTS

Results have provided further elaboration of the complex relationships among dissimilar materials mockup up to represent a MHW heat source. Plutonia remained structurally intact while providing the driving force for materials transport, vent flow reduction, and gas formation. No intrinsic interactions occurred between plutonia and iridium. Several mechanisms appear to contribute to the vent flow reduction which occurred. Graphites showed no degradation othe $r$ than minor erosion caused by oxygen from plutonia decomposition passing through the vent and contacting the graphite. High strain rate tensile testing of microsize specimens at $1400^{\circ} \mathrm{C}$ demonstrated that no degradation had occurred because of exposure with plutonia and graphite.

\subsection{HELIUM RELEASE AND FORMATION OF $\mathrm{CO} / \mathrm{CO}_{2}$}

After completion of the 8000-hour exposure, gases were extracted from the four plutonia-fueled assemblies to determine the extent of helium release from the two fuel forms and two thermal treatments. Results are summarized in Table 3-1 which indicates that other gases were also formed during exposure.

Initial calculations of helium release based on gas release from the entire capsule volumes did not appear to provide an adequate answer to the expected plutonia helium release behavior. Later measurement of very low flow through the inner helium vents provided a strong indication that almost no gas could be extracted from the inner capsule during the short time involved in gas extraction and measurement.

Revised calculations were made on helium release and retention which appear at the bottom of Table $3-1$. The $82 \%$ helium release from the plutonia during the 8000-hr exposure coupled with only $84 \%$ release for the exposed plus $1950^{\circ} \mathrm{C}$ pulse material indicates that the helium vent was essentially plugged during the thermal pulse, and probably before th time. Calculated helium storage of 0.08 to $0.09 \mathrm{cc} / \mathrm{g}$ would occur in the pproximate temperature 
Table 3-1

GAS DATA

\begin{tabular}{|c|c|c|c|c|}
\hline Specimen Number & $\mathrm{T}-2$ & $T-4$ & $M-4$ & $M-3$ \\
\hline Plutonia Form & Pellet & Pellet & Powder & Powder \\
\hline Plutonia Weight (g) & 15.642 & 15.599 & 19.874 & 20.064 \\
\hline \multicolumn{5}{|l|}{ Thermal Treatment } \\
\hline 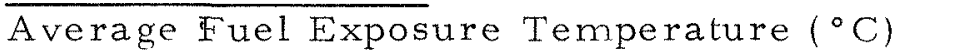 & 1370 & 1370 & 1440 & 1440 \\
\hline Thermal Gradient & Yes & Yes & No & No \\
\hline Thermal Pulse & No & Yes & No & Yes \\
\hline \multicolumn{5}{|l|}{ Helium Generation from Outgas to } \\
\hline Exposure Completion (cc STP) & 7.57 & 7.64 & 9.73 & 9.94 \\
\hline \multicolumn{5}{|l|}{ Gas Composition (mole percent) } \\
\hline $\mathrm{He}$ & 63.9 & 47.3 & 25.2 & 17.6 \\
\hline Ar & 0.24 & 0.02 & 0.02 & 0.01 \\
\hline $\mathrm{H}_{2}$ & $>0.01$ & $>0.01$ & $>0.01$ & $>0.01$ \\
\hline $\mathrm{CH}$ & $>0.01$ & $>0.01$ & $>0.01$ & $>0.01$ \\
\hline $\mathrm{O}_{2}$ & 0.1 & 0.04 & 0.1 & $>0.01$ \\
\hline $\mathrm{N}_{2}^{2}$ & 6.7 & 11.5 & 15.9 & 0.33 \\
\hline $\mathrm{CO}$ & 27.6 & 32.4 & 40.7 & 61.8 \\
\hline $\mathrm{CO}_{2}$ & 1.41 & 8.76 & 18.0 & 20.2 \\
\hline $\mathrm{CO} / \mathrm{CO}_{2}$ Ratio & 19.6 & 3.7 & 2.3 & 3.1 \\
\hline \multirow{2}{*}{\multicolumn{5}{|c|}{ Equilibrium O/Pu Ratio at Thermal }} \\
\hline & & & & \\
\hline Pulse Temp & -- & 1.93 & -- & 1.93 \\
\hline Measured Gas Release Volume (cc STP) & 8.78 & 12.3 & 31.4 & 46.6 \\
\hline \multicolumn{5}{|c|}{ Calculations Based on Gas Release only from Volumes External to Inner Vented } \\
\hline \multicolumn{5}{|c|}{ Capsule } \\
\hline 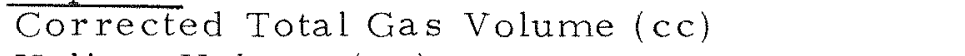 & 9.75 & 13.6 & 38.0 & 56.3 \\
\hline Helium Volume (cc) & 6.23 & 6.45 & 9.59 & 9.91 \\
\hline $\mathrm{CO}+\mathrm{CO}_{2}$ Volume $(\mathrm{cc})$ & 2.83 & 5.61 & 22.3 & 46.2 \\
\hline \multicolumn{5}{|l|}{ Total Gas Pressure - at Exposure } \\
\hline temp $(p s i)$ & 61 & 85 & 180 & 267 \\
\hline - at Thermal pulse (psi) & - - & 115 & -- & 346 \\
\hline Helium Release $(\%)$ & 82 & 84 & 99 & 100 \\
\hline Helium Retention in Plutonia (cc/g) & 0.09 & 0.08 & 0.01 & 0.00 \\
\hline $\begin{array}{l}\text { O/Pu Ratio Change based on Oxygen Loss } \\
\text { to } \mathrm{CO} \text { and } \mathrm{CO}_{2} *\end{array}$ & 0.002 & 0.005 & 0.016 & 0.035 \\
\hline
\end{tabular}

* Assuming no air present initially internally. 
range of $1080^{\circ}$ to $1210^{\circ} \mathrm{C}$ according to information in References 2 and 9. The 0.08 to $0.09 \mathrm{cc} / \mathrm{g}$ storage is probably related to low vent flow which occurred earlier during exposure. According to these calculations, the powder plutonia specimens maintained at only a somewhat higher temperature than the plutonia pellets $\left(1440^{\circ}\right.$ and $1370^{\circ} \mathrm{C}$ respectively) released $99 \%$ to $100 \%$ of the generated helium leaving essentially no stored helium.

Gas analysis also showed that large amounts of carbon monoxide (CO) and carbon dioxide $\left(\mathrm{CO}_{2}\right)$ were formed. Plutonia decomposition provided the oxygen for reaction with graphite in the system. Based on volumes of CO and $\mathrm{CO}_{2}$ present, if all the oxygen came from the plutonia, then the composition change in the plutonia pellets would have been 0.002 to $0.005 \mathrm{O} / \mathrm{Pu}$ for the pellets and 0.016 to $0.035 \mathrm{O} / \mathrm{Pu}$ ratio for the much higher surface area plutonia powder. In either case, all plutonia would have remained single phase during exposure and subsequent cooling.

Volume of $\mathrm{CO}$ plus $\mathrm{CO}_{2}$ was less than that of the helium for the plutonia pellet thermal gradient tests but was several times larger in volume than the helium for the uniform temperature plutonia powder specimens. Total gas pressure at exposure temperature ranged from 61 to 267 psi. The thermal pulse resulted in a maximum calculated pressure of 346 psi but was successfully accommodated in the guard capsules which were designed as pressure vessels for this purpose.

Reaction of oxygen from the plutonia with the graphite external to the vented fuel capsule resulted in formation of $\mathrm{CO}$ and $\mathrm{CO}_{2}$ gas ratio of which is determinable by thermodynamic calculations provided that access between materials occurs. Figure 3-1 shows the thermodynamic aspects of the MHW heat source materials using an approach similar to that of Darken and Gurry (Reference 10). However, this figure does not describe system kinetics which are controlled by other variables such as physical access of different materials to each other. The major difficulty in applying thermodynamics to this situation is that the thermodynamic properties of the oxides and plutonia are subject to varying degrees of error and, in particular, the values of iridium oxide gaseous species are not well known. Accuracies are typically in the $\pm 1 \mathrm{kcal} / \mathrm{mole}$ region for the gaseous reactions but are perhaps as much as $\pm 30 \mathrm{kcal} / \mathrm{mole}$ for oxygen activity in the plutonia. Regardless of the possible errors, the limited data available to permit reasonable interpretation of observed phenomena. 


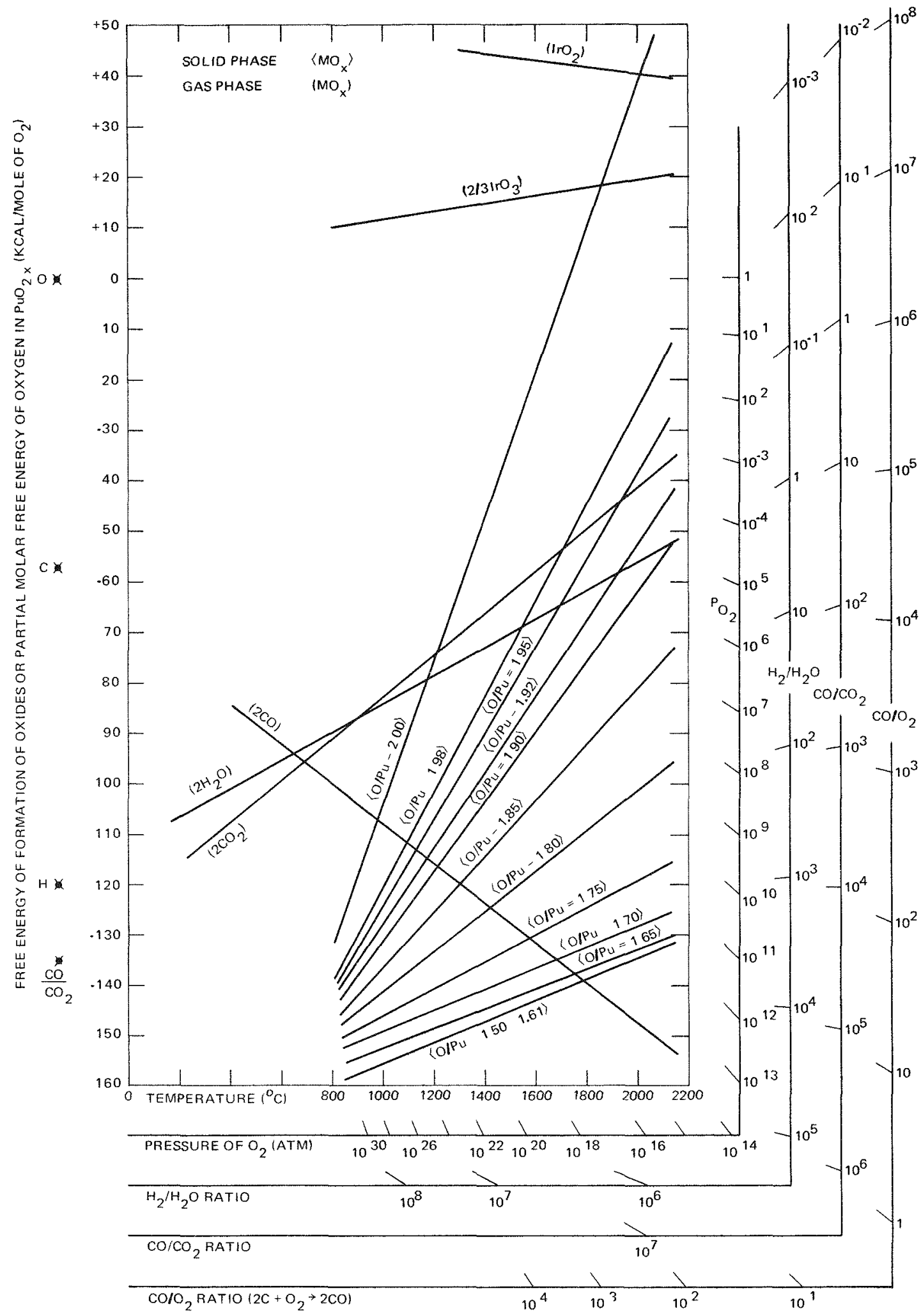

Figure 3-1. Gaseous Oxides and $\mathrm{PuO}_{2-x}$ Free Energy 
Based on the best thermodynamic data currently available, Figure $3-1$ shows that, at $1400^{\circ} \mathrm{C}$, the oxygen partial pressure over $\mathrm{PuO}_{2} .00$ is $6 \times 10^{-7}$ atm but is reduced to $2 \times 10^{-11}$ atm when the solid-phase composition is PuO $1.98^{\circ}$ Presence of carbon in an open system containing plutonia could reduce the oxygen content of the plutonia well below the (2CO) line in Figure $3-1$, depending upon the $\mathrm{CO} / \mathrm{O}_{2}$ ratio. However, in a closed system, reactions are limited by the $\mathrm{CO} / \mathrm{CO}_{2}$ ratio exemplified as the $\left(2 \mathrm{CO}_{2}\right)$ line in Figure $3-1$ for a $1 / 1$ ratio. For example, in $\mathrm{T}-4$ where the $\mathrm{CO} / \mathrm{CO}_{2}$ ratio was measured as 3.7/1, solid $\mathrm{PuO}_{1.99+}$ would have been in equilibrium at $1370^{\circ} \mathrm{C}$, but the equilibrium solid plutonia oxygen content would have been $\mathrm{PuO}_{1.93}$ at $1950^{\circ} \mathrm{C}$. Based on total $\mathrm{CO}$ and $\mathrm{CO}_{2}$ volumes produced, reaction kinetics did not permit the plutonia to become significantly substoichiometric during the $1950^{\circ} \mathrm{C}$ thermal pulse.

\subsection{VENT FLOW}

Before exposure, each vent was measured for airflow characteristics with a one atmosphere pressure differential to vacuum on the outlet side. Comparable tests made after exposure showed decreased airflow in almost every case. with several essentially plugged (Table 3-2).

Only one $1250-$ hr vent appeared to be completely plugged, that with powdered plutonia present. Flow in the thermal gradient specimen which was not thermally pulsed decreased from 103 to $8.2 \mathrm{std}$ cc/hr. The comparable thermally pulsed specimen flow remained essentially unchanged at 47 to $45 \mathrm{std} \mathrm{cc} / \mathrm{hr}$. Flow measurements through the control vents were not comparable because of the absence of a vent cover.

Airflow of the fueled $8000-\mathrm{hr}$ specimens were all reduced to $1 \mathrm{std} \mathrm{cc} / \mathrm{hr}$ or less. Vents were sectioned for metallography before helium flow could be measured. A comparable control vent, with vent cover, did show a decrease in airflow. Helium flow rates were measured on three control vents as listed in Table $3-2$ and were higher than airflow rates by factors of 1.3 to 2.3 . Enhanced flow of helium compared to air is expected by theory, whatever the 
Table 3-2

VENT AIR FLOW DATA

\begin{tabular}{|c|c|c|c|c|c|}
\hline \multirow{2}{*}{$\begin{array}{l}\text { Specimen } \\
\text { No. }\end{array}$} & \multicolumn{3}{|c|}{ Vent Thermal Treatment } & \multicolumn{2}{|c|}{ Vent Air Flow ${ }^{a}$} \\
\hline & $\begin{array}{l}\text { Temperature } \\
\left({ }^{\circ} \mathrm{C}\right)\end{array}$ & $\begin{array}{l}\text { Time } \\
(\mathrm{hr})\end{array}$ & $\begin{array}{l}\text { Thermal } \\
\text { Pulse }\end{array}$ & $\begin{array}{c}\text { Before } \\
\text { Exposure } \\
(\mathrm{cc} / \mathrm{hr})\end{array}$ & $\begin{array}{l}\text { After } \\
\text { Exposure } \\
(\mathrm{cc} / \mathrm{hr})\end{array}$ \\
\hline$T-1$ & $1330^{\mathrm{C}}$ & 1250 & No & 103 & 8.2 \\
\hline$T-3$ & $1330^{\mathrm{c}}$ & 1250 & Yes & 47 & 45 \\
\hline$C-3$ & $1330^{\mathrm{c}}$ & 1250 & Yes & $193^{\mathrm{d}}$ & $153^{d}$ \\
\hline $\mathrm{T}-2$ & $1330^{c}$ & 8000 & No & 199 & 0.0 \\
\hline $\mathrm{T}-4$ & $1330^{\mathrm{c}}$ & 8000 & Yes & 13 & 0.2 \\
\hline $\mathrm{C}-4$ & $1330^{\mathrm{C}}$ & 8000 & No & 80 & $\begin{array}{l}48.1 \\
(80.2 \text { helium } \\
\text { flow) }\end{array}$ \\
\hline$M-1$ & 1440 & 1250 & No & 145 & $<0.05$ \\
\hline$M-4$ & 1440 & 8000 & No & 700 & 1.0 \\
\hline$M-3$ & 1440 & 8000 & Yes & 256 & 0.9 \\
\hline$M C-4$ & 1440 & 8000 & Yes & $157^{\mathrm{d}}$ & $\begin{array}{l}3.7^{\mathrm{d}} \\
(4.7 \text { helium } \\
\text { flow) }\end{array}$ \\
\hline None & 25 & $-10,000$ & No & $224^{\mathrm{d}}$ & $\begin{array}{l}219^{\mathrm{d}} \\
(502 \text { helium } \\
\left.\text { flow }{ }^{\mathrm{d}}\right)\end{array}$ \\
\hline
\end{tabular}

a. Test performed with a pressure differential of one atmosphere of air to vacuum. Accuracy of pre-test flow was $\pm 2 \%$ of recorded value; post-test accuracy was the larger of $\pm 3 \%$ or $0.5 \mathrm{cc} / \mathrm{hr}$.

b. Thermal pulse was 5 min heating from operating temperature to $1950^{\circ} \mathrm{C}$, $5 \mathrm{~min}$ at $1950^{\circ} \mathrm{C}$, and $5 \mathrm{~min}$ cooling from $1950^{\circ}$ to about $800^{\circ} \mathrm{C}$.

c. Calculated vent temperature in thermal gradient configuration.

d. No vent cover. 
detailed flow characteristics are through the complex tortuous iridium powder path in series with the small hole through the lid. Originally, flow appears to have been controlled by the variable tortuous paths through the iridium powder. Post-test flow was more likely controlled by constriction of the lid hole. In either case, helium flow would be higher than airflow.

\subsection{ENCA PSULATION MA TERIA L OBSERVATIONS}

Macroscopic and microscopic observations on the 1250- and 8000-hr specimens are summarized in Tables 3-3 through 3-6. Too many different interactive variables were present for broad conclusions without extensive qualifications. Therefore, mockup test components are described in detail starting with the plutonia at the interior of the capsule.

\subsubsection{Plutonia}

Plutonia remained in excellent condition as shown in the macrograph in Figure 3-2 for the 1250-hr pellets. The appearance of the 8000-hr pellets was identical. Dimensional measurements (Table 3-7) showed no change within the accuracy of the measurements.

Microscopically, all plutonia pellets remained single phase, indicating a minimum oxygen content of $\mathrm{PuO}_{1.98}$ which is consistent with oxygen loss calculations in Section 3.1. Photomicrographs of areas near the hot end of each pellet are shown in Figure 3 -3. The large angular porosity (black areas) has become more spheroidized with longer exposure. There appears to be finer porosity in the longer-term specimens.

Several areas of three of the pellets had metallic precipitates or gray grain boundary phases (Figure 3-4). Handling and polishing were performed with organic-free materials to eliminate the possibility of reaction products. Microprobe examination at LASL determined that the metallic precipitates were tungsten rich, with lesser amounts of iron. The gray grain boundary precipitates contained aluminum, chlorine, plutonium, and oxygen. Chlorine is not included in the routine chemical analysis and therefore its source is unknown. 
Table $3-3$

MACROSCOPIC OBSERVATIONS ON 1250 HOUR SPECIMENS

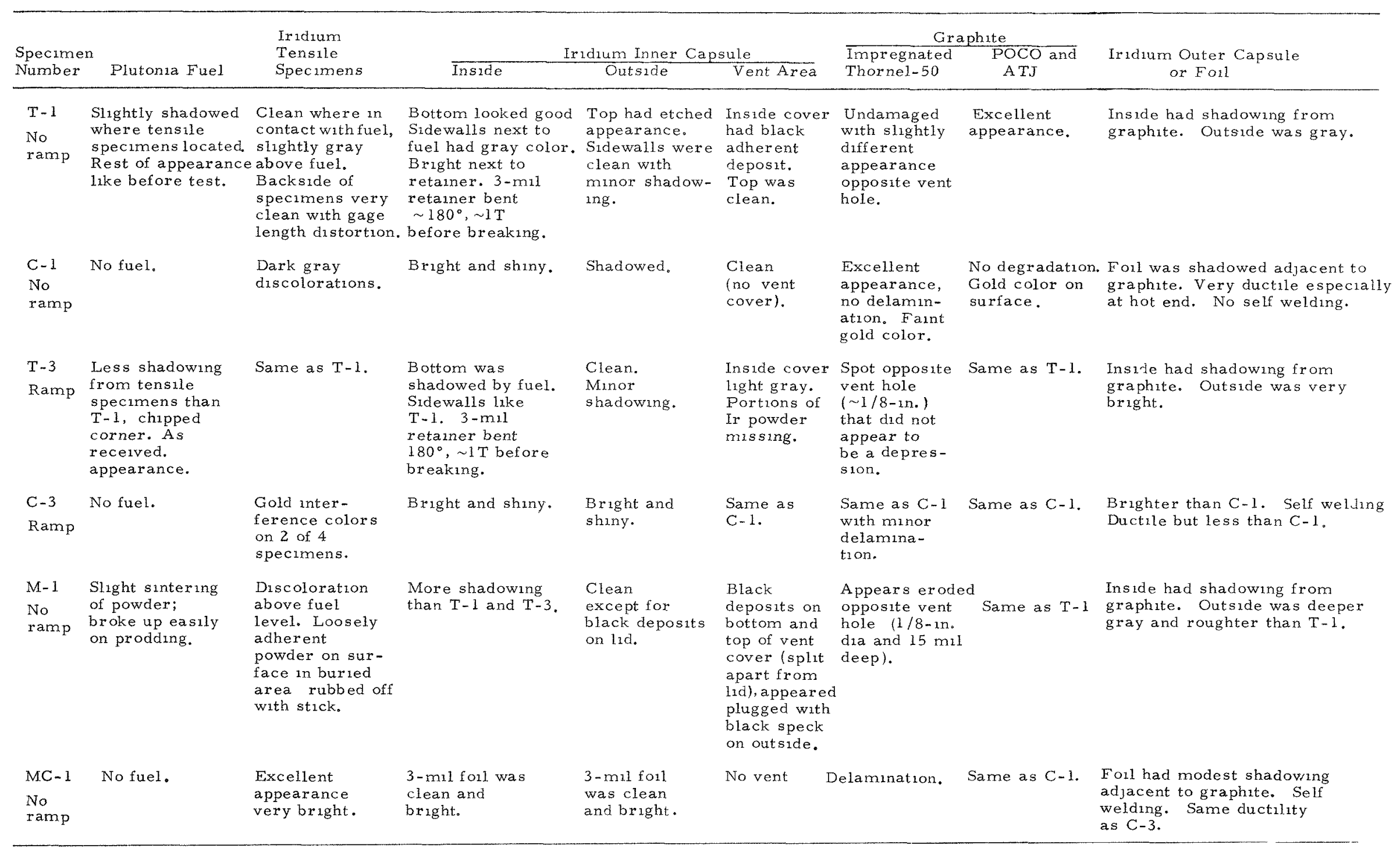


Table 3-4

MACROSCOPIC OBSERVATIONS ON 8000 HOUR SPECIMENS

\begin{tabular}{|c|c|c|c|c|c|c|c|c|}
\hline $\begin{array}{l}\text { Specimen } \\
\text { Number }\end{array}$ & Plutonia Tuel & $\begin{array}{l}\text { Irrdium Tensile } \\
\text { Specimens }\end{array}$ & & Irıdium Inner Caps & & Grap & ohite & Irıdrum Outer Capsule \\
\hline $\begin{array}{l}\text { T } 2 \\
\text { No ramp }\end{array}$ & $\begin{array}{l}\text { Excellent } \\
\text { appearance } \\
\text { Shadowed tensile } \\
\text { specimens. }\end{array}$ & $\begin{array}{l}\text { Gold deposit above } \\
\text { fuel. Rest of surface } \\
\text { quite bright. }\end{array}$ & $\begin{array}{l}\text { Grey and gold color } \\
\text { adjacent to fuel. Shiny } \\
\text { adjacent to tensile } \\
\text { specimen holder. }\end{array}$ & $\begin{array}{l}\text { Shiny with } \\
\text { machine marks } \\
\text { still present. }\end{array}$ & $\begin{array}{l}\text { Inside shiny } \\
\text { except golden } \\
\text { color at periphery. } \\
\text { Burnished in } \\
\text { 2 a eas while } \\
\text { cutting. }\end{array}$ & $\begin{array}{l}\text { Undamaged with no } \\
\text { erosion or marking. }\end{array}$ & $\begin{array}{l}\text { Excellent } \\
\text { appearance }\end{array}$ & $\begin{array}{l}\text { Fine matte surface on } \\
\text { outside with multiple } \\
\text { lumps of bulges. Inside } \\
\text { surface was fine grained } \\
\text { throughout with ring at } \\
\text { T-50 graphite. Vent } \\
\text { visible on both sides. }\end{array}$ \\
\hline $\begin{array}{l}\mathrm{T}-4 \\
\text { Ramp }\end{array}$ & $\begin{array}{l}\text { Same as } 7-2 \\
\text { but more appar } \\
\text { ent shadowing }\end{array}$ & $\begin{array}{l}\text { Gold to gray toward } \\
\text { fuel. Shiny away from } \\
\text { fuel. Black toward } \\
\text { and a bove fuel. }\end{array}$ & $\begin{array}{l}\text { Black and gold color } \\
\text { deposits adjacent to } \\
\text { fuel. Shiny adiacent to } \\
\text { tensile specmen holder. }\end{array}$ & Same as $T-2$ & $\begin{array}{l}\text { Black plutonia } \\
\text { deposit over } \\
\text { most of surface. }\end{array}$ & $\begin{array}{l}\text { Endamaged, no erosion, } \\
\text { a } 0.2 \text { - in. dark a rea in } \\
\text { center opposite vent in } \\
\text { inner Ir capsule }\end{array}$ & Same at $T-2$ & $\begin{array}{l}\text { Same as } T-2 \text { except no } \\
\text { lumps on outside surface. }\end{array}$ \\
\hline $\begin{array}{l}C+ \\
\text { No ramp }\end{array}$ & Vo fue 1 & $\begin{array}{l}\text { Discoloration in } \\
\text { various areas with } \\
\text { deposits (same as } \\
\text { short-term) }\end{array}$ & Bright and shiny & Same as $T-2$ & Clean and shiny & Undamaged & Undamaged & $\begin{array}{l}\text { Dull gray outer surface. } \\
\text { Bright shiny inner surface. }\end{array}$ \\
\hline $\begin{array}{l}\text { M-4 } \\
\text { No : amp }\end{array}$ & $\begin{array}{l}\text { Considcrable } \\
\text { sintering of } \\
\text { pouder }\end{array}$ & $\begin{array}{l}\text { Almost no discolora- } \\
\text { tion above fuel. Loosely } \\
\text { adherent plutonia on } \\
\text { surface }\end{array}$ & $\begin{array}{l}\text { Shiny over top half, } \\
\text { bottom half has black } \\
\text { colored deposit. }\end{array}$ & $\begin{array}{l}\text { Bulged ends. } \\
\text { Shny surface } \\
\text { with no dark } \\
\text { a reas. }\end{array}$ & $\begin{array}{l}\text { Plutonia deposit } \\
\text { over entire } \\
\text { surfacc. }\end{array}$ & $\begin{array}{l}\text { Eroded hole about } \\
0.020 \text { in. deep and } \\
0.060 \text { in, dia plus } \\
\text { charred a rea and } \\
\text {-3/8 ins. dia dark area. } \\
\text { Ir capsule outine } \\
\text { visible. }\end{array}$ & $\begin{array}{l}\text { Excellent } \\
\text { appearance }\end{array}$ & $\begin{array}{l}\text { Coarse spangled surface } \\
\text { on outside. Coarser grains } \\
\text { on inside than M-3. Dif- } \\
\text { ferent texture adjacent to } \\
\text { T-50 graphite. Vent hole } \\
\text { visible only on inside. }\end{array}$ \\
\hline $\begin{array}{l}\text { MC } 3 \\
\text { No ramp }\end{array}$ & No fuel & $\begin{array}{l}\text { Thermally etched but } \\
\text { very bright }\end{array}$ & Foll very shiny. & $\begin{array}{l}\text { Fonl shiny } \\
\text { and quite } \\
\text { ductile. } \\
\text { Graphite con- } \\
\text { tact a rea } \\
\text { roughened. }\end{array}$ & No vent. & Undamaged & $\begin{array}{l}\text { Slightly gold } \\
\text { colored on } \\
\text { some surfaces }\end{array}$ & $\begin{array}{l}\text { Foil stuck at weld area of } \\
\text { tungsten capsule. Inside } \\
\text { bright. Outside shightly } \\
\text { matte finnsh. }\end{array}$ \\
\hline $\begin{array}{l}M-3 \\
\text { Ramp }\end{array}$ & $\begin{array}{l}\text { Considerable } \\
\text { sintering of pou - } \\
\text { der more than } \\
\text { M-4 }\end{array}$ & $\begin{array}{l}\text { Some discoloration } \\
\text { above fuel level. } \\
\text { Loosely adherent } \\
\text { plutona on surface }\end{array}$ & $\begin{array}{l}\text { Shiny except for brown } \\
\text { deposit in bottom. }\end{array}$ & $\begin{array}{l}\text { Shiny surface } \\
\text { with no dark } \\
\text { areas. }\end{array}$ & $\begin{array}{l}\text { Vont cover } \\
\text { golden at periphery } \\
\text { shiny and blackish } \\
\text { powder in center } \\
\text { areas. }\end{array}$ & $\begin{array}{l}\text { Delaminated, eroded } \\
\text { hole a bout } 0.0201 \mathrm{n} \text {, } \\
\text { deep and } 0.060 \mathrm{ma} \text {, dra } \\
\text { plus } 0.150 \text { H1a dark a rea, }\end{array}$ & Same as $M-4$ & $\begin{array}{l}\text { Weld spatter on top. } \\
\text { Coarse spangled surface on } \\
\text { outside. Inside shinser with } \\
\text { different texture adjacent } \\
\text { to T-50 graphite. Vent hole } \\
\text { visible only on inside. }\end{array}$ \\
\hline $\begin{array}{l}\text { MC-4 } \\
\text { Ramp }\end{array}$ & No fuel & Same as MC-3 & Foil shiny & $\begin{array}{l}\text { Shightly golden } \\
\text { color adjacent } \\
\text { to graphite. }\end{array}$ & $\begin{array}{l}\text { Outside very good } \\
\text { appearance. }\end{array}$ & Same as $\mathrm{MC}-3$ & Same as $\mathrm{MC}-3$ & Same as MC-3 \\
\hline
\end{tabular}


Table 3-5

MICROSCOPIC OBSERVATIONS ON 1250 HOUR SPECIMENS

\begin{tabular}{|c|c|c|c|}
\hline $\begin{array}{l}\text { Specimen } \\
\text { Number }\end{array}$ & $\begin{array}{l}\text { Plutonia } \\
\text { Fuel }\end{array}$ & Iridium Capsule & Vent Area \\
\hline$T-1$ & $\begin{array}{l}\text { Single phase } \\
\text { Large angular } \\
\text { porosity and } \\
\text { small spherical } \\
\text { porosity. }\end{array}$ & $\begin{array}{l}\text { Bottom has reaction layer } \\
\text { with voids at interface } \\
\text { with the unattacked } \\
\text { material (0.5 mil thick). } \\
\text { Reaction layer goes up } \\
\text { side wall tapering off } \\
\text { toward the top. } \\
\text { Fine grain structure. }\end{array}$ & $\begin{array}{l}\text { Vent almost plugged } \\
\text { with iridium. } \\
\text { Delaminations in vent } \\
\text { hole. } \\
\text { Plutonia between lid } \\
\text { and vent cover. } \\
\text { Iridium powder still } \\
\text { on vent cover. }\end{array}$ \\
\hline$C-1$ & No plutonia & $\begin{array}{l}\text { Fine grain structure. } \\
\text { No attack. }\end{array}$ & $\begin{array}{l}\text { Delamination in vent } \\
\text { hole. } \\
\text { No deposits or attack. } \\
\text { No vent cover. }\end{array}$ \\
\hline $\mathrm{T}-3$ & $\begin{array}{l}\text { Single phase } \\
\text { except for } \\
\text { small quantity } \\
\text { of gray second } \\
\text { phase in grain } \\
\text { goundaries } \\
\text { Large angular } \\
\text { pores } \\
\text { Same as } \mathrm{T}-1 \text {; } \\
\text { smaller } \\
\text { spherical pores } \\
\text { larger than } \mathrm{T}-1\end{array}$ & $\begin{array}{l}\text { String of pores along } \\
\text { bottom and up sidewalls } \\
\text { which appears inter- } \\
\text { metallic when etched } \\
(0.4 \text { mil thick). } \\
\text { Large grain structure. }\end{array}$ & $\begin{array}{l}\text { Plutonia between lid } \\
\text { and vent cover. } \\
\text { Bottom of vent } \\
\text { bridged over-(not } \\
\text { quite ground to } \\
\text { centerline). } \\
\text { Tungsten rich material } \\
\text { on outside of vent exit. }\end{array}$ \\
\hline$C-3$ & No plutonia & $\begin{array}{l}\text { Coarse grain structure. } \\
\text { No attack. }\end{array}$ & $\begin{array}{l}\text { Delamination in vent } \\
\text { hole. } \\
\text { No deposits or attack. } \\
\text { No vent cover. }\end{array}$ \\
\hline$M-1$ & $\begin{array}{l}\text { Plutonia } \\
\text { powder not } \\
\text { examined }\end{array}$ & $\begin{array}{l}\text { Small pores on bottom } \\
\text { of inside, localized, not } \\
\text { on wall to depth of } 0.1 \text { mil. } \\
\text { (Capsule was not in } \\
\text { direct contact with } \\
\text { plutonia because an } \\
\text { iridium sub-capsule was } \\
\text { used to hold the sub- } \\
\text { size tensile specimens). }\end{array}$ & $\begin{array}{l}\text { Plutonia between lid } \\
\text { and vent cover. } \\
\text { Ground past center- } \\
\text { line of vent hole; } \\
\text { unable to determine } \\
\text { reason for plugging. } \\
\text { Reaction ( } 0.5 \text { mil } \\
\text { thick) on outside at } \\
\text { vent area. (Tungsten } \\
\text { rich by microprobe). } \\
\text { Iridium powder still } \\
\text { on vent cover. }\end{array}$ \\
\hline MC- 1 & No plutonia & No capsule. & No vent. \\
\hline
\end{tabular}


Table $3-6$

MIC ROSCOPIC OBSERV ATIONS ON 8000 HOUR SPECIMENS

\begin{tabular}{|c|c|c|c|}
\hline Specimen & Plutonia Fuel & Iridium Capsule & Vent Area \\
\hline $\begin{array}{c}\text { T-2 } \\
\text { No pulse }\end{array}$ & $\begin{array}{l}\text { Single phase, polycrystal- } \\
\text { line, and porous. No metal } \\
\text { precipitates. Impurity phase } \\
\text { present in pores near edge. } \\
\text { Large pores less than T-1 } \\
\text { short-term specimens. Fine } \\
\text { spherical voids, more } \\
\text { random arrangement. }\end{array}$ & $\begin{array}{l}\text { Bottom surface adjacent to } \\
\text { plutonia roughened, indica- } \\
\text { tive of reaction. Compa- } \\
\text { rable to short-term speci- } \\
\text { men. Slightly coarser grain } \\
\text { size than T-1. No reaction } \\
\text { on outside surfaces. }\end{array}$ & $\begin{array}{l}\text { Small bridge of ceramic } \\
\text { material across vent hole. } \\
\text { Ir powder still on vent } \\
\text { cover. Vent cover opposite } \\
\text { hole eroded to depth of } \\
1 \text { mil. }\end{array}$ \\
\hline $\begin{array}{c}T-4 \\
\text { Pulsed }\end{array}$ & $\begin{array}{l}\text { Single phase, polycrystal- } \\
\text { line, and porous. Uniform } \\
\text { structure over entire sur- } \\
\text { face. A few intergranular } \\
\text { metal precipitates near edge } \\
\text { of pellet. Large pores are } \\
\text { larger than in } \mathrm{T}-2 \text {; small } \\
\text { pores about the same as } \\
\text { T-2. }\end{array}$ & $\begin{array}{l}\text { Bottom surface adjacent to } \\
\text { plutonia roughened and } \\
\text { appeared ponetrated by dark } \\
\text { nonmetallic phase. Inside } \\
\text { surface area has very small } \\
\text { grains associated with } \\
\text { reaction area. No reaction } \\
\text { on outside surfaces. Larger } \\
\text { grains than } \mathrm{T}-3 \text {. }\end{array}$ & $\begin{array}{l}\text { Ground and/or polished } \\
\text { past centerline of vent with- } \\
\text { out ever seeing a hole. It } \\
\text { is probable that the vent } \\
\text { was plugged with Ir. Ir } \\
\text { powder still on vent cover. }\end{array}$ \\
\hline $\begin{array}{c}\mathrm{C}-4 \\
\text { No pulse }\end{array}$ & No fuels. & $\begin{array}{l}\text { Surfaces smooth with minor } \\
\text { thermal etching. Medium } \\
\text { grain size larger than C3. } \\
\text { No attack. }\end{array}$ & $\begin{array}{l}\text { Ground and/or polished } \\
\text { past centerline of vent. EB } \\
\text { fracture cracks present. } \\
\text { Ir powder still on vent cover } \\
\text { but central area thinned } \\
\text { from about } 6 \text { mils thick to } \\
\text { about } 1 \text { mil. }\end{array}$ \\
\hline $\begin{array}{l}\mathrm{M}-4 \\
\text { No pulse }\end{array}$ & $\begin{array}{l}\text { Plutonia powder not } \\
\text { examined. }\end{array}$ & Not examined. & $\begin{array}{l}\text { Vent appeared plugged with } \\
\text { nonmetallic semi- } \\
\text { transparent material. } \\
\text { (DPH } 35 \text { l) Vent cover tipped } \\
\text { over in mount and did not } \\
\text { polish. }\end{array}$ \\
\hline $\begin{array}{c}M-3 \\
\text { Pulsed }\end{array}$ & $\begin{array}{l}\text { Plutonia powder not } \\
\text { examined. }\end{array}$ & Not examined. & $\begin{array}{l}\text { Vent cavity filled with } \\
\text { epoxy (DPH } 33 \text { ). No other } \\
\text { foreign material in vent. } \\
\text { Ground post vent. Vent } \\
\text { cover not polished. Large } \\
\text { grain size. }\end{array}$ \\
\hline $\begin{array}{l}\mathrm{MC}-4 \\
\text { Pulsed }\end{array}$ & No fuel. & Not examined. & Not examined. \\
\hline
\end{tabular}




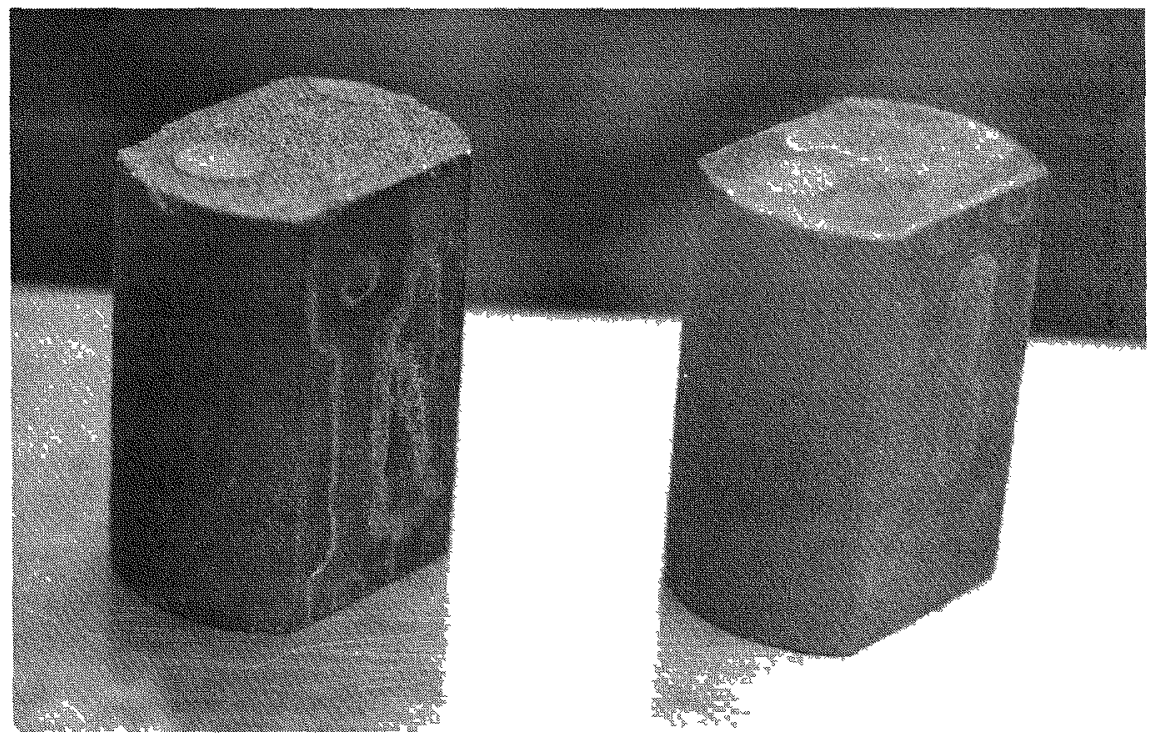

T-1, NO PULSE

T-3, PULSED

Figure 3-2. Post-Test Macrographs of Plutonia, Exposed $1250 \mathrm{hr}$

Table 3-7

PLUTONIA FUEL DIMENSION DATA

\begin{tabular}{|c|c|c|c|c|c|c|}
\hline \multirow[b]{2}{*}{$\begin{array}{l}\text { Specimen } \\
\text { Number }\end{array}$} & \multicolumn{3}{|c|}{ Pre-Test } & \multicolumn{3}{|c|}{ Post-Test } \\
\hline & $\begin{array}{l}\text { Length } \\
\quad \text { (in.) }\end{array}$ & $\begin{array}{l}\text { Diameter } \\
\text { (in.) }\end{array}$ & $\begin{array}{l}\text { Across } \\
\text { Flats } \\
\text { (in.) }\end{array}$ & $\begin{array}{l}\text { Length } \\
\text { (in.) }\end{array}$ & $\begin{array}{l}\text { Diameter } \\
\text { (in.) }\end{array}$ & $\begin{array}{c}\text { Across } \\
\text { Elats } \\
\text { (in.) }\end{array}$ \\
\hline $\begin{array}{c}\mathrm{T}-1 \\
1250 \mathrm{Hr} \\
\text { No Pulse }\end{array}$ & 0.6466 & 0.4890 & 0.3545 & 0.645 & $\begin{array}{l}0.486- \\
0.488\end{array}$ & $\begin{array}{l}0.353- \\
0.354\end{array}$ \\
\hline $\begin{array}{l}\quad \mathrm{T}-3 \\
1250 \mathrm{Hr} \\
\text { Pulse }\end{array}$ & 0.6531 & 0.4888 & 0.3556 & $\begin{array}{l}0.652- \\
0.654\end{array}$ & $\begin{array}{l}0.489- \\
0.490\end{array}$ & 0.355 \\
\hline $\begin{array}{c}\mathrm{T}-2 \\
8000 \mathrm{Hr} \\
\text { No Pulse }\end{array}$ & 0.6497 & 0.4880 & 0.3549 & $\mathrm{a}$ & 0.4887 & 0.3554 \\
\hline $\begin{array}{l}\text { T-4 } \\
8000 \mathrm{Hr} \\
\text { Pulse }\end{array}$ & 0.6447 & 0.4880 & 0.3553 & $\mathrm{a}$ & 0.4885 & 0.3550 \\
\hline
\end{tabular}

a. Slice taken off bottom for metallography prior to measurement. 


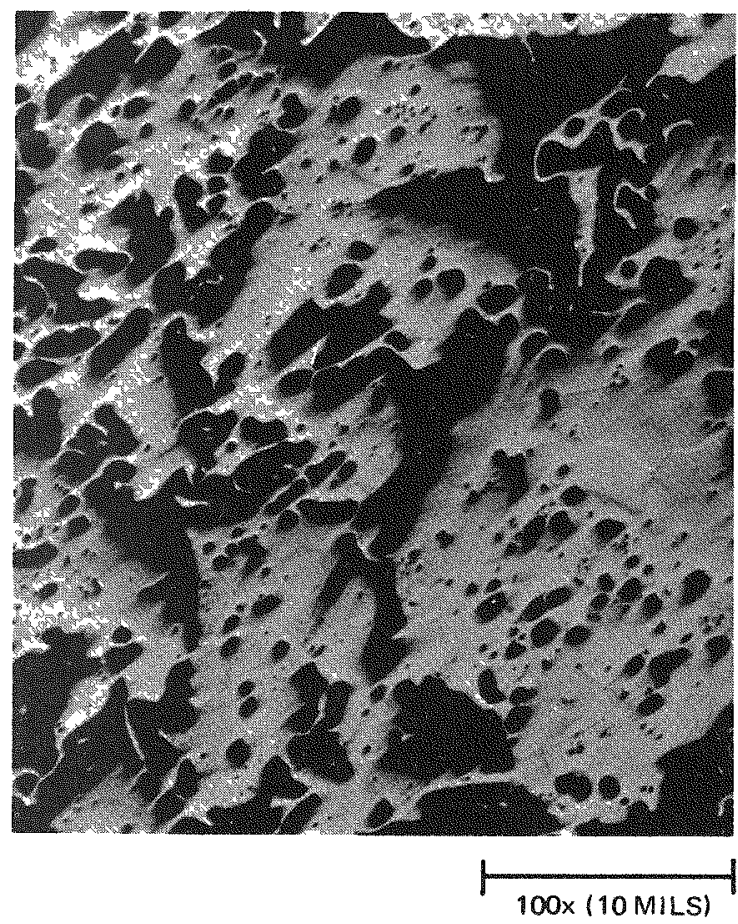

A. T 1, 1250 HR, NO PULSE

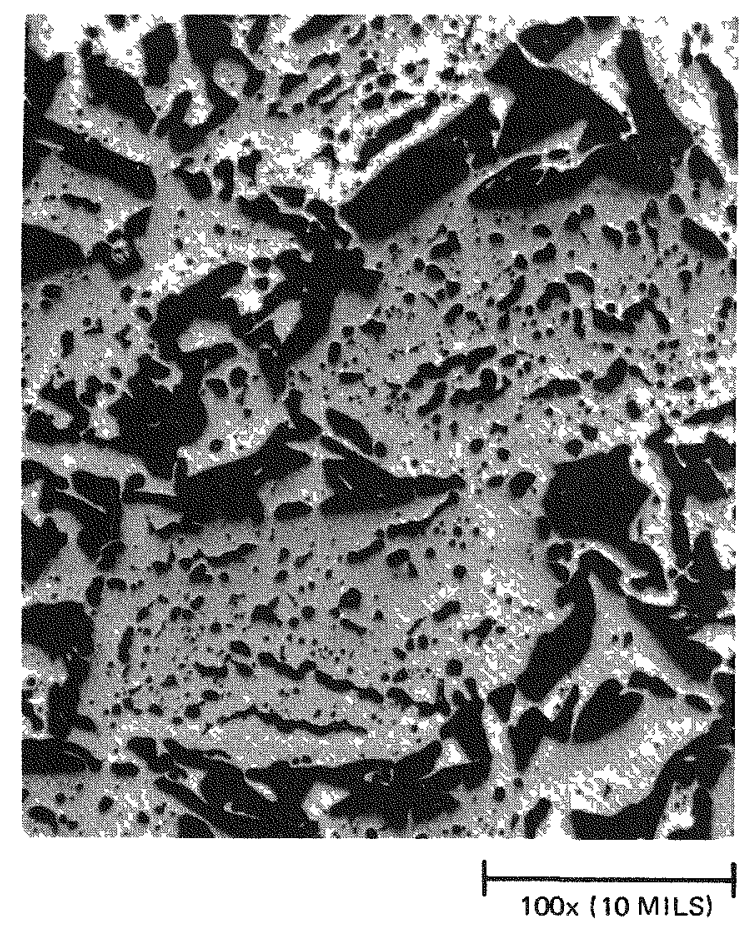

B. T 2, 1250 HR, PULSED

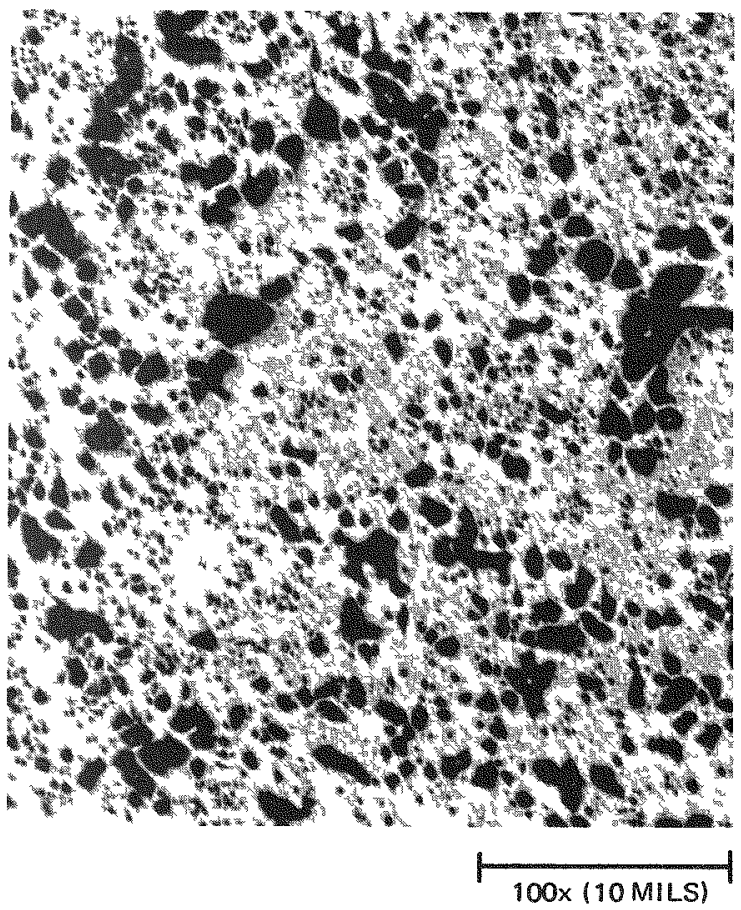

C. T-2, $8000 \mathrm{HR}$, NO PULSE

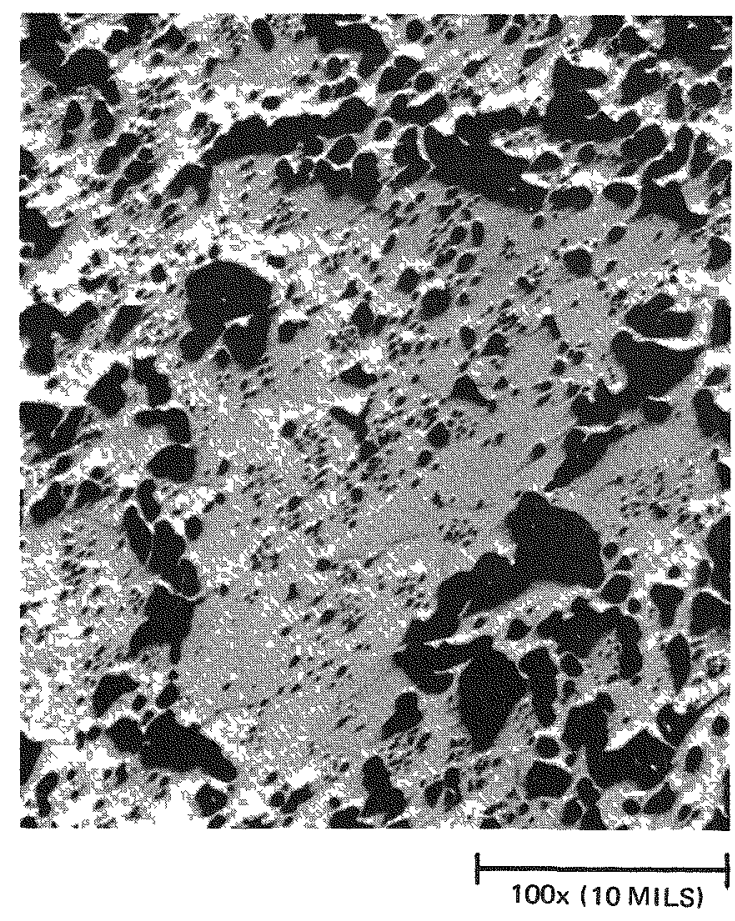

D. T-4, 8000 HR, PULSED

Figure 3-3. Plutonia Pellets After Exposure 


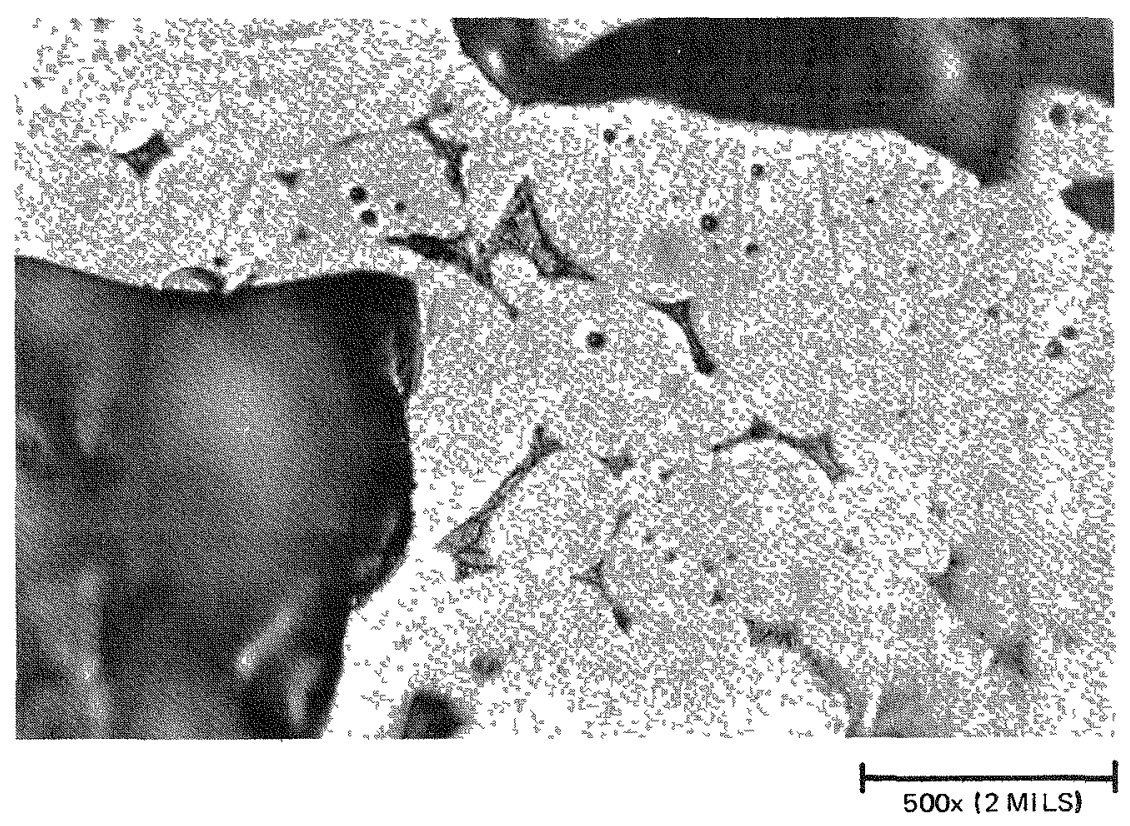

Figure 3-4. Specimen No. T-3, $1250 \mathrm{hr}$, Pulsed

Post-test chemical analyses of the 1250-hr exposure plutonia pellets and plutonia powder are listed in Table 3-8, as reported by LASL. The most significant difference between pre-test and post-test results was the 2000 to $3000 \mathrm{ppm}$ tungsten in the plutonia pellets. It is believed that this tungsten was picked up during the DWDL $1500^{\circ} \mathrm{C}$ argon atmosphere thermal treatment prior to assembly. All furnace components are tungsten and no attempt was made to shield pellets from tungsten pickup. However, this has been corrected for subsequent tests.

Another impurity increase was calcium, increasing from 130 to between 600 and $1200 \mathrm{ppm}$. The source is unknown. Decreases in volatile oxide impurities such as iron, chromium, lead, and zinc were also observed.

Plutonia powder in the uniform-temperature series sintered into loose clumps which could easily be broken into fine particles. The clumps would be maintained if handled carefully but broke with relatively gentle pressure with tweezers. There did not appear to be any major difference attributable to exposure length or thermal pulse. 
Table $3-8$

POST-TEST SPECTROCHEMICAL DATA ON PLUTONIA (ppm by weight)

\begin{tabular}{lrrr|rrrr}
\hline Element & $\mathrm{T}-1$ & $\mathrm{~T}-3$ & $\mathrm{M}-1$ & Element & $\mathrm{T}-1$ & $\mathrm{~T}-3$ & $\mathrm{M}-1$ \\
\hline $\mathrm{B}$ e & $<1$ & $<1$ & $<1$ & $\mathrm{Sr}$ & 20 & 30 & 8 \\
$\mathrm{~B}$ & $<1$ & $<1$ & 1 & $\mathrm{Zr}$ & $<250$ & $<250$ & $<250$ \\
$\mathrm{Na}$ & $<50$ & $<50$ & $<50$ & $\mathrm{Nb}$ & $<100$ & $<100$ & $<100$ \\
$\mathrm{Mg}$ & 15 & 20 & 2 & $\mathrm{Mo}$ & $<5$ & $<5$ & $<5$ \\
$\mathrm{Al}$ & 75 & 100 & 75 & $\mathrm{Cd}$ & $<10$ & $<10$ & $<10$ \\
$\mathrm{Si}$ & 110 & 180 & 100 & $\mathrm{Sn}$ & 60 & 40 & 5 \\
$\mathrm{Ca}$ & 800 & 1200 & 600 & $\mathrm{Ta}$ & $<100$ & $<100$ & $<100$ \\
$\mathrm{Ti}$ & $<100$ & $<100$ & $<100$ & $\mathrm{~W}$ & 2000 & 3000 & $<50$ \\
$\mathrm{~V}$ & $<10$ & $<10$ & $<10$ & $\mathrm{Ir}$ & $<100$ & $<100$ & $<100$ \\
$\mathrm{Cr}$ & 80 & 85 & 5 & $\mathrm{~Pb}$ & 5 & 7 & $<5$ \\
$\mathrm{Mn}$ & 5 & 6 & $<1$ & $\mathrm{Bi}$ & $<1$ & $<1$ & $<1$ \\
$\mathrm{Co}$ & $<5$ & $<5$ & $<5$ & $\mathrm{C}$ & 100 & 260 & 50 \\
$\mathrm{Ni}$ & $<5$ & 10 & $<5$ & & & & \\
$\mathrm{Cu}$ & 2 & $<1$ & $<1$ & & & & \\
$\mathrm{Zn}$ & $<10$ & 10 & $<10$ & & & & \\
\hline
\end{tabular}

Plutonia produces various species containing plutonium. These tend to transport in a thermal gradient. The amount of transport is a complex function of temperature, plutonia surface area, thermal gradients between surfaces. and geometric configuration. Examples of plutonia transport to the colder iridium capsule lids exposed for $8000 \mathrm{hr}$ are shown in Figures $3-5$ and 3-6. Transport to the pellet-fueled thermal gradient $I-2$ lid seems relatively minimal, except at the darkened periphery of the vent cover the central area is covered with iridium powder). The T-1 lid, the short-term match for T-2. appeared to have a deposit much more comparable to T-4. Much more trans.port of the black plutonia is shown on the $\mathrm{T}-4$ lid which had the $1950^{\circ} \mathrm{C}$ the rmal pulse. The two uniform-temperature lids for the powder plutonia specimens appeared to have more plutonia deposited than for the thermal gradient pellet lids. Burnishing by the cut-off saw during sectioning caused the shiny area in the center of the M-3 lid; otherwise. deposits appeared cor arable between M-3 and M-4. Metallographic comparison as to thickness d not provide sufficient information to be useful. 


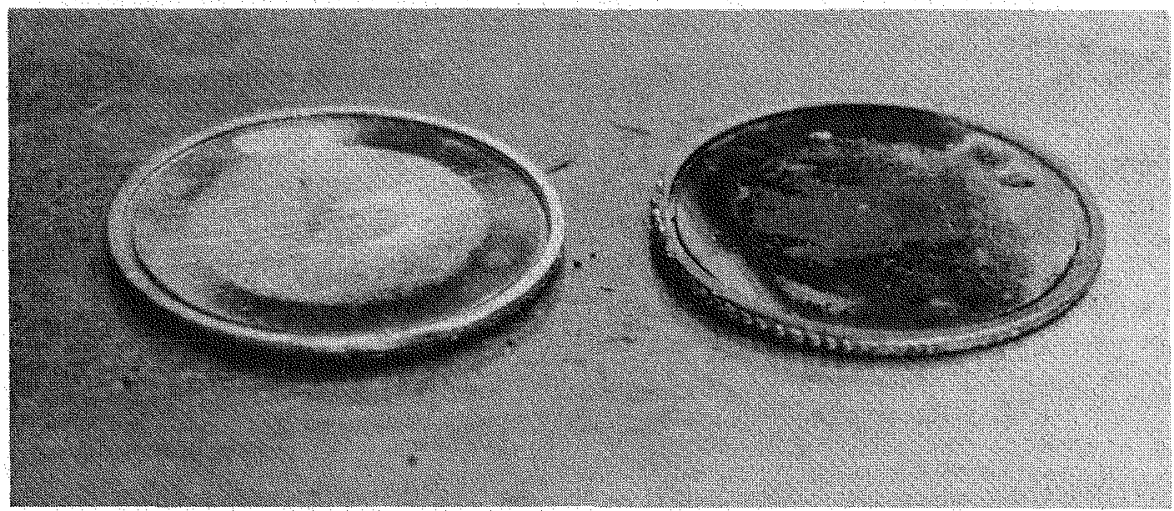

Figure 3-5. Inner Iridium Lid Surfaces of T-2 (left) and T-4 (right)

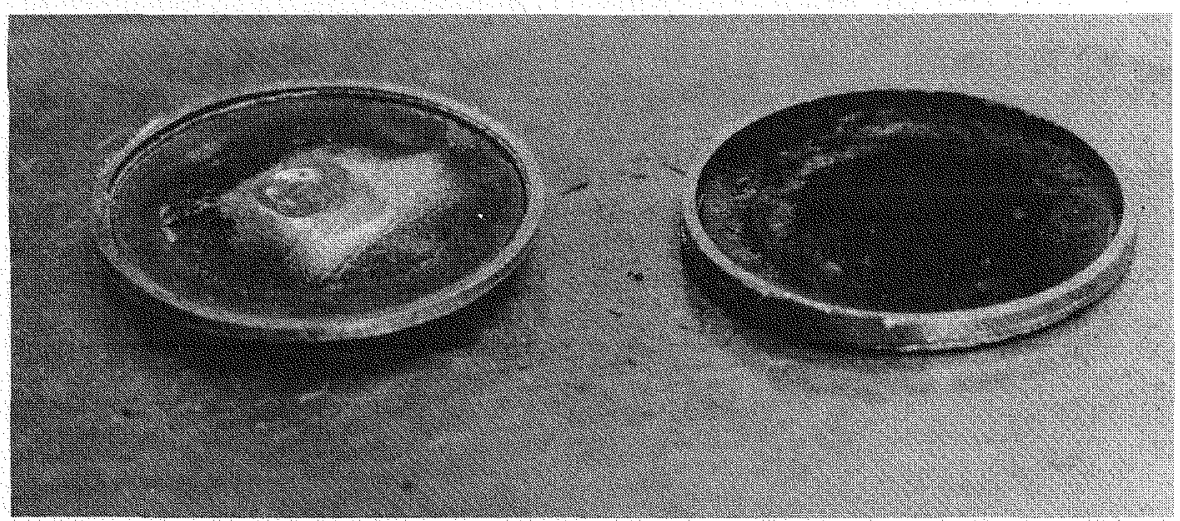

Figure 3-6. Inner Iridium Lid Surfaces of M-3 (left) and M-4 (right) 
Plutonia transport to the capsule sidewalls was minimal for all specimens. However, plutonia transported to the tensile specimens above the fuel.

\subsubsection{Iridium Inner Containers}

Internal contents of the thermal gradient inner iridium containers stayed in place during both the 1250 and 8000-hr exposures (Figure 3-7). All four of each set of tensile specimens remained in direct contact with the plutonia. The darkened surfaces of the tensile specimens and container walls above the pellets show the plutonia deposits. Removal of the capsule contents showed that only minor discoloration was observable on the inside surfaces and more on the outside surfaces.

Tensile specimen holders for the uniform temperature series are shown in Figure 3-8. Some plutonia is evident around the filling hole at the top. but the remainder of the surfaces were thermally etched and uncoated. Microprobe examination at LASL of the inside surface of the holder lid showed a black deposit containing predominantly $\mathrm{Pu}$ and $\mathrm{O}$ with lesser amounts of Fe. Ca. and $\mathrm{Si}$.

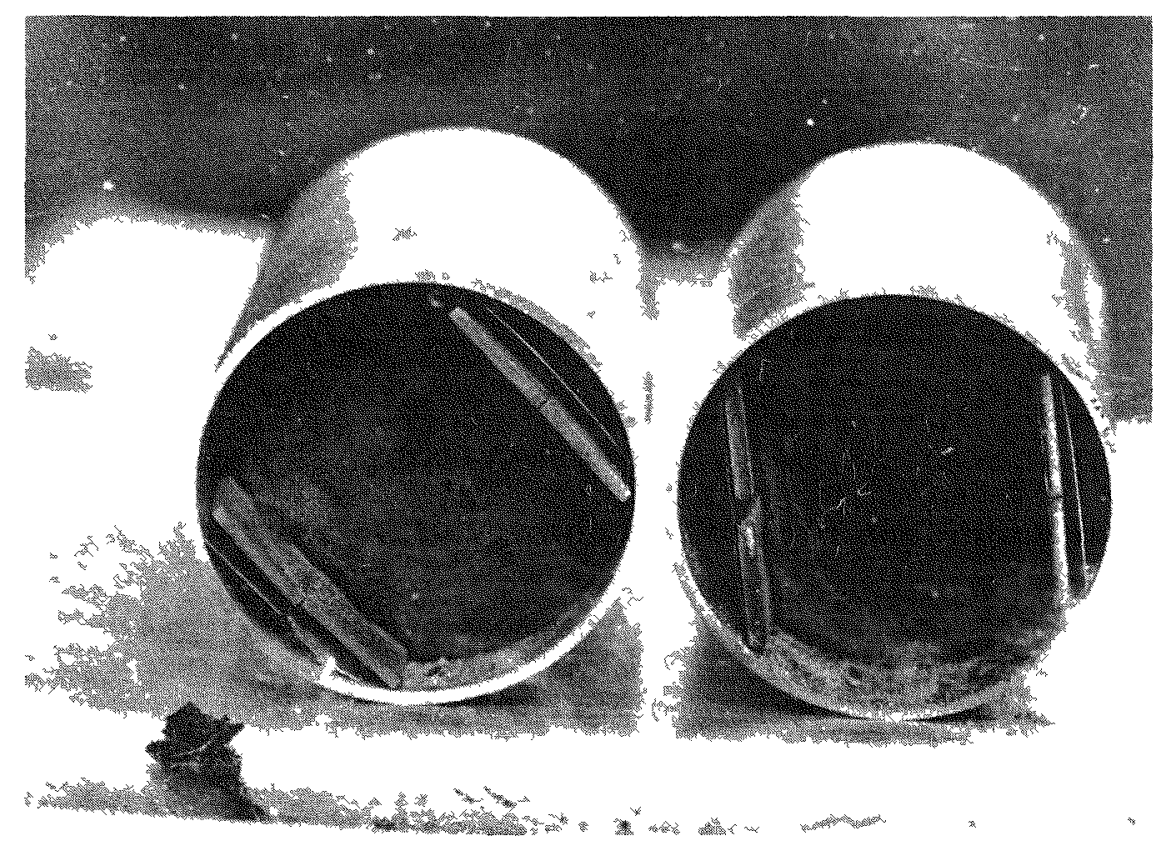

Figure 3-7. Sectioned Inner Iridium Containers, T-2 (left) and T-4 (right) 


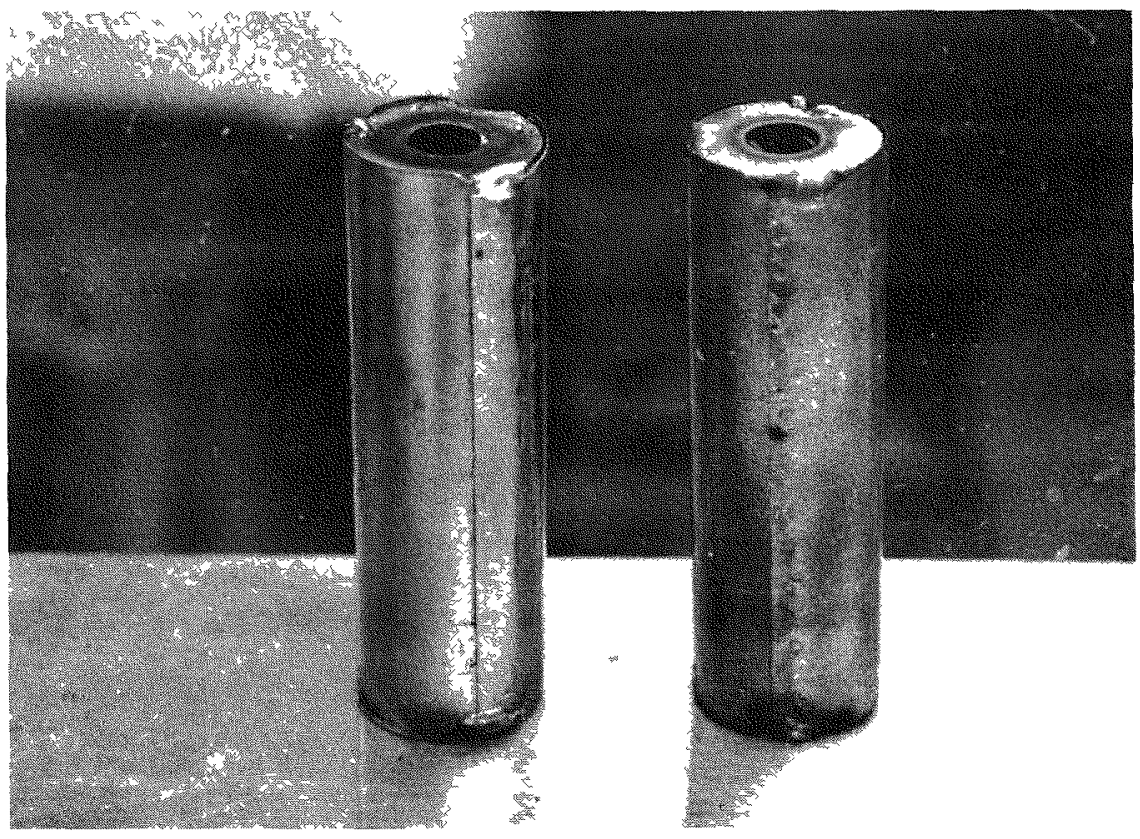

Figure 3-8. Subsize Tensile Specimen Holders, M-3 (left) and M-4 (right)

All 1250-hr and the 8000-hr thermal gradient capsules were sectioned axially for metallographic examination and microhardness measurement. Iridium capsules reacted with the tungsten present in the plutonia but not with the plutonie or the external graphite. The most significant reaction ( 0.5 mil deep) was observed on the bottom and up the walls of specimens $T-1$ and $T-4$ as typified in Figure 3-9 for T-1. Both reaction layers were continuous and were accompaniec by a layer of voids. Both specimen No. T-3 and $M-1$ also had strings of fine pores very close to the inner surface but no visual reaction layer as such (Figures 3-10 and 3-11). The presence of this layer was unexpected in specimen No. M-1, inasmuch as there was no physical contact between the plutonia and the iridium capsule. Comparative examination of $1250-$ and $8000-\mathrm{hr}$ reaction zones showed no increase with time (Figure 3-12). Microprobe examination at Battelle Northwest Laboratories of the zone conclusively shows the tungsten-rich nature of the layer, accompanied by iridium, indicating that the layer is an intermetallic compound. The microprobe also indicated a very limited amount of grain boundary diffusion into the iridium. Surface microprobe analyses at LASL showed the presence of Fe and W, generally distributed 

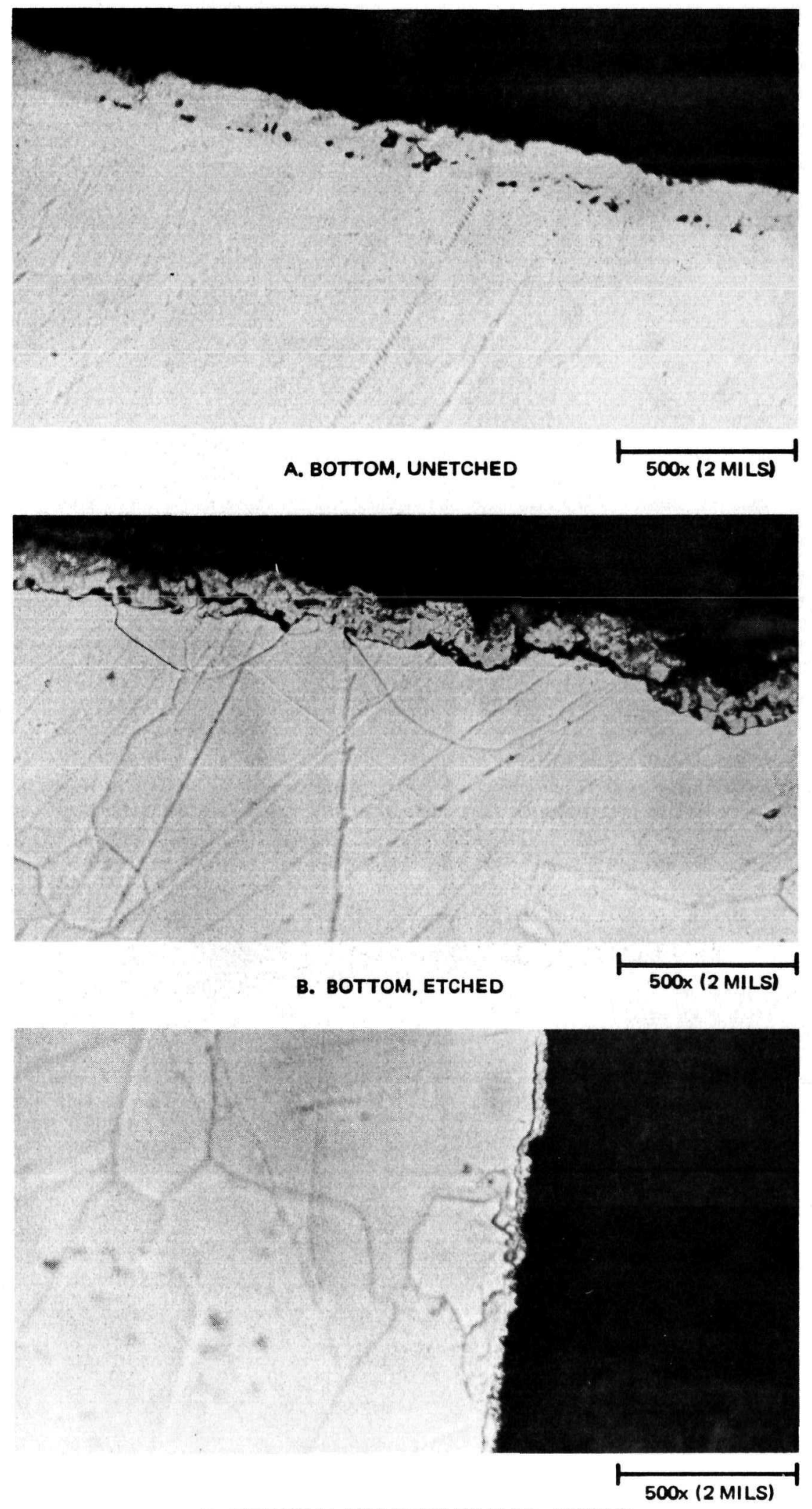

C. SIDE WALL NEAR TOP OF FUEL, ETCHED

Figure 3-9. Specimen No. T-1 Iridium Capsule Reaction Areas 


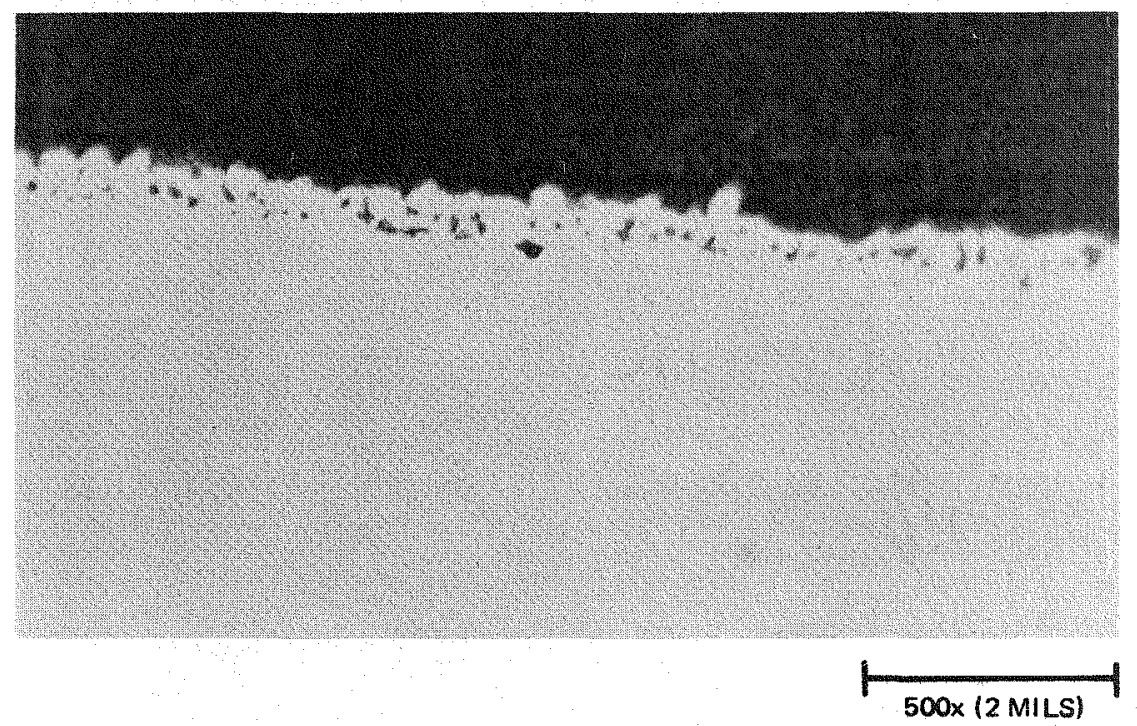

A. BOTTOM, UNETCHED

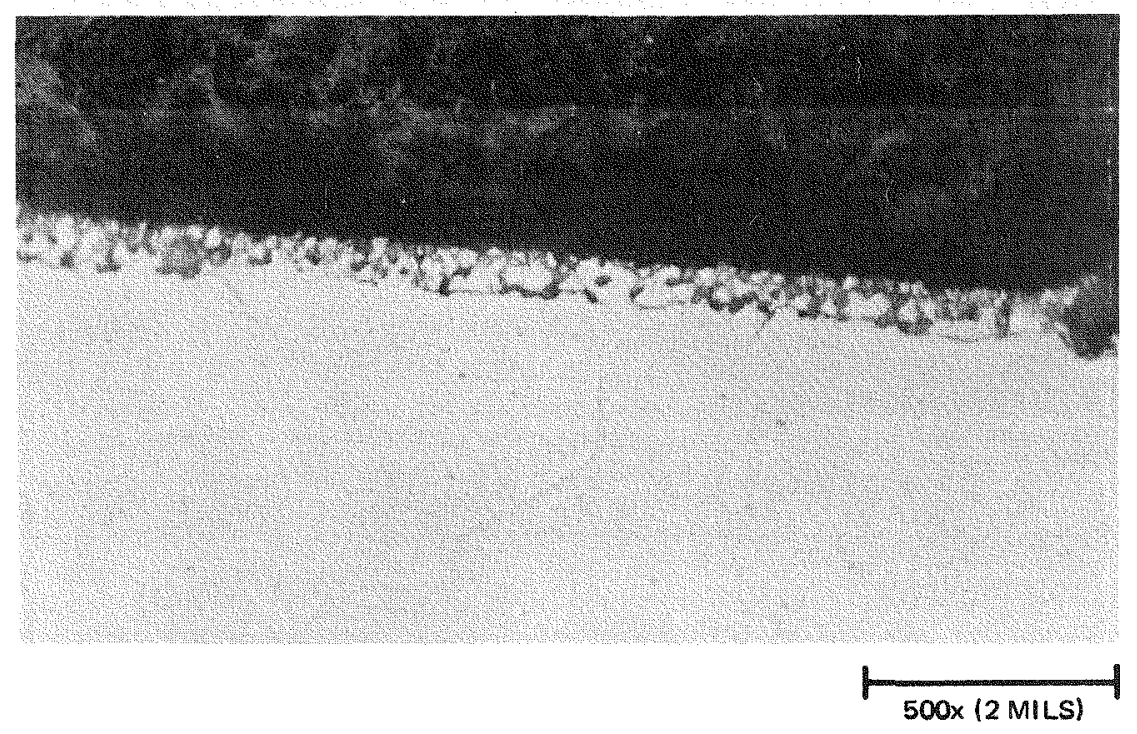

B. BOTTOM, ETCHED

Figure 3-10. Specimen No. T-3 Iridium Capsule Reaction Area 

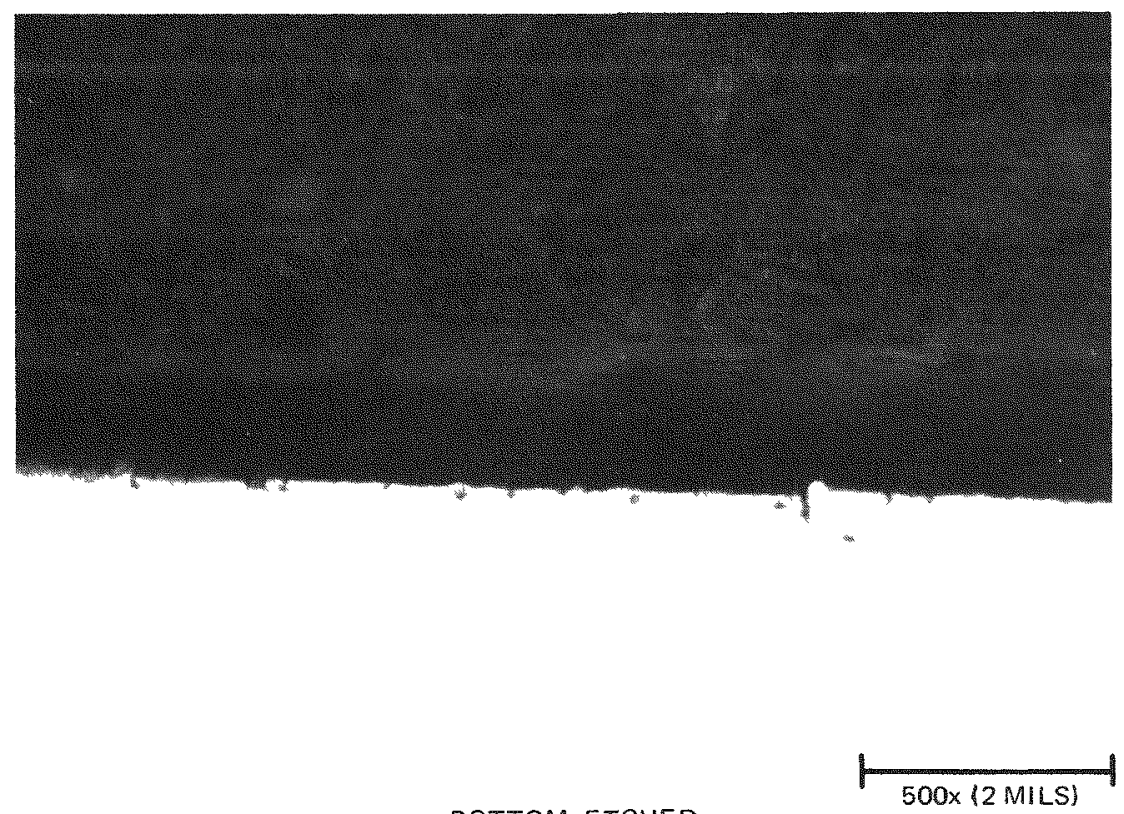

Figure 3-11 Specimen No M 1 Iridium Capsule Reaction Area

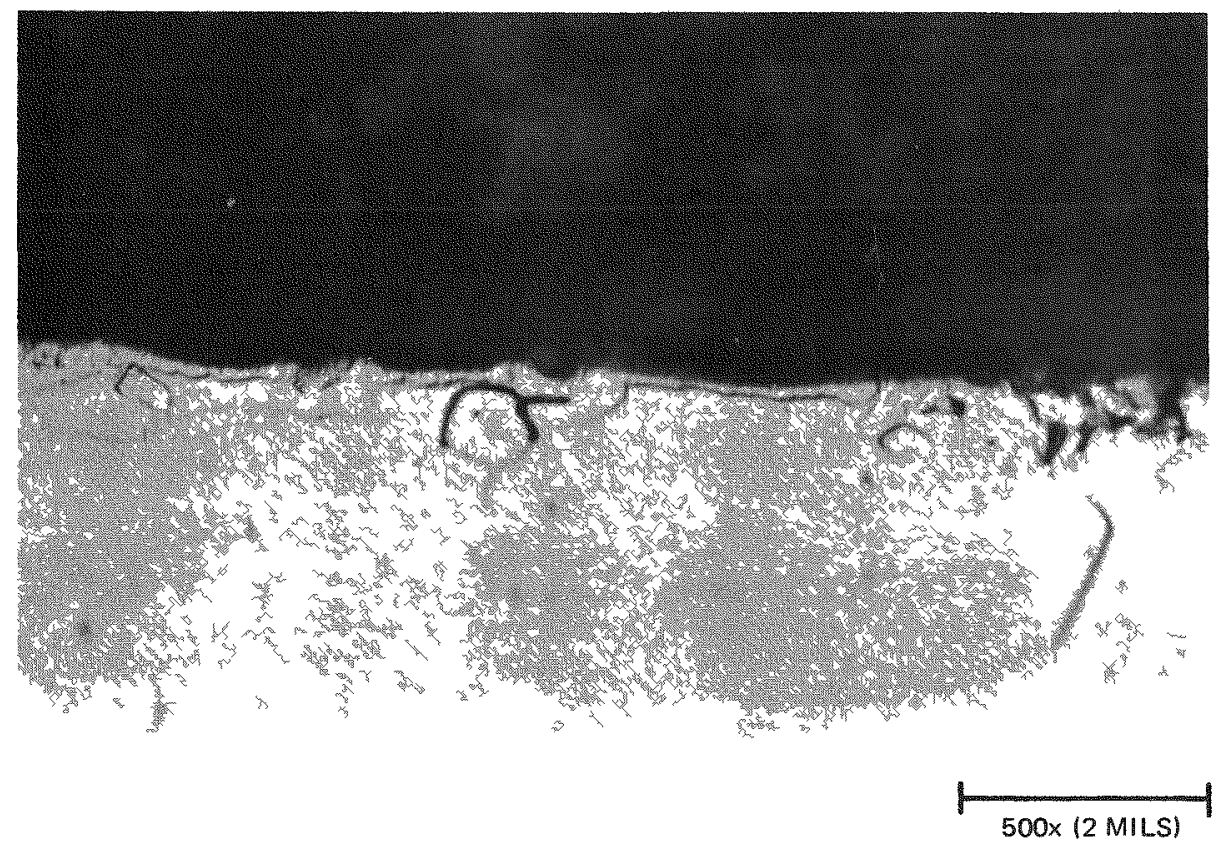

Figure 3-12. Irıdium Capsule Reaction Area in Specimen T-2 
With rariable amounts of Si, Ca, and sometimes $\mathrm{Na}, \mathrm{O}$, and $\mathrm{Al}$. Iridium containers exposed only at $1400^{\circ} \mathrm{C}$ exhibited a fine gran size, but the specimens sublected to the 5 -min-at- $1950^{\circ} \mathrm{C}$ thermal pulse exhibited grain growth to the point that major areas of the wall had only 2 to 3 grains across the wall as visible in the etched specimens. Longer exposure qualitatively resulted in increased grain size for both types of specimens. Thermal elching was evident in scanning electron micrographs of the thermal-pulsed iridium but not for iridium not pulsed. Microhardness measurements were all in the range of 278 to $354 \mathrm{DPH}$, with no trend caused by exposure time, thermal pulse, or exposure to plutonia. These values are comparable to those measured at LASI on similar materials.

Chemical analyses performed by LASL are listed in Table 3-9. Included are analyses for the Ta-10W guard capsules.

The iridium containers had 1900 to 3000 ppm tungsten, which is normal, and 45 to 290 ppm carbon, which appears somewhat high. The carbon most likely came from the graphite external to the capsule.

\subsubsection{Iridium Vents}

Airflow rates are reported in Table 3-2. Macroscopic and microscopic observations have been included in Tables $3-3$ to $3-6$. Figure $3-13$ shows the clean appearance of the control specimen vent in $\mathrm{C}-1$ exposed for 1250 hours. The horizontal fracturing is believed to be induced by the harsh thermal pulse occurang during electron-beam hole drilling.

Major problems have been encountered at all laboratories in attempting to section, grind, and polish vents which are around 1 mil diameter. This problem is exacerbated by oxide or metal transport into the hole. This particular effect is shown in Figure 3-14 for specimen $T-1$ (thermal gradient. $1250 \mathrm{hr}$. no thermal pulse) where an iridium plug was transported and fllled the hole. Microprobe examination showed that this plug was iridium. This plug did not completely prevent air/flow but did slow the flow. Malched control specimen $\mathrm{C}-1$ showed no plugging propensity whatsoever. 


$$
\text { Table 3-9 }
$$

POST TEST IMPURITY ANALYSES

(ppm by weight)

\begin{tabular}{cccccc}
\hline Element & \multicolumn{2}{c}{ Iridium } & Inner Containers & \multicolumn{2}{c}{ Ta-10W Lids } \\
\hline $\mathrm{Mg}$ & $\mathrm{T}-1$ & $\mathrm{~T}-3$ & $\mathrm{M}-1$ & $\mathrm{~T}-1$ & $\mathrm{M}-1$ \\
$\mathrm{Al}$ & 10 & 5 & 10 & $\mathrm{ND}$ & $\mathrm{ND}$ \\
$\mathrm{Fe}$ & 30 & $<20$ & $<20$ & 3 & 3 \\
$\mathrm{Cu}$ & 300 & 150 & 150 & 30 & 30 \\
$\mathrm{Nb}$ & 20 & 20 & 20 & $\mathrm{ND}$ & $\mathrm{ND}$ \\
$\mathrm{W}$ & $\mathrm{NS}$ & $\mathrm{NS}$ & $\mathrm{NS}$ & 200 & 200 \\
$\mathrm{O}$ & 3000 & 2400 & 1900 & $\mathrm{NR}$ & $\mathrm{NR}$ \\
$\mathrm{C}$ & $\mathrm{NR}$ & $\mathrm{NR}$ & $\mathrm{NR}$ & 840 & 1200 \\
& 290 & 45 & 70 & $\mathrm{NR}$ & $\mathrm{NR}$
\end{tabular}

Not Detected within Following Detection Limits:

\begin{tabular}{lll}
\hline & \multicolumn{1}{c}{ Iridium } & \multicolumn{1}{c}{$\mathrm{Ta}-\mathrm{I0w}$} \\
\hline$<1$ & & $\mathrm{Be}, \mathrm{Mg}, \mathrm{Ni}, \mathrm{Cu}, \mathrm{Ge}, \mathrm{Pb}$ \\
$<3$ & $\mathrm{Be}$ & $\mathrm{Co}, \mathrm{Ag}, \mathrm{Bi}$ \\
$<5$ & $\mathrm{Ag}, \mathrm{Au}$ & \\
$<10$ & $\mathrm{Ni}, \mathrm{Pd}, \mathrm{Bi}$ & $\mathrm{B}, \mathrm{Ca}, \mathrm{Cr}, \mathrm{Mn}, \mathrm{Sr}, \mathrm{Sn}, \mathrm{Il}$ \\
$<20$ & $\mathrm{Co}$ & $\mathrm{Ti}, \mathrm{V}, \mathrm{In}$ \\
$<30$ & $\mathrm{Ca}, \mathrm{Ti}, \mathrm{V}, \mathrm{Cr}, \mathrm{Sr}, \mathrm{Zr}, \mathrm{Ba}, \mathrm{Pt}, \mathrm{Pb}$ & \\
$<50$ & $\mathrm{Si}$ & $\mathrm{Na}, \mathrm{Si}, \mathrm{Zn}, \mathrm{Zr}, \mathrm{Mo}, \mathrm{Cd}, \mathrm{Sb}, \mathrm{Ba}$ \\
$<100$ & $\mathrm{Zn}, \mathrm{Ru}, \mathrm{Rh}, \mathrm{Cd}$ & \\
$<300$ & & $\mathrm{Te}$ \\
Not stated & $\mathrm{Li}, \mathrm{B}, \mathrm{Na}, \mathrm{Nb}, \mathrm{Mo}, \mathrm{Sn}, \mathrm{Sb}$ & \\
Not reported & $\mathrm{O}$ & $\mathrm{W}, \mathrm{C}$
\end{tabular}


The thermal gradient vent exposed 1250 hours and thermal pulsed ( $\mathrm{T}-3$ ) $1 \mathrm{~s}$ shown in Figure 3-15; there is no ascertainable plugging. The bridging remaining at the hole exit was left intentionally, because it has been determined that additional grinding frequently results in going well beyond the hole centerline. The thinner vent cover shown in $A$, Figure 3-15, retained the original powder plutonia on the surface toward the plutonia (downward in Figure 3-15), but difficulty in specimen mounting resulted in an inability to determine whether the powder remained between the vent cover and lid. Matched control specimen C-3 also exhibited comparable behavior.

The thermal gradient vent exposed $8000 \mathrm{hr}(\mathrm{T}-2)$ is shown in Figure 3-16; a barely visible semi-transparent material is plugging the hole. Microprobe examination at BNWL showed the material to contain neodymium, cerium, and some calcium. Otherwise, the vent appears clean with no other substances causing plugging. Within experimental accuracies, this vent permitted no airflow. The uniform temperature non-pulsed $M-4$ vent had a very comparable appearing material in the vent. This material had a hardness of $351 \mathrm{DPH}$

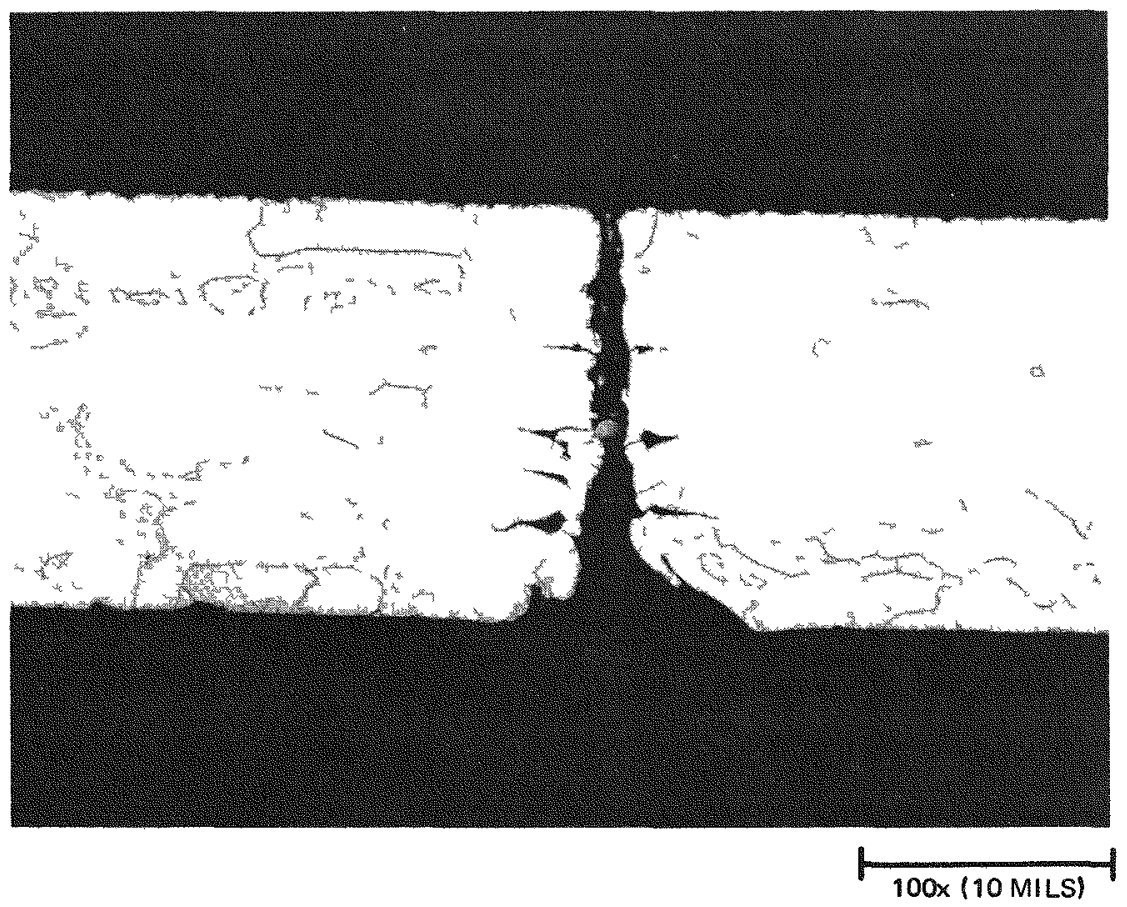

Figure 3-13. Specimen No. C-1 Vent Area 

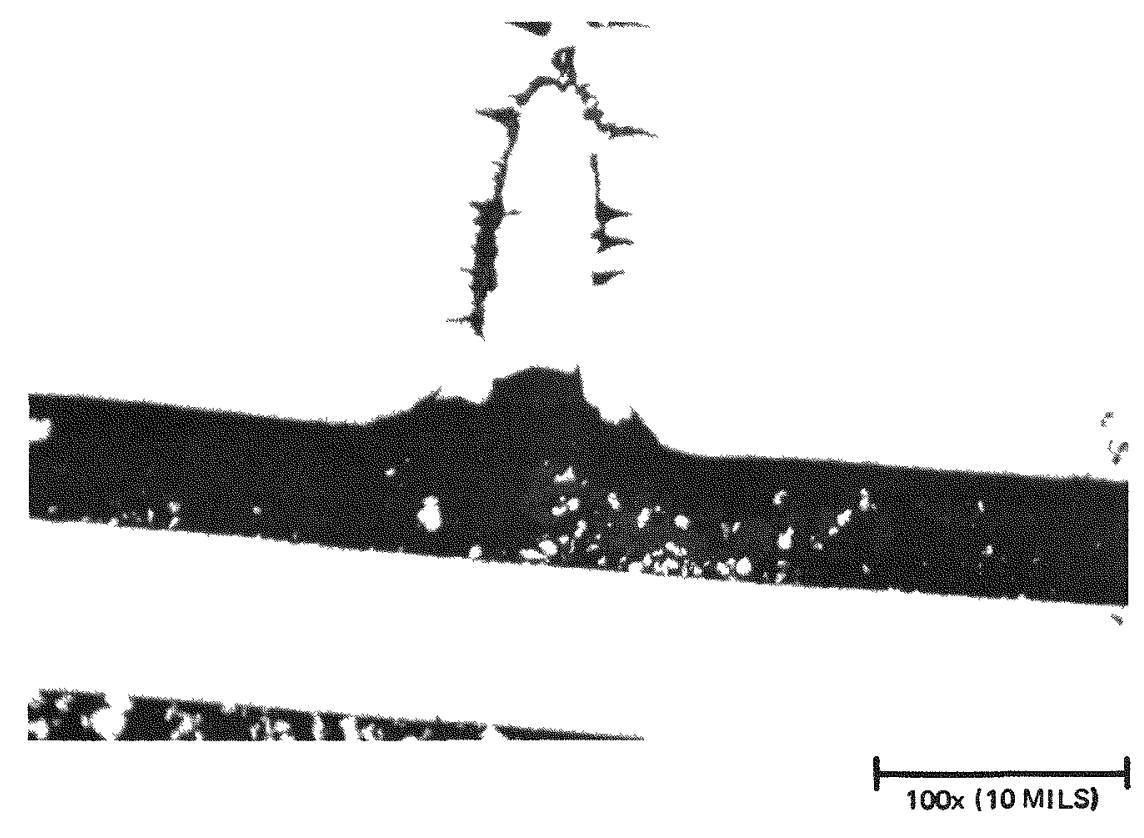

A. LID WITH VENT (TOP) AND VENT COVER (BOTTOM), UNETCHED

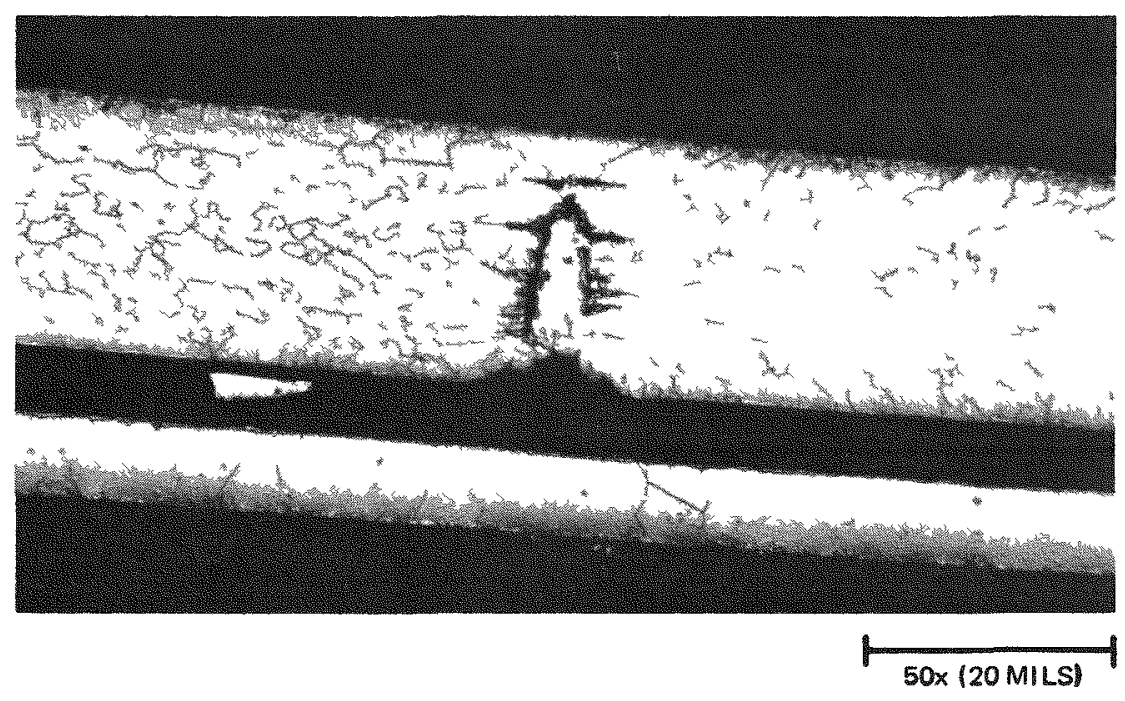

B. LID WITH VENT (TOP) AND VENT COVER (BOTTOM), ETCHED

Figure 3-14. Specimen No. T-1 Vent Area 

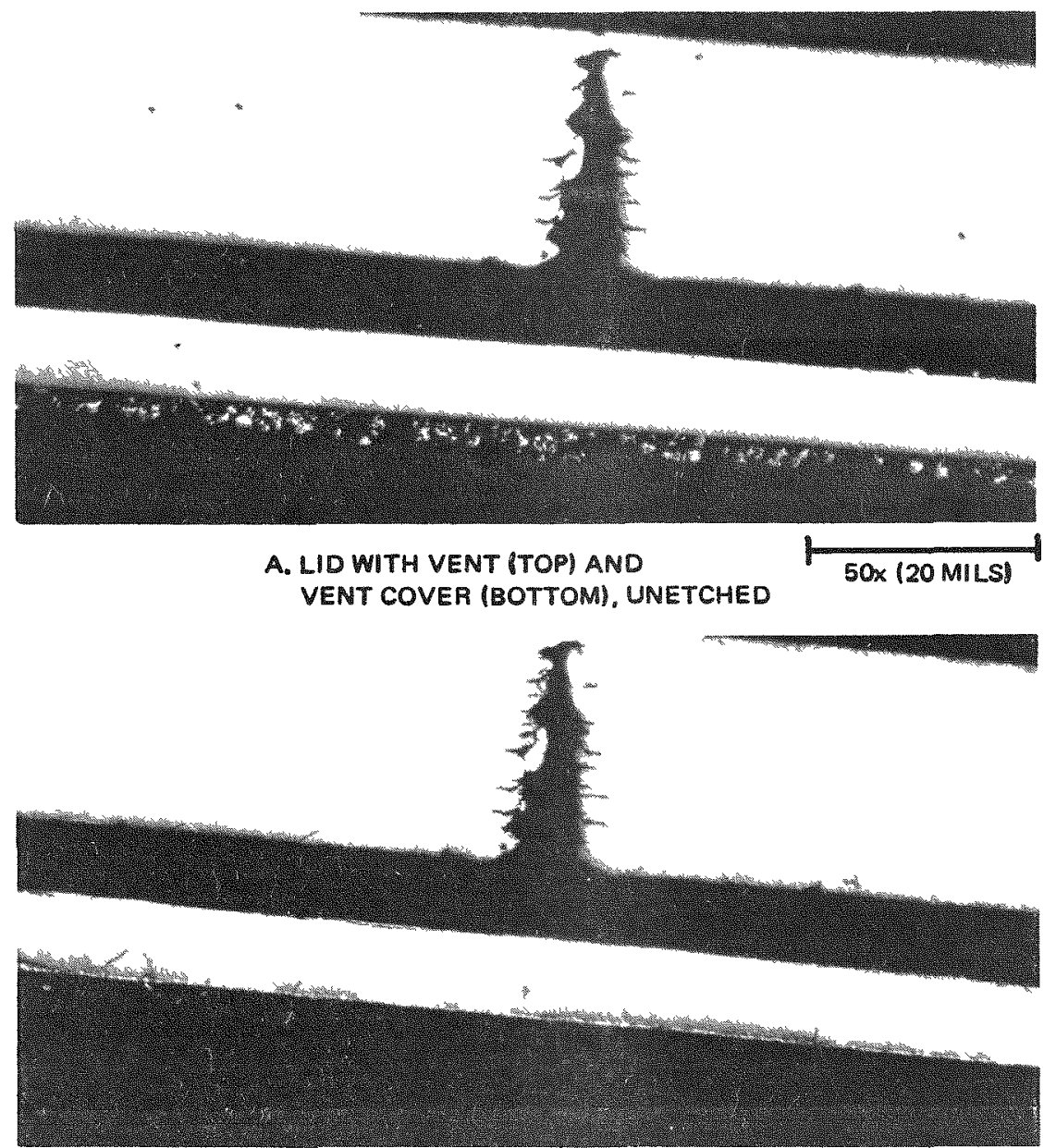

B. LID WITH VENT (TOPI AND VENT COVER (BOTTOM), ETCHED

$50 \times$ (20 MILS)

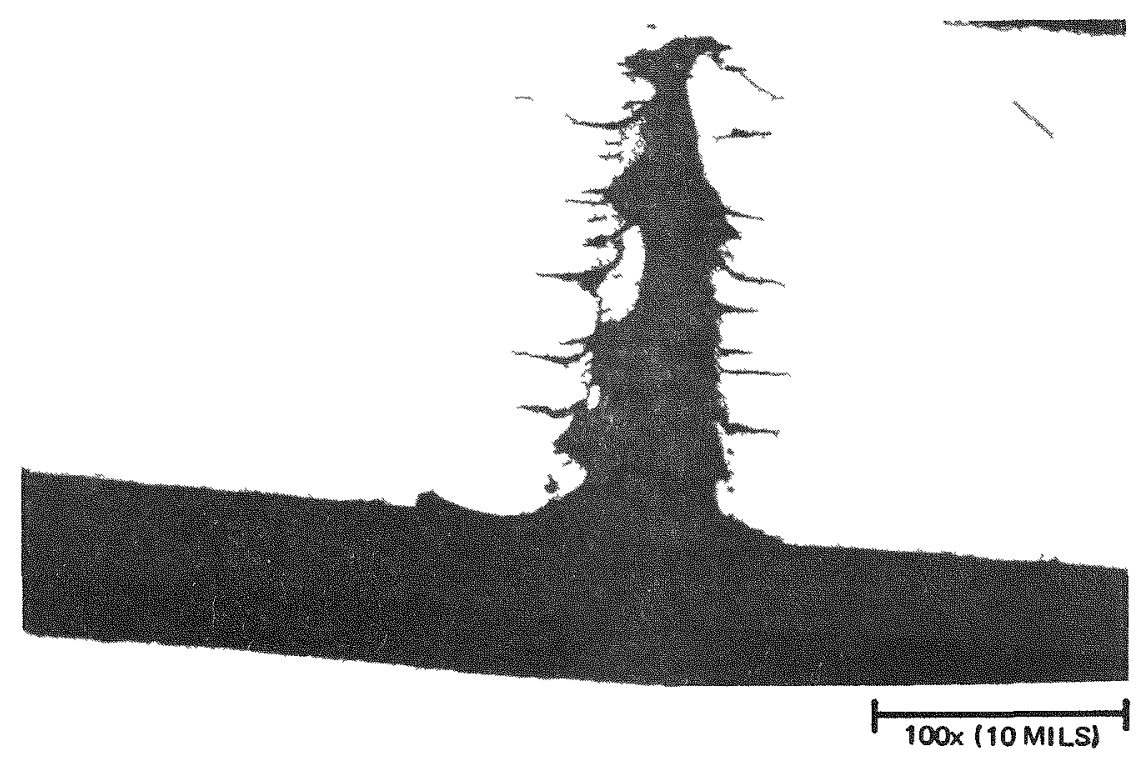

C. VENT AREA SHOWING DELAMINATIONS, ETCHED

Figure 3-15 Specimen No. T-3 Vent Area 


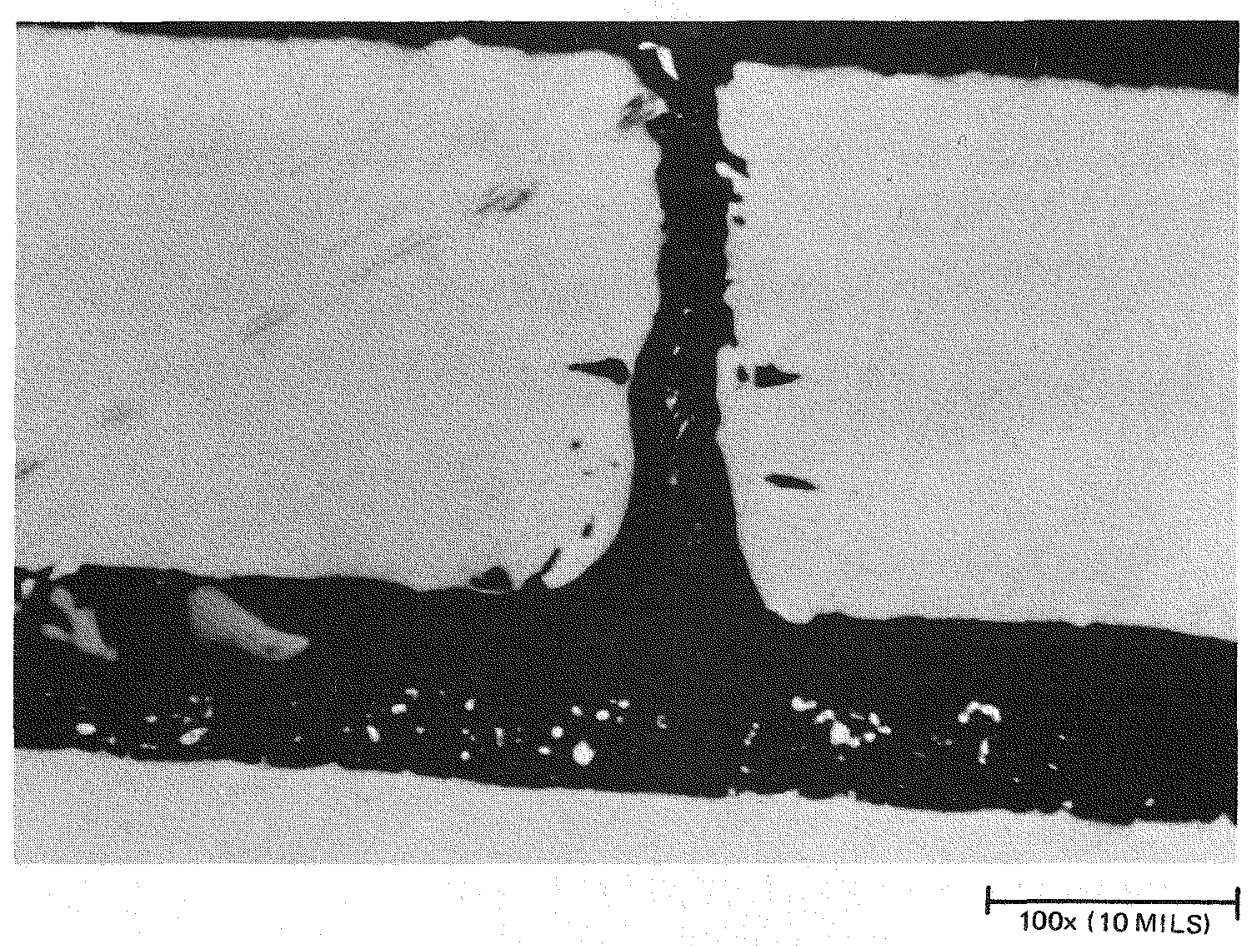

A. LID WITH VENT (TOP) AND VENT COVER (BOTTOM)

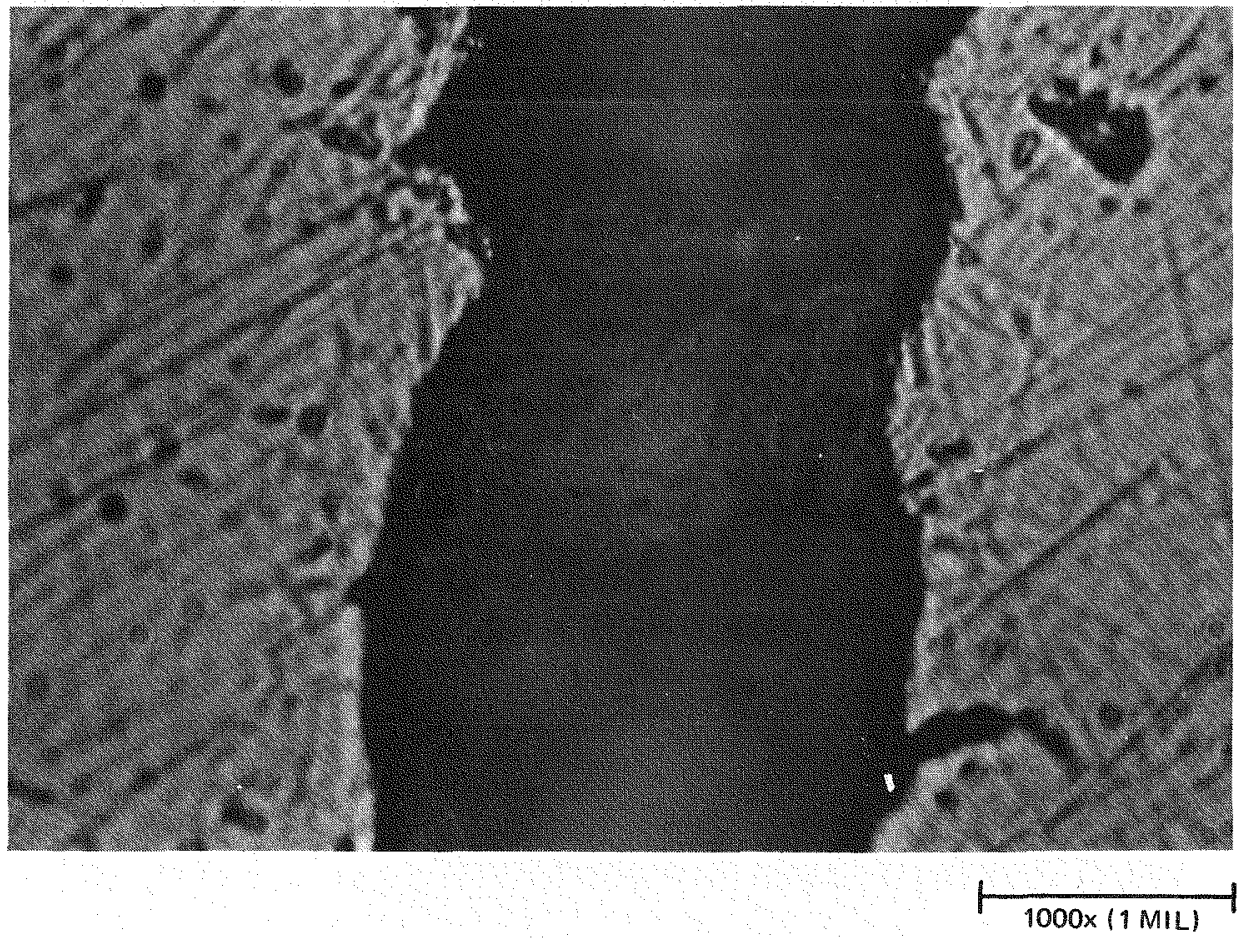

B. VENT WITH SEMI-TRANSPARENT PLUG

Figure 3-16. Specimen T-2 Vent Area 
using a $15-g$ load. Because of the fragile nature of the plugging material it was not found in microprobe examination of the $M-4$ vent area. The T-2 vent had iridium powder still present between the vent cover and lid as shown in $A$, Figure 3-16. The gray material between the two iridium surfaces appears to be plutonia as seen previously in several other specimens.

Several vent holes were ground past without ever seeing more than the major entry depression. These included $M-1, M-3, T-4$, and $C-4$. Other than $C-4$, it is most likely that these vent holes were plugged with iridium. In $M-1$, the surface available for microprobe examination was beyond the centerline of the hole and no firm conclusion could be made about the plugging mechanism. However, the laminations present from the electron-beam hole drilling were enriched in tungsten, and the outer surface had a tungsten-iridium compound layer.

Vent flow, as measured by post-test airflow techniques, decreased as a function of time. Tests conducted at GE-SSO demonstrated that restriction of flow could occur without the presence of plutonia. This test series confirmed that fact. Mound Laboratory and LASL tests utilizing 100 -watt spheres resulted in plugging with either oxides or iridium. In this program iridium was found to have plugged one vent and may have plugged at least three more. Additionally, a ceramic material was found in two vents and perhaps occurred in at least one more. This program has thus independently verified the multiplicity of mechanisms which can contribute to vent plugging.

The general conditions which contribute to vent plugging can be summarized as follows. Volatile oxides or metals that tend to form oxides transport across thermal gradients particularly when an oxygen source is present. Transport depends on a number of complex interactive variables including fuel temperature and purity, system thermal gradients, iridium purity, and relative locations of materials.

\section{3 .4 Graphite}

Graphite exhibited no structural damage, other than minor erosion opposite the vent hole of the impregnated Thornel-50 as shown in Figure 3-17. As described in Tables $3-3$ and $3-4$, the depths and areas of erosion are relatively small and 


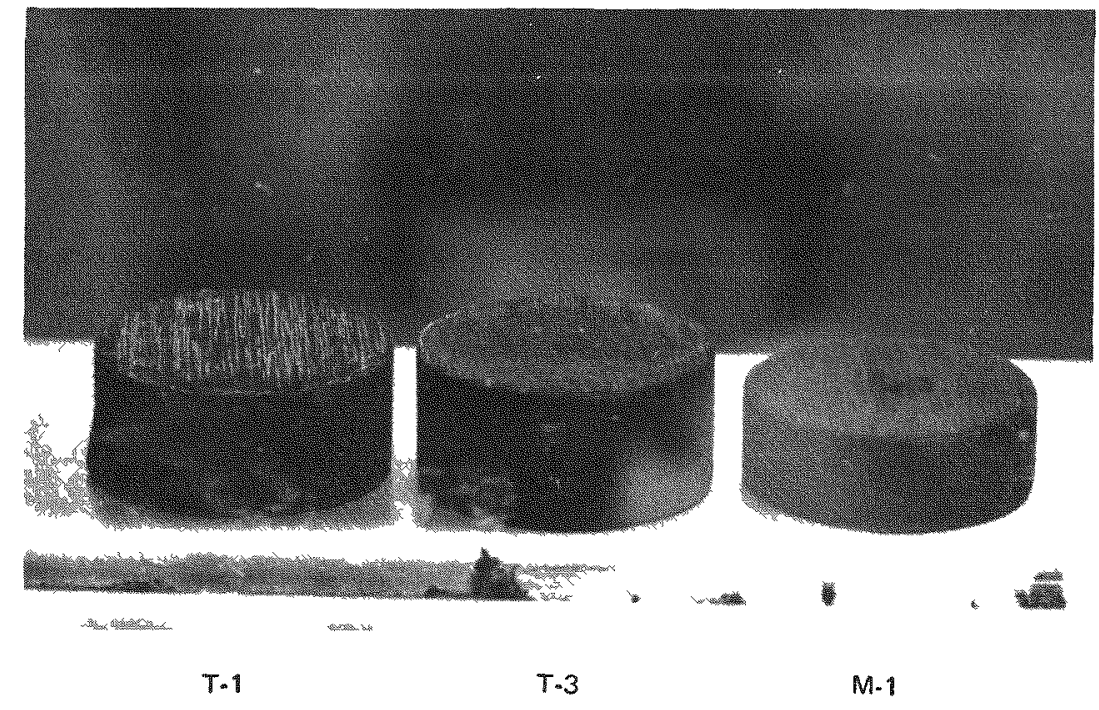

A. 1250 HOUR EXPOSURE

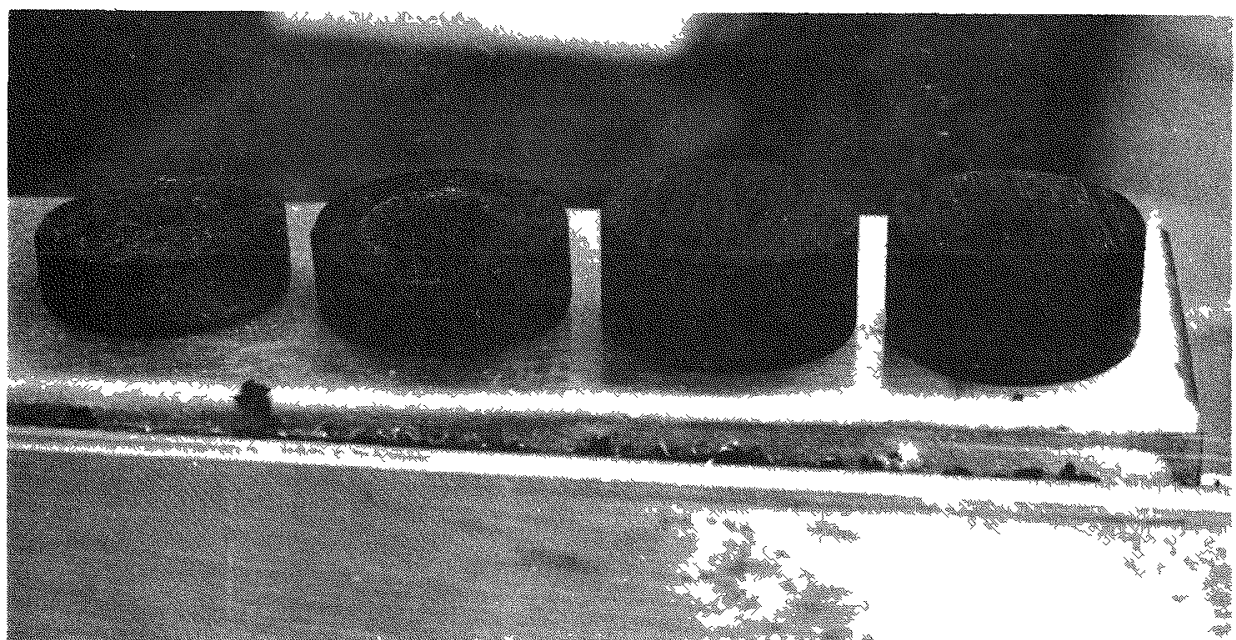

$M-3$

M॰4

$T-2$

T 4

B. 8000 HOUR EXPOSURE

Figure 3-17. Post-Test Macrographs of Impregnated Thornel-50 Graphite 
somewhat erratic. The uniform temperature series exhibited more erosion because of (1) powdered plutonia, and (2) the graphite rested directly on top of the iridium capsule. In the thermal gradient series, the radial graphite held the impregnated Thornel-50 graphite approximately 0.050 in above the iridium capsule.

Calculated erosion volumes resulted in estimated carbon mas losses of 1.1 to $3.6 \mathrm{mg}$. These mass losses are approximately a decade less than the carbon contained in $\mathrm{CO}$ and $\mathrm{CO}_{2}$ as determined by chemical analyses for the $\mathrm{M}-4$ and M-3 test specimens which were 25 and 12 mg respectively.

The fact that extended exposure did not cause discernible increased erosion indicates that either the bulk of the excess oxygen from the plutonia was raporized early during exposure or that vent plugging inhibited continued erosion. Both mechanisms probably contributed to this result with excess oxygen loss being the major factor.

Several of the ATJ and POCO-AXF-5Q graphite pieces, particularly those exposed in the control specimens, had thin $(<0.1 \mathrm{mil})$ gold-colored surface areas. This color is believed to be a tungsten carbide, partially caused by tungsten volatilization during vacuum outgassing before test. Also, volatilization of tungsten from the tungstem guard capsules surrounding the graphite occurred during test. Iridium foil was purposely added to present direct contact but did not eliminate vapor contact.

\subsubsection{Outer Iridium Containers}

Outer iridium containers were made at the same time and from the same lot of iridium as the inner iridium containers. Visual appearance of the inner surfaces of the outer containers were comparable to the bright and shiny surface observed on the outside of the inner iridium containers. The outside surfaces of the outer containers were dull because of vapor transport of tungsten from the guard capsule. 
Metallographic examination showed structures similar to those of the inner containers. Microhardness was also about the same with increased hardness at the outer surface from tungsten presence. In one specimen, $\mathrm{T}-1$ with a $1250-h r$ exposure and no the rmal pulse, about 4 mils of iridium was eroded away from the outside surface immediately adjacent to the vent. No other specimen exhibited comparable behavior.

\subsubsection{Tungsten and Tantalum-10\% Tungsten Guard Capsules}

The tungsten guard capsules all had matte finish interior surfaces. Exterior surfaces were bright except for M-4 (uniform temperature, 8000 hr no therma: pulse) which had a discoloration.

The $\mathrm{Ta}-10 \mathrm{~W}$ guard capsules had bright interiors and generally bright exteriors, A milky discoloration indicative of some form of deposition occurred in several capsules. Chemical a nalyses (Table 3-9) indicated that 840 to 1200 ppm oxygen was picked up but nothing else was detectable within analytical limits. This oxygen content caused hardening resulting in an inability lo drill for gas measurement. The main source of the oxygen was probably from the degradation of beryllia-packed tantalum sheathed $W / W-25 R e$ thermocouples used to monitor remperature. After completion of exposure, Beo was found throughout the furnace system. Observations of the guard capsule indicate that it was successful in isolating this disturbance from the interior test components.

\subsection{IRIDIUM TENSILE TESTS}

\subsubsection{Preparation}

Aiter exposure, the microsize DWDL iridium tensile specimens were removed from their capsules in which 15 of 16 specimens had remained in direct contact with the plutonia. Typical specimens illustrated in Figure 3-18 show that direct contact with plutonia produced only minor surface dulling (left specimens). Darkened areas occurred above the fuel having a distinct black plutonia appearance. The iridium foil retainer (farthest left) was shadowed with plutonia deposits. The back sides of the tensile specimens (righi side pair) showed darkening in the gage length. The back side of the foil retainer (farthest right) remained bright except for some minor discoloration. 


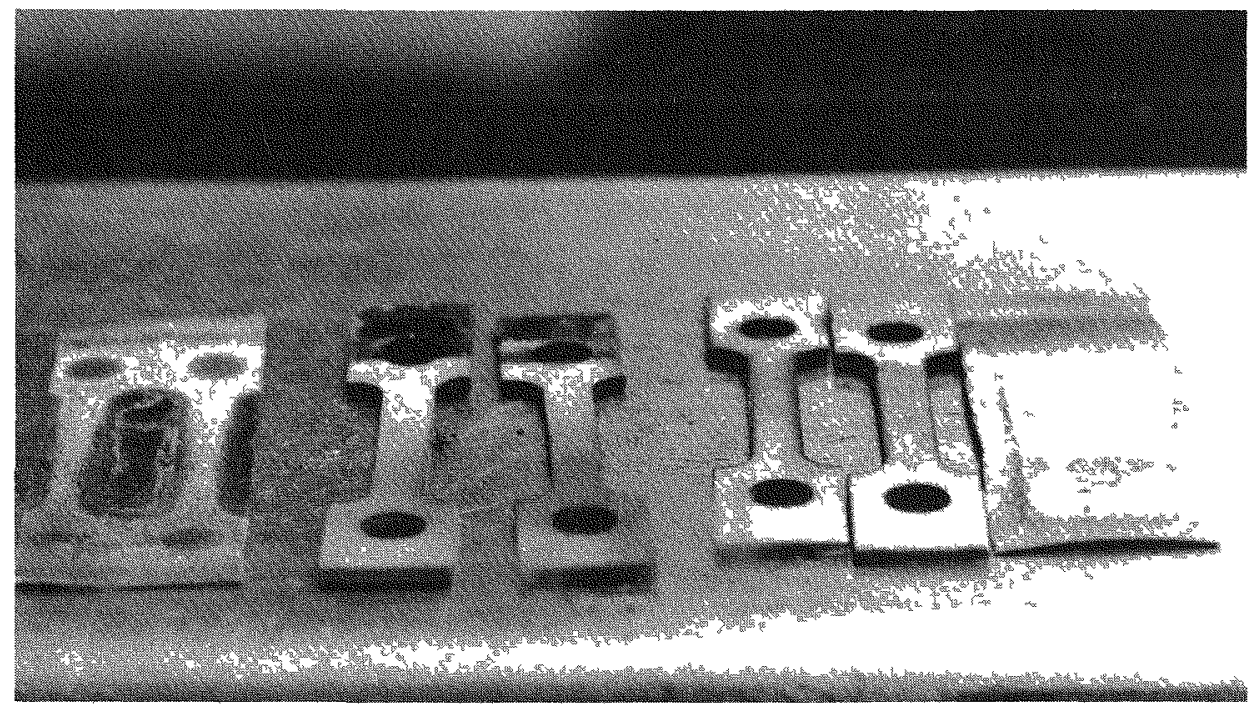

Figure 3-18. Macrograph of T-4 Microsize Tensıle Specimens

Microsize specimens in contact with graphite retained a bright shiny appearance in all cases.

Subsize iridium tensle specimens were easily removable from the partially sintered plutonia vertical bed but particles adhered over most of the surface a reas as shown in Figure 3-19. Scrubbing with a wooden stick removed all the loosely adherent powder leaving only minor areas of gray-to-black discoloration.

All tensile specimens were decontaminated by immersion in concentrated solutions of hydrofluoric acid. At roughly weekly intervals, the specimens were ultrasonically rinsed in water and placed in a new acid solution. After the second cycle, smearable contamination remained about 100,000 counts $/$ min which was satisfactory for testing at DWDL. After four cycles and some additional ultrasonic agitation, the subsize specimens scheduled for testing 


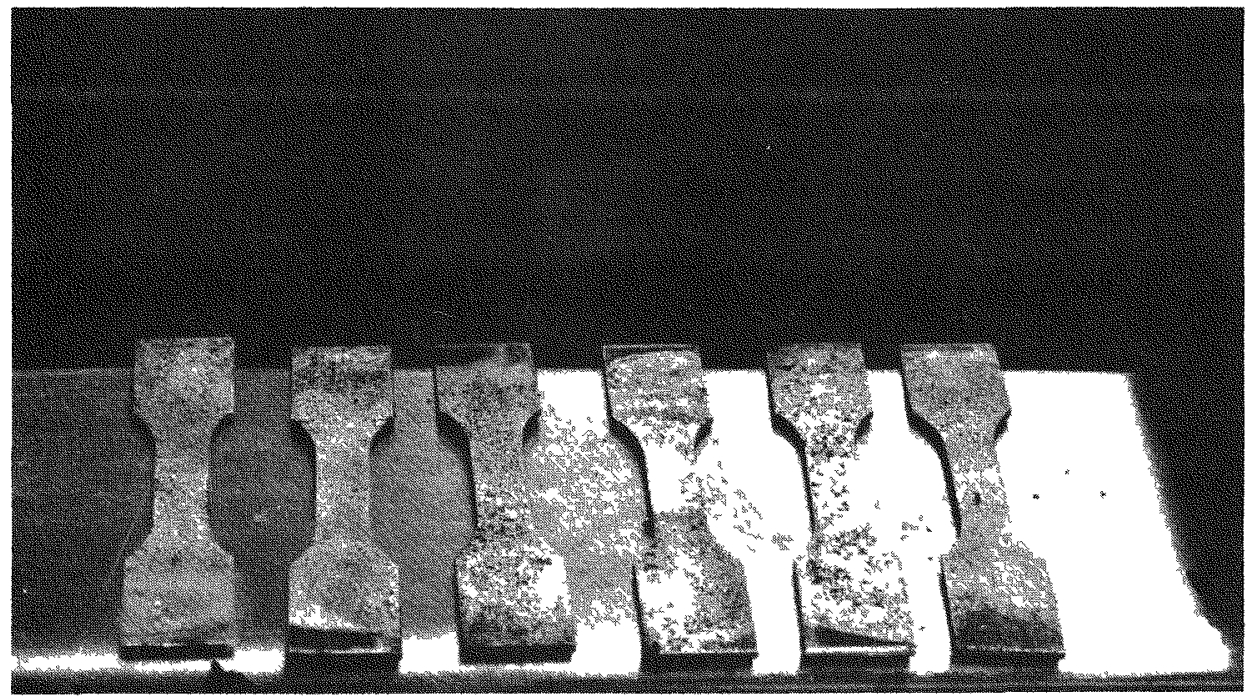

Figure 3-19. Macrograph of M-I Subsize Specimens

at $G E$ had smearably contamination below 100 counts/min. Direct counting of the specimens resulted in estimates of $1 \times 10^{6}$ to $3 \times 10^{6}$ counts $/ \mathrm{min}$ indicating eithe $r$ induced radiation or diffused plutonia.

Several of the microsize control tensile specimens had surface deposits as shown in Figure 3-20. These deposits, a 1-to 2 -mil thick gold colored deposit and a very thin localized matte gray discoloration, were identified as platinum rich with iridium as being the only detectable impurity above about $0.1 \%$. Source of platinum remains unknown. The deposits were random and did not appear to affect tensile properties. The subsize control specimens all had distinctive thermally etched appearances.

All subsize specimens, both fueled and control, have been transferred to General Electric Vallecitos Nuclear Center for testing. 


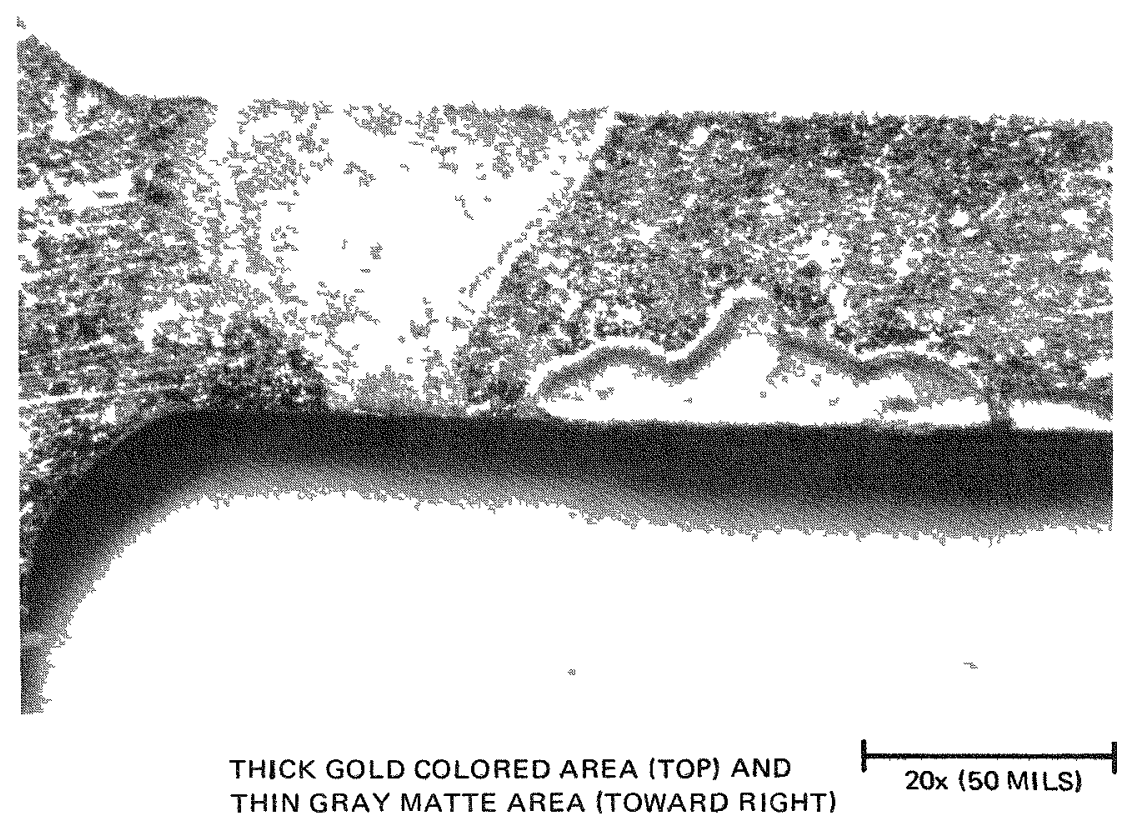

Figure 3-20. Macrograph of Control Microsize Tensıle Specimen C-1CG-1

\subsubsection{Testing}

A series of 7 pre-test, 14 post-test control, and 16 post-test fueled microsize iridium high-strain rate tensile tests were completed at $1400^{\circ} \mathrm{C}$ in January 1973 on the 1250-hr exposed specimens. Several specimens were held for later disposition and were tested in November 1973 with the 8000-hr specumens. Tests were identical, except for replacement of the rubber weight stop before the November series with a slightly harder material. Verification tests conducted at that time indicated that, for Type 1100 aluminum, nickel-270, and Type 304 stainless steel, a yield strength was now attainable comparable to that reported in the literature (References 5 and 6). Thus, for all tests conducted in November 1973, yield strengths were determined for comparison with other information obtained at other sites. 
Results demonstrated that contact with plutonia or graphite did not produce detrimental effects in either the strength or ductility of iridium exposed for 1250 or $8000 \mathrm{hr}$ at temperatures from $1400^{\circ}$ to $1200^{\circ} \mathrm{C}$. Tables $3-10$ and $3-11$ list individual tests data, including accompanying unexposed, or pre-test specimen information. Tensile specimen group averages listed in Table $3-12$ show that the date of testing had no significance. Additionally, thermal ramps, specimen location, and exposure duration all had no measurable effect on yield strength, ultimate tensile strength or elongation. It appears that the control specimens were somewhat weaker, which could be related to the extensive post-exposure cleaning of the fueled specimens in hydrofluoric acid and the lack of cleaning for the control specimens. Ductility measurements, after removal of lowelongation questionable specimens, were all within expected experimental variation, with averages in the range of $45 \%$ to $52 \%$.

In discussing the tensile testing experimental approach, only the term "deformation rate" was used to indicate separation rate of the specimen grips. Rates mentioned varied from $3 \mathrm{in.} / \mathrm{s}$ average during the first $0.1 \mathrm{~ms}$ and $125 \pm 25 \mathrm{in}$. / s average during the majority of deformation. Using the $0.190 \mathrm{in}$. effective gage

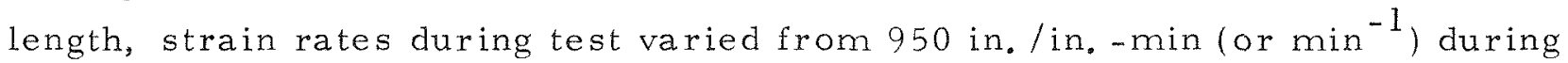
the first $0.1 \mathrm{~ms}$ to an estimated maximum of $39,500 \pm 7900 \mathrm{~min}^{-1}$ during most of the deformation. Included in Tables $3-10$ and $3-11$ are average strain rates determined by dividing measured elongation by total time from load application to break, and by the effective gage length. These average strain rates typically ranged from 19,000 to $26,000 \mathrm{~min}^{-1}$, and were primarily dependent upon deformation. During the latter stages of conducting tests, relatively accurate estimates of specimen elongation could be made solely by determining the time to break, indicating the strong correlation that, after the 0.6 to 0.8 ms time span required to obtain maximum deformation rate, a relatively constant strain rate occurred. Assuming zero strain during the first $0.6 \mathrm{~ms}$, average strain rates were calculated to be $51,200 \pm 5900 \mathrm{~min}^{-1}$ to which the strain correction during the first $0.6 \mathrm{~ms}$ must be applied. For example, if $20 \%$ of total strain occurred during the first $0.6 \mathrm{~ms}$, the n average maximum strain rate is approximately $41,000 \mathrm{~min}^{-1}$, similar to that estimated previously. 
Table $3-10$

IRIDIUM SHORT-TERM EXPOSURE TENSILE TEST DATA

\begin{tabular}{|c|c|c|c|c|c|c|c|c|c|c|c|}
\hline $\begin{array}{l}\text { Specimen } \\
\text { No. (a) }\end{array}$ & $\begin{array}{l}\text { Temp } \\
\left({ }^{\circ} \mathrm{C}\right)\end{array}$ & $\begin{array}{l}\text { Yield } \\
\text { Strength } \\
(\mathrm{ks} 1)(\mathrm{i})\end{array}$ & $\begin{array}{l}\text { Tensile } \\
\text { Strength } \\
\text { (ksi) }\end{array}$ & $\underset{(\%)}{\text { Elongation }}(b)$ & $\begin{array}{c}\text { Average } \\
\text { Strain Rate (c) } \\
\left(10^{3} \text { in./nn. } / \text { min }\right)\end{array}$ & $\begin{array}{l}\text { Specimen } \\
\text { No. (a) }\end{array}$ & $\begin{array}{l}\text { Temp } \\
\left({ }^{\circ} \mathrm{C}\right)\end{array}$ & $\begin{array}{l}\text { Yold } \\
\text { Strength } \\
\text { (ksil(i) }\end{array}$ & $\begin{array}{l}\text { Tensile } \\
\text { Strength } \\
\text { (ksi) }\end{array}$ & Elongation $(b)$ & $\begin{array}{c}\text { Average } \\
\text { Strain Rate }(r) \\
\left(10^{3} \text { n. } / 1 n .-m i n\right)\end{array}$ \\
\hline
\end{tabular}

\begin{tabular}{ll} 
Pre-Test & \\
\hline 1 Notch & 1320 \\
2 Notch & 1320 \\
P-1 & 1390 \\
P-2 & 1400 \\
P-3 & 1400 \\
P-4 & 1395 \\
P-5 & $1350(\mathrm{~g})$
\end{tabular}

$\begin{array}{lll} & & \\ 44 & 52 & 22 \\ 46 & 57 & 22 \\ 34 & 57 & 19 \\ 42 & 63 & 23 \\ 40 & 55 & 21 \\ 42 & 55 & 21 \\ 47 & 58 & 21\end{array}$

\section{Post-Test}

$C-1-I-1$

$C-1-I-1$
$C-1-I-2$

C $-1-1-3$

(h) 1400

1400
1400

$\mathrm{C}-1-\mathrm{HG}-3$

1400
1390

C-1-HG-4 (h) 1395

C-1-CG-1 (h) 1395

-CG-2

$C-3-I-1$

C-3-I-2

C $-3-I-3$

1385
-1405

(h) 1395

C- $-3-1,-1$

$\mathrm{C}-3-\mathrm{HG}-3$

1395

$\mathrm{C}-3-\mathrm{CG}-1(\mathrm{~h})$
$\mathrm{C}-3-\mathrm{CG}-2$

1395
1400

37
39
38
37
45
38
36
40
44
40
36
36
31
34
38
33
35
32
32
37

47
49
54
46
47
46
44
47
45
$33(e)$
49
47
53
48
46
32
51
28
38
$24(d)$

19
20
20
24
18
19
16
26
25
14
19
20
19
24
20
14
19
20
21
13

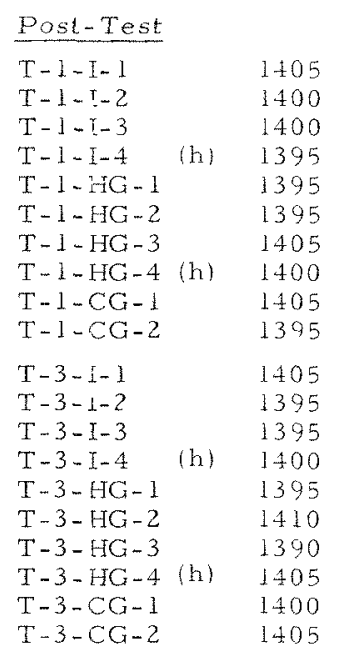

a. Specimen designations are: T- 1 fueled, $1250 \mathrm{nr} ; \mathrm{C}-1$ control, $1250 \mathrm{hr}$

T-3 fueled, $1250 \mathrm{hr}+5 \mathrm{~min}$ at $1950^{\circ} \mathrm{C}, \mathrm{C}-3 \mathrm{Control} 1250 \mathrm{hr}+5 \mathrm{mmin}$ at $1950^{\circ} \mathrm{C}$

I, inside iridium capsule at $1370^{\circ} \mathrm{C}$

$H G$, Ontside iridium capsule adjacent to ATJ graphite at $1400^{\circ} \mathrm{C}$

$\mathrm{CG}$, In $\mathrm{POCO}$ graphite at $1200^{\circ} \mathrm{C}$

b. Estimated effective gage length of $0.190 \mathrm{in}$. used for all elongation measurements.

c. Average strain rate based on specimen elongation, effective gage length, and time to break.

d. Broke near end of gage section.

e. Broke at pin.

f. Rubber bumper stuck to bottom of weight causing slower strain rate buildup.

g. Specimen held $3 \mathrm{~min}$ at temperature; all other specimens held 10 to $30 \mathrm{sec}$.

$h$. Tests conducted in November; all other tests performed in January.

i. Yield strengths measurable only on tests conducted in November. 
Table $3-11$

IRIDIUM LONG-TERM EXPOSURE TENSILE TEST DATA

\begin{tabular}{|c|c|c|c|c|c|c|c|c|c|c|c|}
\hline $\begin{array}{l}\text { Specimen } \\
\text { No. a }\end{array}$ & $\begin{array}{l}\text { Temp } \\
\left({ }^{\circ} \mathrm{C}\right)\end{array}$ & $\begin{array}{l}\text { Yield } \\
\text { Strength } \\
\text { (ksi) }\end{array}$ & $\begin{array}{l}\text { Tensile } \\
\text { Strength } \\
(\mathrm{ksi})\end{array}$ & $\begin{array}{c}\text { Elongation (b) } \\
(\%)\end{array}$ & $\begin{array}{l}\text { Average } \\
\text { Strain Rate (c) } \\
\left(10^{3} / \mathrm{min}\right)\end{array}$ & $\begin{array}{l}\text { Specimen } \\
\text { Vo. }\end{array}$ & $\begin{array}{l}\text { Temp } \\
\left({ }^{\circ} \mathrm{C}\right)\end{array}$ & $\begin{array}{l}\text { Yield } \\
\text { Strength } \\
\text { (hsi) }\end{array}$ & $\begin{array}{l}\text { Tensile } \\
\text { Strength } \\
\text { (ksi) }\end{array}$ & $\begin{array}{c}\text { Flongation }(b) \\
\left(\sigma_{0}\right)\end{array}$ & $\begin{array}{c}\text { Average } \\
\text { Strain Rate (c) } \\
\left(10^{3} / \mathrm{mm}\right)\end{array}$ \\
\hline
\end{tabular}

Pre-Test

$\begin{array}{llllll}P-6 & 1400 & 25 & 38 & 48 & 22 \\ P-7 & 1400 & 23 & 36 & 35 & 22\end{array}$

Post-Test

$C-4-I-1$

C $-4-I-2$

C $-4-I-3$

C $-4-\mathrm{I}-4$

1410

C $-4-\mathrm{HG}-1$

$\mathrm{C}-4-11 \mathrm{G}-2$

$\mathrm{C}-4-\mathrm{HG}-3$

$1395-25$

$1410 \quad 28$

$1415 \quad 25$

C. $4-\mathrm{CG}-1$

1395

C-4-CG-2

1405
1395

24

24
24

$\begin{array}{ll}39 & 51 \\ 36 & 48 \\ 40 & 48 \\ 36 & 50 \\ 37 & 53 \\ 32 & 50 \\ 39 & 43 \\ 37 & 40 \\ 36 & 48 \\ 38 & 51\end{array}$

\section{2}

\section{Post-Test}

T-2-I - $\quad 1400$

$T-2-I-2$

$T-2-I-2$

$\begin{array}{ll}1-2 \\ T-2 & -1-1\end{array}$

$\mathrm{T}-2-\mathrm{HC}-1$

$\mathrm{T}-2-\mathrm{HG}-2$

$\mathrm{T}-2-\mathrm{HG}-3$

$\mathrm{T}-2-\mathrm{HG}-4$

$\mathrm{T}-2-\mathrm{CG}-1$

$\mathrm{T}-2-\mathrm{CG}-2$

T-4-I- 1

$T-4-I-2$

T-4-I-3

T-4-HG -1

T-4-1HG-2

$\mathrm{T}-4-\mathrm{HG}-3$

T-4-HGi-t

$\mathrm{T}-4-\mathrm{CG}-1$

$T-4-C G-2$

$\begin{array}{lll}1400 & 32 & 42 \\ 1395 & 27 & 42 \\ 1400 & 26 & 40 \\ 1410 & 28 & 50 \\ 1400 & 29 & 42 \\ 1405 & 29 & 42 \\ 1400 & 26 & 41 \\ 1395 & 27 & 43 \\ 1405 & -- & 42 \\ 1400 & 30 & 43 \\ 1405 & 27 & 42 \\ 1395 & 29 & 43 \\ 1390 & 32 & 48 \\ 1395 & 22 & 43 \\ 1400 & 24 & 38 \\ 1385 & 24 & 35 \\ 1395 & 19 & 36 \\ 1395 & 22 & 42 \\ 1400 & 23 & 42 \\ 1395 & 26 & 42\end{array}$

49
46
47
51
44
47
49
47
45
65
46
48
55
60
46
48
41
44
$-\cdots(d)$
.$-(d)$

a. Specimen designations are: T-2 fueled, $8000 \mathrm{hr}, \mathrm{C}-4$ control, $800 \mathrm{chr}$

b. Estimated effective gage length of $0.190 \mathrm{kn}$ 。 used for all elongation measurement

c. Average strain rate based on specimen elongation, effective gage length, and time to break

d. Unable to measure elongation, broke near end of gage area. 
Table $3-12$

IRIDIUM TENSILE SPECIMEN GROUP AVERAGES

\begin{tabular}{|c|c|c|c|c|c|c|c|}
\hline \multirow{2}{*}{$\begin{array}{l}\text { Specimen } \\
\text { Group }\end{array}$} & \multirow{2}{*}{$\begin{array}{l}\text { Number of } \\
\text { Specimens }\end{array}$} & \multicolumn{2}{|c|}{$\begin{array}{l}\text { Yield Strength } \\
\text { (Ksi) }\end{array}$} & \multicolumn{2}{|c|}{$\begin{array}{c}\text { Tensile Strength } \\
\mathrm{Ksi} \\
\end{array}$} & \multicolumn{2}{|c|}{$\begin{array}{c}\text { Elongation } \\
\left(m_{0}\right)\end{array}$} \\
\hline & & Mean & $\bar{S}$ & Mean & $\bar{S}$ & $\overline{\text { Mean }}$ & $\mathrm{S}$ \\
\hline \multicolumn{8}{|l|}{ Short Term Exposure $(1250 \mathrm{hr})$} \\
\hline $\begin{array}{l}\mathrm{T}-1 \text { (Fueled, no pulse) } \\
\mathrm{C}-1 \text { (Control, no pulse) } \\
\mathrm{C}-1 \text { (Control, no pulse) } \\
\mathrm{T}-3 \text { (Fueled, pulsed) } \\
\mathrm{T}-3 \text { (Fueled, pulsed) } \\
\mathrm{C}-3 \text { (Control, pulsed) } \\
\mathrm{C}-3 \text { (Control, pulsed) } \\
\text { I (In contact with plutonia) } \\
\mathrm{HG} \text { (In hotgraphite, }\left(400^{\circ} \mathrm{C}\right) \\
\left.\mathrm{HG} \text { (In hot graphite, } 1400^{\circ} \mathrm{C}\right) \\
\mathrm{CG} \text { (In coldgraphite, } 1200^{\circ} \mathrm{C} \text { ) } \\
\mathrm{CG} \text { (In cold graphite, } 1200^{\circ} \mathrm{C} \text { ) } \\
\text { January Tests } \\
\text { January Tests } \\
\text { November Tests } \\
\text { November Tests } \\
\text { All } \\
\text { All }\end{array}$ & $\begin{array}{l}10 \\
10 \\
9(b) \\
10 \\
9(b) \\
10 \\
8 \text { (b) } \\
16 \\
16 \\
15 \text { (b) } \\
8 \\
5 \text { (b) } \\
30 \\
27 \text { (b) } \\
10 \\
9 \text { (b) } \\
40 \\
36 \text { (b) }\end{array}$ & $\begin{array}{l}21^{d} \\
24^{f} \\
23^{f} \\
26^{c}\end{array}$ & $\begin{array}{l}2.5 \\
1.9\end{array}$ & $\begin{array}{l}40 \\
39\end{array}$ & $\begin{array}{l}5.1 \\
4.0 \\
4.9 \\
4.2\end{array}$ & $\begin{array}{l}51 \\
46 \\
47 \\
47 \\
50 \\
42 \\
45 \\
49 \\
46 \\
48 \\
41 \\
50 \\
47 \\
49 \\
44 \\
46 \\
46 \\
48\end{array}$ & $\begin{array}{l}4.4 \\
5.2 \\
2.8 \\
9.0 \\
4.5 \\
10.4 \\
7.1 \\
3.4 \\
7.5 \\
5.9 \\
13.5 \\
8.2 \\
8.4 \\
5.1 \\
6.9 \\
4.3 \\
8.1 \\
6.1\end{array}$ \\
\hline \multicolumn{8}{|l|}{ Long Term Exposure (8000hr) } \\
\hline $\begin{array}{l}\text { T-2 (Fueled, no pulse) } \\
\mathrm{C}-4 \text { (Control, no pulse) } \\
\mathrm{T}-4 \text { (Fueled, pulsed) } \\
\mathrm{T}-4 \text { (Fueled, pulsed) } \\
\text { I (In contact with plutonia) } \\
\left.\mathrm{HG} \text { (In hot graphite } 1400^{\circ} \mathrm{C}\right) \\
\mathrm{CG} \text { (In cold graphite, } 1200^{\circ} \mathrm{C} \text { ) } \\
\left.\mathrm{CG} \text { (In cold graphite, } 1200^{\circ} \mathrm{C}\right) \\
\text { All } \\
\text { All }\end{array}$ & $\begin{array}{l}10 \\
10 \\
10 \\
8 \text { (a) } \\
12 \\
12 \\
6 \\
4(a) \\
30 \\
28 \text { (a) }\end{array}$ & $\begin{array}{l}28 \\
25 \\
25 \\
27 \\
25 \\
26\end{array}$ & $\begin{array}{l}2.0 \\
1.6 \\
3.9 \\
2.9 \\
3.1 \\
2.6\end{array}$ & $\begin{array}{l}42 \\
38 \\
41 \\
40\end{array}$ & $\begin{array}{l}4.1 \\
3.3 \\
2.6 \\
3.7\end{array}$ & $\begin{array}{l}49 \\
48 \\
48 \\
50 \\
46\end{array}$ & $\begin{array}{l}5.8 \\
3.9 \\
6.3 \\
4.0 \\
3.9 \\
8.7 \\
5.2\end{array}$ \\
\hline \multicolumn{8}{|l|}{ Pretest (Annealed at $1500^{\circ} \mathrm{C}, 1 \mathrm{hr}$ ) } \\
\hline $\begin{array}{l}\text { January Tests } \\
\text { November Tests } \\
\text { All }\end{array}$ & $\begin{array}{l}4 \\
2 \\
6\end{array}$ & 24 & 1.5 & $\begin{array}{l}40 \\
37 \\
39\end{array}$ & $\begin{array}{l}3.5 \\
0.8 \\
3.0\end{array}$ & $\begin{array}{l}58 \\
41 \\
52\end{array}$ & $\begin{array}{l}3.6 \\
9.5 \\
9.8\end{array}$ \\
\hline
\end{tabular}

a. Unable to measure elongation for 2. specimens.

b. Specimens having low elongation eliminated from averaging.

Specimen elimination did not affect tensile strengths.

c. One specimen

d. Two specimens

e. Three specimens

f. four specimens 
Current estimates of iridium sphere strain rates at impact range up to about $300,000 \mathrm{~min}^{-1}$. Strain rate buildup to this level is uncertain, but expected to be more rapid than that obtained in this test program. However, during the time interval when the majority of deformation occurred, the DWDL technique provided a strain rate less than a factor of 10 slower than that expected during actual impact. This is in contrast to a typical crosshead motion rate of $0.05 \mathrm{in} / \mathrm{min}$ used in routine tensile testing which translates to approximately $0.1 \mathrm{~min}^{-1}$ strain rates, or about 400,000 times slower than the DWDLtechnique. Thus the DWDL approach provides a much closer approximation to impact than does the typically used test techniques.

\subsubsection{Data Comparison}

Averages for the DWDL $1400^{\circ} \mathrm{C}$ high-strain-rate tensile data were $25 \mathrm{ksi}$ yield strength, $30 \mathrm{ksi}$ ultimate tensile strength, and about $49 \%$ elongation for the Englehard Industries iridium sheet containing approximately $0.8 \%$ tungsten. Somewhat slower strain rate tests conducted at $1380^{\circ} \mathrm{C}$ reported by General Electric in Reference 11 indicate much lower yield strengths ( $7 \mathrm{ksi}$ average), lower tensile strength (28 ksi), and comparable elongation (45\%). Their conclusions were that strain rate had little effect on any of the properties of iridium when tested at $1370^{\circ} \mathrm{C}$. Least squares analysis of their data indicates a 1.39 increase in ultimate tensile strength from 0.2 to $40,000 \mathrm{~min}^{-1}$ strain rates. Recent ORNL data on iridium indicate that tungsten strengthens iridium when tensile tested at $1316^{\circ}$ and $1370^{\circ} \mathrm{C}$ (Reference 12 and 13) with expected ultimate tensile strengths of $30 \pm 1 \mathrm{ksi}$ and yield strengths of $12 \pm 1.5 \mathrm{ksi}$ for $0.8 \%$ tungsten material, as derived from Table $3-13$. Normalization of the tensile strength to DWDL strain rates would result in estimated tensile strengths of approximately $42 \mathrm{ksi}$, very near the actual measurements. Normalization of yield strength, using comparable analyses from Type 304 stainless steel reported in Reference 5, would result in high strain rate values of $20 \mathrm{ksi}$ or higher. The ORNL data also corroborated the lack of any effect caused by exposure of iridium to graphite (Reference 13). 
Table $3-13$

ORNL IRIDIUM TENSILE TEST DATA ${ }^{a, b}$

\begin{tabular}{llccc}
\hline $\begin{array}{c}\text { Alloy } \\
(\text { wt } \%)\end{array}$ & $\begin{array}{c}\text { Temperature } \\
\left({ }^{\circ} \mathrm{C}\right)\end{array}$ & \multicolumn{2}{c}{ Strength $($ Ksi) } & $\begin{array}{c}\text { Elongation } \\
(\%)\end{array}$ \\
\hline Ir $-0.001 \% \mathrm{~W}$ & $1316^{(\mathrm{e})}$ & 5.5 & 26.3 & 50.2 \\
$\mathrm{Ir}-1 \% \mathrm{~W}$ & $1316(\mathrm{e})$ & 16.0 & 29.5 & 43.5 \\
$\mathrm{Ir}-1.92 \% \mathrm{~W}$ & $1316^{(\mathrm{e})}$ & 17.0 & 45.2 & 36.0 \\
$\mathrm{Ir}-1.92 \% \mathrm{~W}$ & $1316^{(\mathrm{e})}$ & 16.0 & 47.1 & 37.0 \\
$\mathrm{Ir} \quad 0.02 \% \mathrm{~W}$ & $1370^{(\mathrm{d})}$ & 7.5 & 22.0 & 41.8 \\
$\operatorname{Ir}-0.3 \% \mathrm{~W}$ & $1370^{(\mathrm{d})}$ & 5.2 & 24.4 & 50.4 \\
$\operatorname{Ir}-1.92 \% \mathrm{~W}$ & $1370^{(\mathrm{d})}$ & 17.0 & 45.1 & 42.0 \\
$\operatorname{Ir}-384 \% \mathrm{~W}$ & $1370^{(\mathrm{d})}$ & 21.7 & 46.9 & 25.1 \\
\hline
\end{tabular}

a. Tested in vacuum at a crosshead speed of 0.05 to $0.2 \mathrm{in.} / \mathrm{min}$.

b. All sheet specimens annealed $1 \mathrm{hr}$ at $1500^{\circ} \mathrm{C}$ in vacuum prior to test.

c. Tested after contact for 1000 hrs with ATJ Graphite on one side and exposed to oxygen at $1 \times 10^{-5}$ torr at $1300^{\circ} \mathrm{C}$.

d. Reference 13

e. Reference 12

\subsubsection{Metallography and Microhardness}

Metallography was performed on one pre-test, ten 1250 -hr and four $8000 \mathrm{hr}$ tensile specimens after testing. Thin intermetallic layers were evident on one side of the specimens in direct contact with plutonia. This layer appears to be the same as the tungsten iridium intermetallic layer on the bottom of the capsules as described previously. The majority of fractures exhibited high ductility like that shown in A, Figure 3-21. Only one of the specimens selected for metallography exhibited intermediate ductility as shown in B, Figure 3-21. Two of the specimens exposed in the lower temperature graphite started deforming in the hot area of the gage length but fractured in the colder test region as shown in C. Figure 3-21. Slip markings were observed in most of the fracture regions along with the large reduction in area. Grain size of the pre-test and all exposed specimens not thermally pulsed was fine (such as A, Figure 3-21). Coarse grain structures were observed on all thermally pulsed specimens such as $B$ and $C$, Figure $3-21$. 


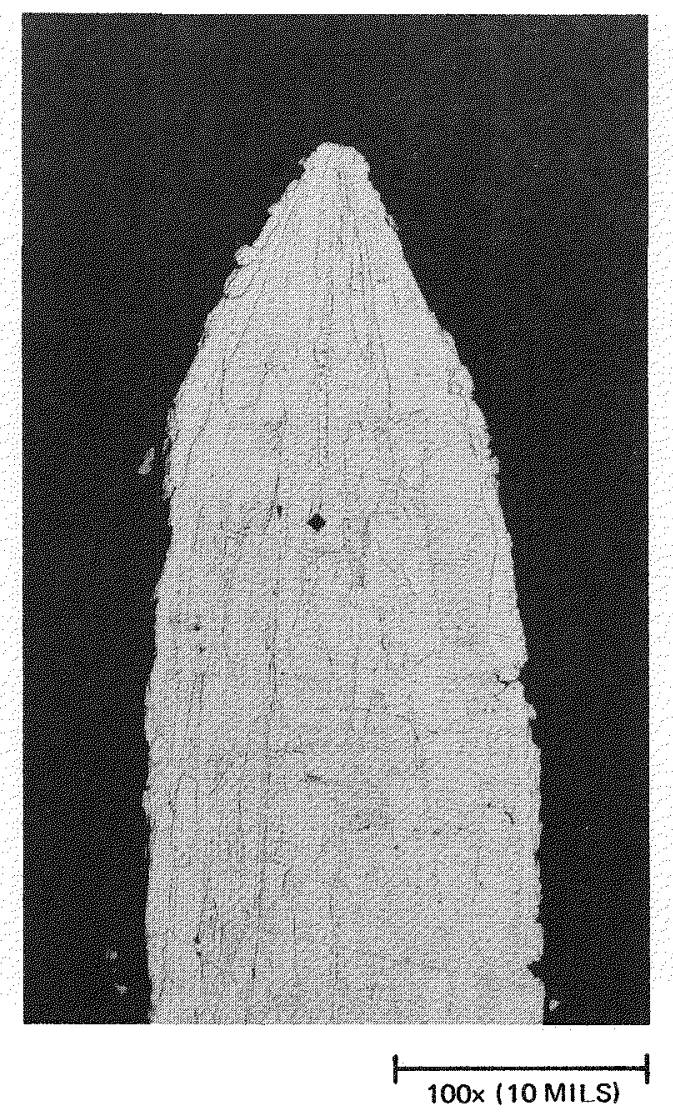

HIGH DUCTILITY

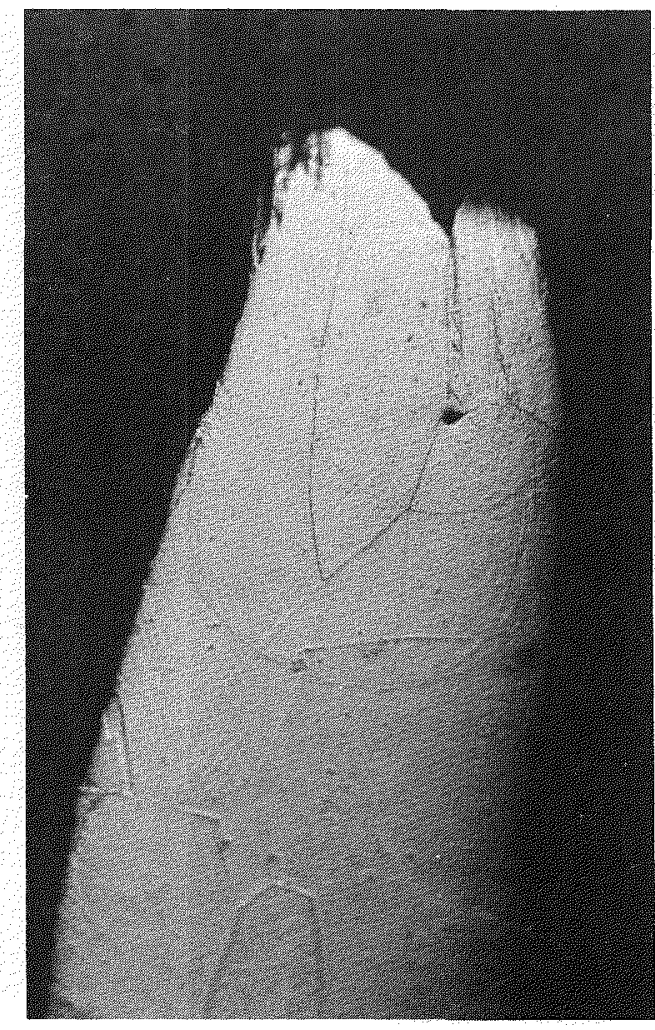

$\vdash_{100 \times(10 \mathrm{MILS})}$

INTERMEDIATE DUCTILITY

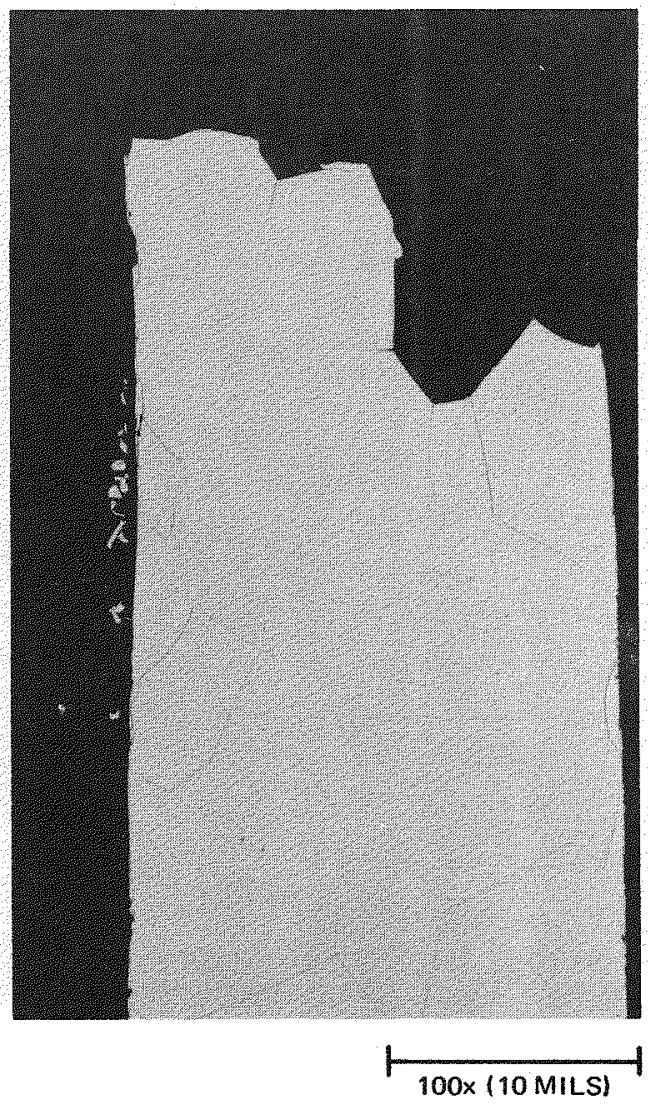

LOW DUCTILITY 
Erratic values in the microhardness measurements on the post-test specimens inhibited anything other than generalized observations. Softening occurred on all exposed specimens. However, the re were little or no noticeable differences caused by exposure duration, specimen location, or presence of plutonia. Hardening was associated with slip markings near the fracture surface. All groups of tensile specimens remained harder than comparable capsules with a lower tungsten content. 
Section 4

CONCLUSIONS

Conclusions have been reached in this technology effort that are relevant to MHW heat source materials interactions, vent plugging, and iridium tensile properties. These conclusions are based on information from DWDL tests along with supplemental information from other aspects of the MHW program. Tests of this type are intended to be an economical and efficient use of resources to identify potential systems problems and, with additional system oriented tests, to produce solutions prior to actual production of heat solice hardware.

\subsection{Iridium Did Not Chemically React with Either Plutonia or Graphite} under MHW Heat Source Conditions

No reaction attributable to either plutonia or graphite alone or in combination was observed in or on the iridium containment. Tungsten-rich surface reactions that were observed were the result of pre-treatment conditions. Deposition of vapor transported plutonia caused no chemical reactions on the iridium. Contact with graphite did not degrade the iridium under operating conditions $\left(1440^{\circ} \mathrm{C}\right.$ ) or potential reentry temperatures $\left(1950^{\circ} \mathrm{C}\right)$.

\subsection{Mechanical Properties of Iridium Were Not Degraded by Simulated} MHW Life Cycles

Tensile strength and elongation of iridium exposed in contact with plutonia or graphite at $1370^{\circ} \mathrm{C}$, with or without subsequent $1950^{\circ} \mathrm{C}$ thermal pulses, were actually somewhat higher than control specimens when tested at high strain rates at $1400^{\circ} \mathrm{C}$. The fueled test specimens retained the pre-test $\left(1500^{\circ} \mathrm{C}\right.$, $1 \mathrm{hr}$ vacuum annealing) strength and ductility. The control test specimens had slightly reduced strength and ductility. The strain rate used in these tests was less than a factor of 10 lower than what is expected in an impacting iridium sphere, but about 400, 000 times higher than that attained in routine tensile testing. 
4.3 Plutonia Maintained Its Integrity under MHW Heat Source Conditions

The 6-watt plutonia pellets exposed for 1250 and 8000 hours at average temperatures in excess of $1370^{\circ} \mathrm{C}$ with or without subsequent thermal pulses to $1950^{\circ} \mathrm{C}$ retained dimensional stability and remained single phase. Dimensions were unchanged by the thermal treatment. Post-test structures were single phase with only minor additional phases attributable to impurities. Porosity appearance changed, tending toward spheriodization with time. Direct analytical techniques and calculations of oxygen loss in reactions with graphite both indicate final oxygen composition in the fuel to be in excess of $\mathrm{PuO}_{1.99^{\circ}}$

\section{4 Helium Vents Plugged as a Function of Time Due to Two} Separate Mechanisms

Airflow through the one-mil vent hole, as measured by pre- and post-test techniques, decreased as a function of time. Iridium was found to be plugging some of the vents; an oxide was determined to be plugging others. These two mechanisms have been confirmed in other fueled tests at ML and LASL.

Material transport depends on fuel temperature and purity, system thermal gradients, iridium purity, and relative locations of materials. Discussions in the text deal with recommendations to alleviate plugging. 
Section 5

REFERENCES

1. J.D. Watrous, J.C. Walker and W.E. Ferguson. Investigation of Compatibility Barriers Between Plutonia-238 and Noble Metals at $1500^{\circ} \mathrm{C}, \mathrm{MDC}$ G 4404 , April 1973.

2. R. D. Baker. Monthly Reports by Los Alamos Scientific Laboratory to Division of Space Nuclear Systems, USAEC, under Contract W-7405-ENG-36.

3. D. L. Roesch. The $\mathrm{PuO}_{2}$ - Iridium-Graphite Performance Test (Goldenberg Test), Mound Laboratory, 1972.

4. A. Nadai, and M. J. Manjoine. High-Speed Tension Tests at Elevated Temperature - Parts 2 and 3. Journal of Applied Mechanics, V8, A77, 1941.

5. J.M. Steichen and M. M. Paxton. The Effect of Strain Rate of the Mechanical Properties of Austenitic Stainless Steels. HEDL-TME-71-56, May 1971.

6. J.M. Steichen. High Strain Rate Mechanical Properties of Type 304 Stainless Steel and Nickel-200. HEDL-TME 71-145, September 1971.

7. R. J. Ackermann, R. L. Faircloth, and M.H. Rand. A Thermodynamic Study of the Vaporization Behavior of the Substoichiometric Plutonium Dioxide Phase. J. Physical Chemistry, V70, No. 11. November 1966, pp. 3698-3706.

8. R. A. Kent. Thermodynamic Analys is of MHW Space Electric Power Generator, LA-5202-MS, March 1973.

9. R.E. Schafer. Bi-Monthly Progress Report on Multi-Hundred Watt Radioisotope Thermoelectric Generator Program, Period from March 1, 1973 to April 30, 1973.

10. L. S. Darken and R. W. Gurry. Physical Chemistry of Metals. McGraw-Hill, 1953.

11 R. L. Mehan. Tensile Properties of Iridium, GE-PIR 3937, April 11, 1972.

12. R.G. Donnelly. Isotopic Power Materials Development Progress Report for September 1973, ORNL-TM-4383, December 1973.

13. R. G. Donnelly. Isotopic Power Materials Development Progress Report for May 1973, ORNL-TM-4314, August 1973. 
- Donald W. Douglas Laboratories • 2955 George Washington Way • Richland, Washington 99352 MCDONNELL DOUGLAS ASTRONAUTICS COMPANY

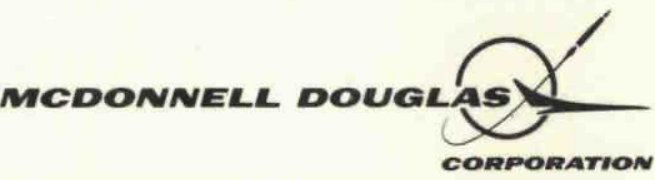

